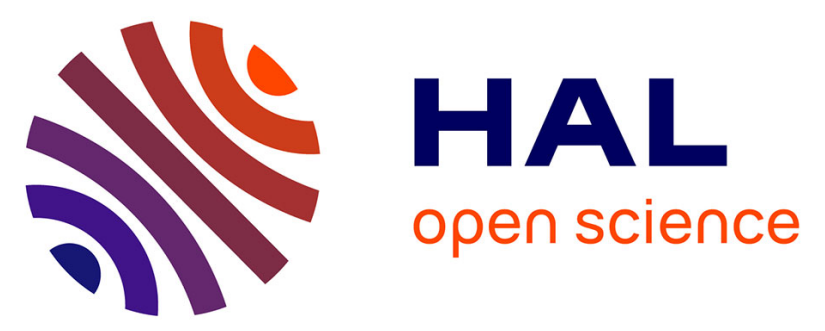

\title{
Le Roc de Marcamps 2 (Prignac-et-Marcamps, Gironde) : nouvelles données sur la subsistance et les traditions techniques au début du Magdalénien moyen
}

Delphine Kuntz, Anthony Sécher, Sandrine Costamagno, Jean-Baptiste Mallye, Jean-Marc Pétillon, Caroline Peschaux, Éric Pubert, William Rendu, Myriam Boudadi-Maligne, Véronique Laroulandie, et al.

\section{To cite this version:}

Delphine Kuntz, Anthony Sécher, Sandrine Costamagno, Jean-Baptiste Mallye, Jean-Marc Pétillon, et al.. Le Roc de Marcamps 2 (Prignac-et-Marcamps, Gironde) : nouvelles données sur la subsistance et les traditions techniques au début du Magdalénien moyen. Bulletin de la Société préhistorique française, 2015, 112 (3), pp.475-516. 10.3406/bspf.2015.14551 . hal-01842672

\author{
HAL Id: hal-01842672 \\ https://hal.science/hal-01842672
}

Submitted on 23 Oct 2018

HAL is a multi-disciplinary open access archive for the deposit and dissemination of scientific research documents, whether they are published or not. The documents may come from teaching and research institutions in France or abroad, or from public or private research centers.
L'archive ouverte pluridisciplinaire HAL, est destinée au dépôt et à la diffusion de documents scientifiques de niveau recherche, publiés ou non, émanant des établissements d'enseignement et de recherche français ou étrangers, des laboratoires publics ou privés. 


\title{
Le Roc de Marcamps 2 (Prignac-et-Marcamps, Gironde)
}

\section{Nouvelles données sur la subsistance et les traditions techniques au début du Magdalénien moyen}

\author{
Delphine Kuntz, Anthony Sécher, Sandrine Costamagno, \\ Jean-Baptiste Mallye, Jean-Marc Pétillon, Caroline Peschaux, Éric Pubert, \\ William Rendu, Myriam Boudadi-Maligne, Véronique Laroulandie, \\ Carolyn BARSHAY-SzMIDT et Mathieu LANGLAIS
}

Résumé : Le Roc de Marcamps (Prignac-et-Marcamps, Gironde) est un site du Magdalénien moyen connu notamment par la découverte de nombreuses navettes dans les fouilles anciennes du secteur 1. Les travaux menés par Michel Lenoir dans le secteur 2 durant les années 1980 n'ont pas livré ce type de marqueur osseux mais un ensemble de vestiges attribués également à cette période. Plusieurs dates radiocarbone raisonnées placent ce gisement autour de 18900$18600 \mathrm{cal}$. BP, soit lors des premiers temps du Magdalénien moyen. Cette phase de transition apparait synchrone de l'événement climatique d'Heinrich 1 marquant une péjoration climatique avec des conditions froides et steppiques. Elle se caractérise en outre par d'importants changements techno-économiques ou symboliques. À l'interface des « faciès » à navettes, à pointes de Lussac-Angles ou à lamelles scalènes, le Roc de Marcamps 2, et plus largement la Gironde, occupe une place privilégiée pour la compréhension de la mosaïque géoculturelle structurant la genèse du Magdalénien moyen. Dans le cadre d'une révision collective du gisement par des membres du projet « Magdatis », cet article présente une approche croisée, détaillant les analyses taphonomiques et archéozoologiques des restes de faune (ongulés, mésomammifères et avifaune) ainsi que les études typotechnologiques des industries lithique et osseuse et de la parure. La stratigraphie du Roc de Marcamps 2 comprend un ensemble supérieur mêlant dépôts récents, déblais de carrières, céramiques et vestiges paléolithiques brassés par des animaux fouisseurs. L'ensemble inférieur apparaît mieux conservé et renferme les vestiges magdaléniens. Les restes fauniques documentent une chasse principalement axée sur les bisons, les antilopes saïga, les chevaux et les rennes durant la mauvaise saison et au début de la bonne saison. L'exploitation de ces ressources animales est intensive et orientée vers la récupération de la moelle en complément de la viande. L'étude des matières premières siliceuses, préférentiellement d'origine locale, atteste toutefois un apport de silex de Saintonge (silex « grain-de-mil »). La production lithique est principalement composée de débitages lamellaires voués à la confection d'éléments d'armatures de chasse. Le débitage laminaire fournit des supports normalisés pour la fabrication d'outils. L'industrie en matières dures d'origine animale est assez pauvre et comprend un équipement en os (aiguilles, lissoirs, retouchoirs) et en bois de renne (essentiellement des armatures de projectile) ainsi que des éléments de parure sur coquillages (en majorité des dentales) et sur dents (en majorité des incisives de renne sciées).

L'étude typotechnologique des industries lithique et osseuse et de la parure suggère des rapprochements tant avec le « Magdalénien à navettes » qu'avec le « Magdalénien à pointes de Lussac-Angles », deux faciès dont le Roc de Marcamps 2 est contemporain. Ceci doit conduire à s'interroger sur la pertinence de l'utilisation de ces faciès pour définir des « cultures exclusives » qui finalement se recouvrent chronologiquement et géographiquement, notamment en Gironde.

Mots-clés : Roc de Marcamps 2, Magdalénien moyen ancien, technologie lithique, industrie en matière dure animale, parure, archéozoologie.

\footnotetext{
Abstract: Discovered in 1929 by P. David and G. Malvesin-Fabre, Roc de Marcamps (Prignac-et-Marcamps, Gironde) is known as a Middle Magdalenian site due, in particular, to the discovery of numerous antler shuttles in the old excavation of sector 1. The more recent work carried out in the 1980s by Michel Lenoir in sector 2, located a few meters below sector 1, did not yield this diagnostic osseous artefact-type specifically, but a set of other remains equally attributed to the same period. Six radiocarbon dates (of which four are new and until now unpublished) place the occupation of this site in the 18900-18600 cal. BP timeframe, i.e. at the very beginning of the Middle Magdalenian. This transition period seems to be synchronous with the Heinrich 1 climatic event, a period marked by climatic deterioration in which cold, steppe-like conditions existed. This period is characterized by major techno-economic and symbolic changes. Located
} 
at the crossroads of three 'facies' of this period (the 'shuttle', 'Lussac-Angles' and 'scalene bladelets' facies), Roc de Marcamps 2 and, more generally, the Gironde region, occupies a privileged place for understanding the geocultural mosaic that influenced the formation of the Middle Magdalenian.

In the context of a site reassessment by members of the Magdatis project, this paper aims to examine multiple records, in particular taphonomic and archaeozoological analyses of faunal remains (ungulates, small mammals and birds), as well as techno-typological studies of lithic, osseous and ornament industries. The stratigraphy of Roc de Marcamps 2 includes an upper unit in which recent deposits, backdirt from former quarrying activities, ceramics, as well as Palaeolithic material are found, all mixed together as a result of the actions of burrowing animals. The lower unit seems to be better preserved and includes Magdalenian remains dispersed over a number of layers $(2 a, 2 b, 2 c$ and 3$)$ identified during excavation in approximately 1 metre of deposits. Our work in digitizing the field notebooks as well as in creating projections of the artefacts in three dimensions did not reveal the reality of these subdivisions, however. In addition, the very similar ${ }^{14} \mathrm{C}$ dates and the homogeneous lithic industry, all of which point to the beginning of the Middle Magdalenian, incited us to ignore these stratigraphic subdivisions for this overall site reevaluation and to consider instead layers 2 and 3 as one archaeological unit.

The faunal remains of RM2 are abundant and well preserved; they demonstrate that hunting was primarily aimed at bison, saiga antelope, horse and reindeer during the cold season and the beginning of the warm season. Carcass processing of these ungulates was intensive and oriented towards marrow extraction in addition to meat recovery, as demonstrated by numerous impact scars and cutmarks on the bones. By contrast, small mammals and birds were barely used by Magdalenian people on this site.

Lithic raw material was primarily obtained close to the site, within a $10 \mathrm{~km}$ radius (grey-black or blonde varieties of Senonian flint, Maastricht flint and Tertiary flint). Other varieties of flint attest to the use of more distant sources, such as 'grain-de-mil' flint from Charente Maritime. A small number of artefacts demonstrate links with even more distant places such as Chalosse (Upper Maastricht flint with Lepidorbitoides sp. inclusions, from $200 \mathrm{~km}$ south of the site) and the Middle Cher Valley (Lower Thuronian formations, $250 \mathrm{~km}$ north of the site). Lithics are composed primarily of bladelet knapping intended as part of hunting tools, mainly simple backed bladelets, retouched bladelets and truncated bladelets. Blade knapping provided standardized blanks for the production of other tools, primarily burins and simple endscrapers, as well as some composite tools (burin-endscrapers).

The osseous industry is relatively poor. It includes bone tools comprised of needles, for which splinters were extracted using a groove and splinter technique. There are also smoothers obtained by bilateral longitudinal grooving; and retouchers whose shape and dimensions are quite standardized and whose impact scars are only minimally noticeable. The groove and splinter technique was also used to extract splinters from the main beam of large reindeer antlers. Most antler objects are projectile points, among which the only identified base is a single-bevelled type. Finally, ornaments are also present on this site. Shells, mainly Dentalium sp., were intentionally sectioned by the saw and snap technique. A good number of segments are clearly finished products, as seen by finishing traces on them (smoothing of edges by abrasion) and by usewear marks (partially blunt edges). The presence of complete unworked shells as well as segments probably come from manufacturing waste and suggest in situ production. Pierced teeth ornaments are less common; these are comprised of cut reindeer and hare incisors, one pierced fox canine as well as one horse incisor decorated with a grid pattern.

The techno-typological analysis of the lithic and osseous industries as well as of the personal ornaments point to affinities with both the 'shuttle' facies (truncated-backed bladelets, shell and teeth personal ornaments) and the 'LussacAngles' facies (truncated backed bladelets, smoothers, and decorated bone incisor), two Magdalenian facies with which Roc de Marcamps 2 is contemporaneous. This fact should cause us to reconsider the relevance of these facies in defining exclusive cultures which, in the end, overlap each other chronologically and geographically, notably in Gironde.

Keywords: Roc de Marcamps 2, early Middle Magdalenian, lithic technology, osseous and antler raw materials, ornaments, zooarchaeology.

$\mathrm{D}$ ANS L'Évolution des sociétés du Paléolithique supérieur récent en Europe de l'Ouest, la transition entre Magdalénien inférieur et moyen, vers 19000 cal. BP, apparaît comme un moment clé. D'abord parce qu'elle est synchrone de la première phase de l'événement climatique d'Heinrich 1 (Stanford et al., 2011), durant lequel les groupes humains ont été confrontés à des changements environnementaux importants. Ensuite parce que cette période voit le développement de pratiques symboliques originales (sépultures primaires, sculptures pariétales, représentations humaines, etc.). De plus, après la relative uniformité du Magdalénien inférieur tel que nous pouvons le percevoir aujourd'hui, les débuts du Magdalénien moyen - ou Magdalénien moyen ancien - semblent marqués par une pluralité de « faciès » qui ont reçu, au fil des recherches, des dénominations variées s'appuyant sur la présence de types lithiques ou osseux considérés comme des «marqueurs» (Magdalénien « à navettes", « à pointes de Lussac-Angles », « à lamelles scalènes »: Allain et al., 1985; Pinçon, 1988; Demars et Laurent, 1989; Langlais, 2007a et b). Or, la nature, les critères d'identification, les rapports chronologiques et géographiques de ces faciès restent largement débattus, notamment parce que certains des ensembles archéologiques sur lesquels s'appuie la définition de ces faciès n'ont pas toujours été documentés de façon détaillée. Il apparaissait donc urgent de contrebalancer l'importance donnée à ces «marqueurs" par un examen de l'ensemble des vestiges. Le projet « Magdatis » nous a permis 


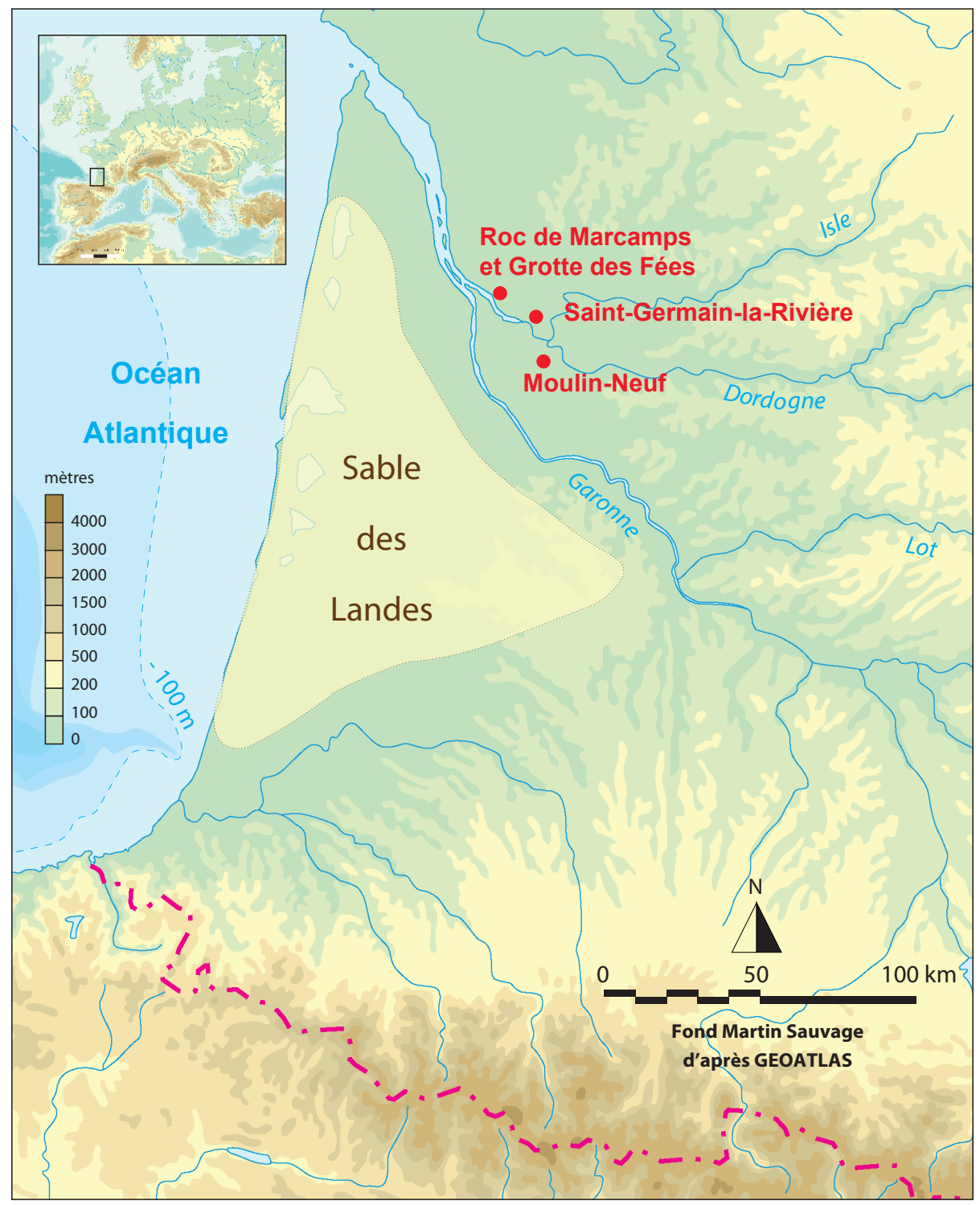

Fig. 1 - Localisation du gisement du Roc de Marcamps et des gisements mentionnés dans le texte.

Fig. 1 - Location of Roc de Marcamps and sites mentioned in the text.

d'appréhender différemment cette transition en réévaluant un certain nombre d'ensembles archéologiques des débuts du Magdalénien moyen en Gironde. Cette région occupe en outre une position cruciale, à l'interface géographique de plusieurs des faciès évoqués cidessus (Langlais et al., soumis; Sécher, sous presse).

Connu depuis la fin des années 1920, le Roc de Marcamps a fait l'objet pendant une vingtaine d'années de multiples fouilles ayant livré un matériel très abondant qui en a fait un gisement paléolithique de premier plan à l'échelle régionale et un des sites de référence dans la définition du "Magdalénien à navettes » (Allain et al., 1985). Le Roc de Marcamps n'échappait cependant pas aux problèmes habituellement rencontrés avec les fouilles anciennes : récolte sélective du matériel, absence de contrôle stratigraphique et de tamisage systématique, etc. Les fouilles conduites par M. Lenoir entre 1978 et 1988 dans deux secteurs du gisement ont toutefois permis de constituer de nouvelles séries recueillies dans des conditions compatibles avec les exigences d'une étude moderne. Ces séries, qui ont déjà fourni la matière de plusieurs publications dans les années 1980 et 1990 (Slott-Moller, 1988, Lenoir, 1993a, b et c; etc.), ont ainsi fait l'objet d'un réexamen collectif incluant l'analyse typotechnologique et économique des industries lithique et osseuse, celle de la parure, l'étude taphonomique et archéozoologique des restes fauniques et une nouvelle série de datations radiocarbone par AMS. La présentation des résultats de l'étude collective des différents registres archéologiques provenant du secteur $2 \mathrm{du}$ Roc de Marcamps (RM2, collection M. Lenoir) est alors l'occasion de réfléchir à la caractérisation d'une série du Magdalénien moyen ancien à priori dépourvue de marqueurs « classiques » et de la replacer dans les scénarios des débuts du Magdalénien moyen à l'échelle de la Gironde (fig. 1) et au-delà. 


\section{HISTORIQUE DES TRAVAUX}

$\mathrm{L}$ e gisement du Roc de Marcamps est localisé en Gironde, sur la rive gauche du Moron à proximité de sa confluence avec la Dordogne et proche de l'estuaire de la Gironde. Découvert en 1929 par P. David et G. Malvesin-Fabre lors de sondages entrepris en contrebas de la grotte des Fées (fouillée par F. Daleau en 1874), le gisement occupe un vaste talus au pied d'une falaise contenant des cavités naturelles détruites par d'anciennes carrières. Des tranchées de fouilles furent ouvertes en 1930 et poursuivies jusque dans les années 1940 par différents acteurs, dont les membres de l'école de fouilles de la Société linnéenne de Bordeaux, avant que le site ne soit abandonné et pillé par des fouilleurs clandestins. L'étude typologique de l'ensemble des séries anciennes du Roc de Marcamps a été réalisée par M. Lenoir (1983). De nouveaux travaux de terrain ont alors été réalisés de 1979 à 1988. Contrairement à ce qui était admis (Lacorre, 1938; Cousté, 1959; Roussot et Ferrier, 1970), M. Lenoir considère alors le gisement comme indépendant de la grotte des Fées et plus vraisemblablement lié à des occupations en pied de falaise dans un secteur situé à quelques mètres plus au sud (Lenoir, 1993a, b, c et 2000).

Les sondages puis les fouilles de M. Lenoir se sont concentrés dans deux secteurs distants d'une vingtaine de mètres (fig. 2). Nous rappellerons brièvement les résultats obtenus sur le secteur 1 (Lenoir, 1993a, b et 2000 ; SlottMoller, 1988) avant de développer les données acquises pour le secteur 2, qui fait l'objet de cet article.

Le secteur 1, situé à proximité immédiate des tranchées de fouilles anciennes, a concerné une vingtaine de $\mathrm{m}^{2}$ et livré, dans l'ensemble 2, plusieurs niveaux dont les industries présentent des caractères typotechnologiques communs attribués au Magdalénien moyen. L'industrie lithique est constituée de deux composantes - lamellaire et laminaire - réalisées presque exclusivement en silex sénoniens recueillis dans les alluvions proches du site. Les sous-produits issus de ces chaînes opératoires comportent de nombreux éclats dont un pourcentage notable a servi à la réalisation d'outils. Ces derniers, dominés par les burins dièdres et les grattoirs, sont préférentiellement réalisés sur lames. Les lamelles à dos sont très abondantes (Lenoir, 1993a). L'industrie osseuse est peu représentée (une soixantaine de pièces) et très fragmentée. Elle montre l'exploitation par rainurage longitudinal multiple de bois de chute de renne, principalement de gros module, pour la production d'outils intermédiaires et de pointes (ces dernières à section quadrangulaire ou ovale, à biseau simple ou double, portant parfois une rainure sur la face supérieure : Pétillon, obs. pers.). Plusieurs os longs ont été débités par rainurage longitudinal multiple pour la fabrication d'aiguilles à chas. Quelques éléments de parure ainsi que des fragments d'ocre complètent cet inventaire (Lenoir, 1993a, b et 2000). La grande faune (Slott-Moller, 1988) fait apparaître, dans les deux sous-ensembles de la séquence magdalénienne la prédominance du bison et de l'antilope saïga, accompagnés du cheval (et de quelques restes d'hydruntin) et des cervidés (renne et cerf). Les spectres fauniques indiquent ainsi des conditions climatiques rigoureuses dans un environnement steppique.

Le secteur 2, dont il est question dans cet article, est situé à quelques mètres au sud-est du secteur 1 (fig. 2). La fouille de la partie haute du talus, menée de 1983 à 1985 par M. Lenoir, s'est étendue sur $11 \mathrm{~m}^{2}$. Les sédiments ont été systématiquement tamisés et les vestiges, parfois prélevés en lots, ont été coordonnés en trois dimensions. D'après les précédents travaux, les industries lithique et osseuse de ce secteur présentent de grandes similitudes avec celles du secteur 1 (Lenoir, 2000). Très peu d'éléments d'art mobilier ont été découverts, hormis cinq fragments d'ossements gravés. Il existe en revanche divers éléments de parure, notamment des dentales sciés (Lenoir, 1993c et 2000). Enfin, la faune comporte des restes d'antilope saïga, de bison, de renne et de cheval et témoigne de conditions steppiques (Slott-Moller, 1988; Lenoir 1993c et 2000).

\section{ARCHÉOSTRATIGRAPHIE, DATATIONS ET INTÉGRITÉ DES VESTIGES DU RM2}

$\mathrm{D}$ eux grands ensembles ont été identifiés à la fouille (Lenoir, 1993c et 2000). La stratigraphie observée dans l'ensemble 1 indique la présence de dépôts récents, provenant de déblais de carrière et remaniés par des terriers d'animaux fouisseurs. Des vestiges paléolithiques lithiques et osseux ainsi que quelques tessons de poterie y ont été découverts. L'ensemble 2 renferme les couches pléistocènes, au sein desquelles plusieurs niveaux ( $2 \mathrm{a}, 2 \mathrm{~b}$, $2 c$ et 3 ) ont été distingués sur environ un mètre de profondeur selon des critères granulométriques et sédimentaires (Lenoir, 1993c et 2000).

Dans un souci d'archivage et de conservation et afin de tester l'homogénéité des ensembles décrits à la fouille, l'informatisation des données spatiales issues des carnets de fouille a été entreprise. Comme cela est classiquement le cas lors de la reprise d'études anciennes, nous nous sommes heurtés à plusieurs difficultés. Au RM2, il s'agit particulièrement d'erreurs de notation, de doublons, d'absence de correspondance entre les pièces numérotées et les indications des carnets et d'hétérogénéité dans la notation des couches, problèmes inhérents à tout travail de terrain. La projection des vestiges coordonnés sur un plan vertical a révélé un ensemble de points répartis de manière uniforme du bas en haut de la séquence. Il faut toutefois noter que la concentration des vestiges tend à augmenter significativement pour les pièces les plus profondes. Les nappes de vestiges semblent suivre un pendage général vers le sud-est (fig. 3 et 4).

Une fois projetées, les différentes appellations de couches créées lors la fouille semblent davantage être le résultat de lithofaciès plutôt que de limites de couches archéologiques. L'absence de niveau stérile entre les couches définies à la fouille plaide en faveur de cette hypothèse. 


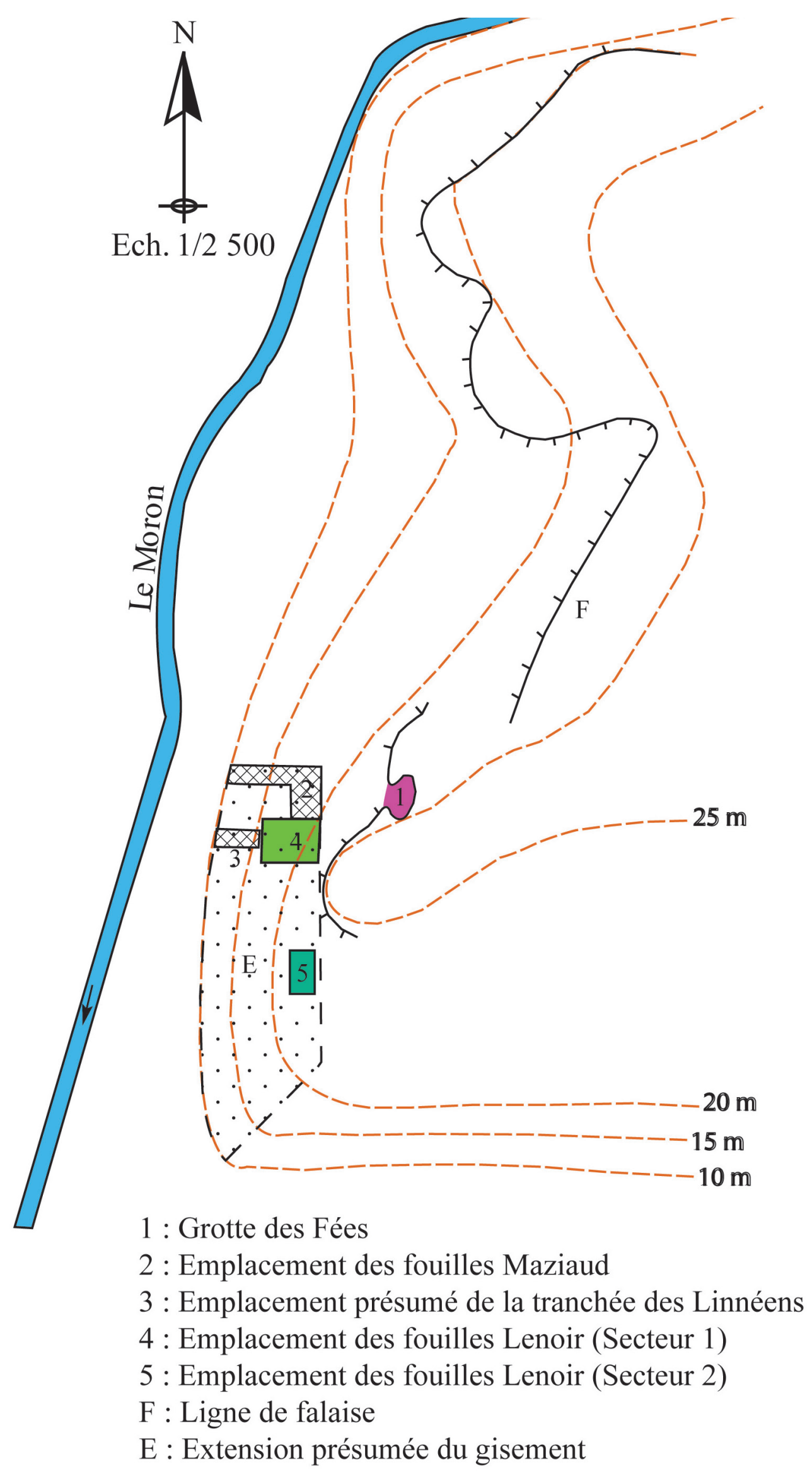

Fig. 2 - Plan d'ensemble du gisement (d'après Lenoir, modifié).

Fig. 2 - General layout of the site (after Lenoir, modified). 

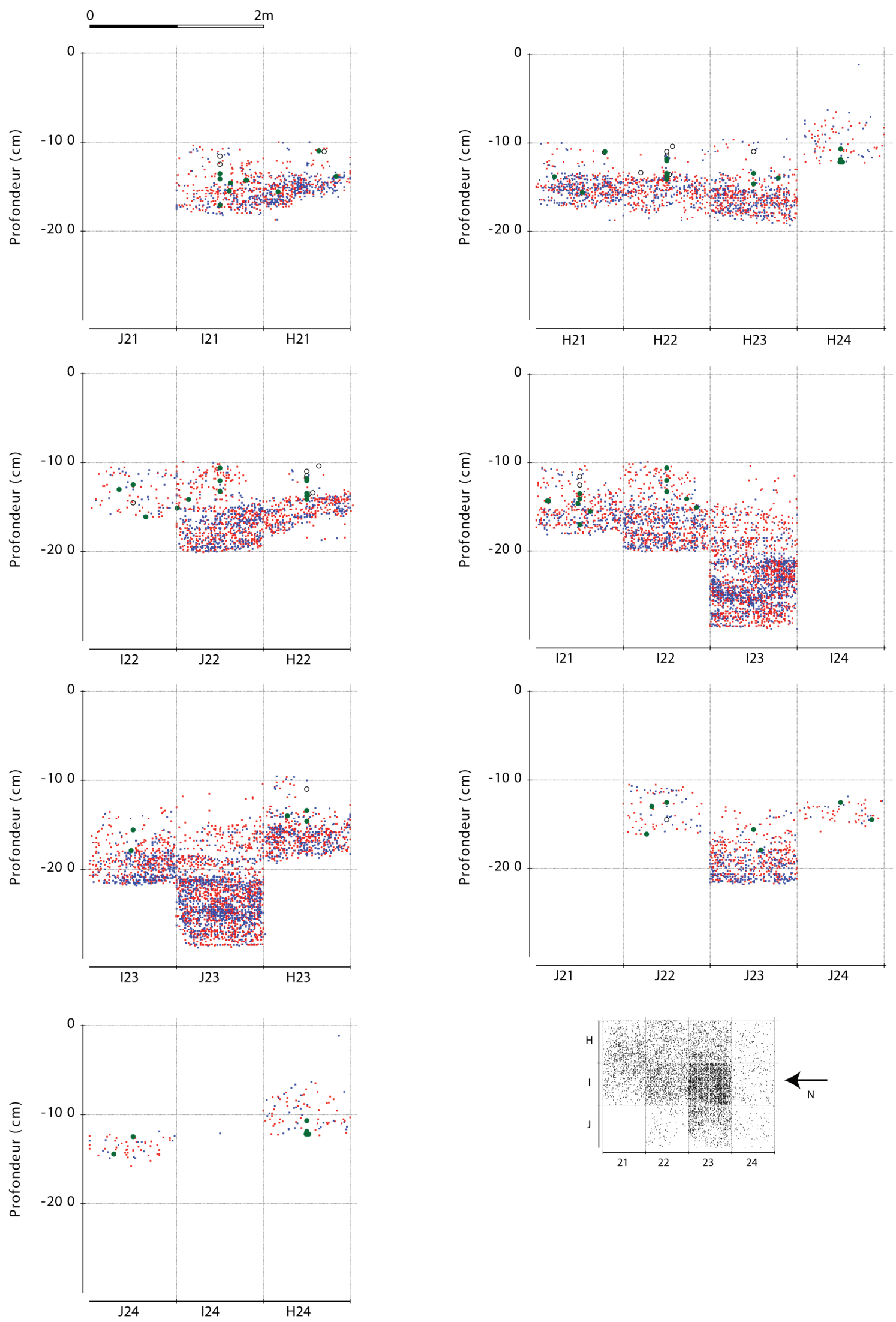

Fig. 3 - Distribution spatiale des vestiges du RM2. Points bleus : restes fauniques; points rouges : vestiges lithiques; cercles noirs : céramique; points verts : faune à cachet récent.

Fig. 3 - Spatial distribution of the remains at RM2. Blue dots: faunal remains; red dots: lithic artifacts; black circles: ceramics; green dots: current fauna. 

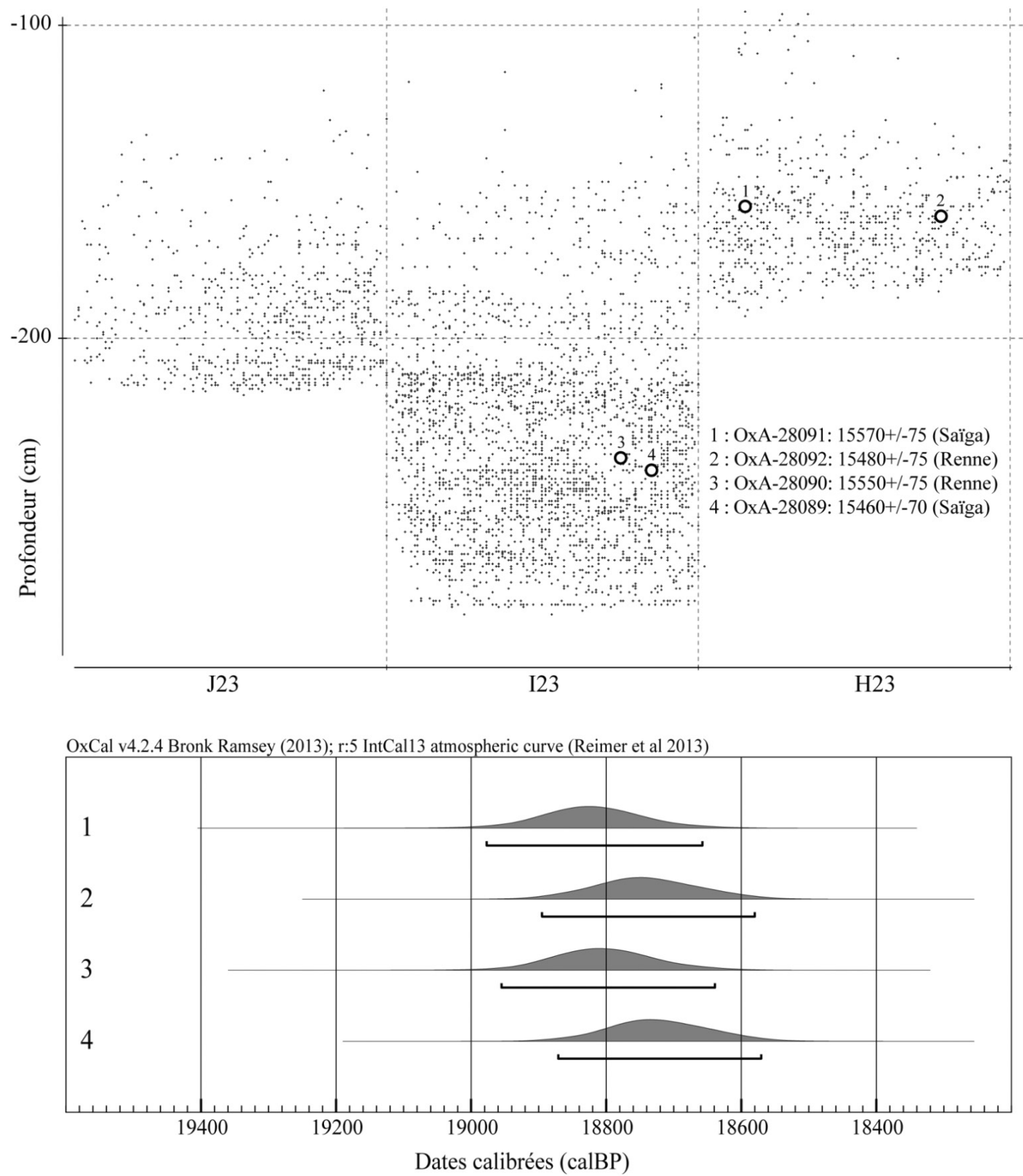

Fig. 4 - Localisation stratigraphique des échantillons datés et résultats des nouvelles datations radiocarbone du RM2.

Fig. 4 - Stratigraphic location of dated samples and results of new radiocarbon dates at RM2.

En sommet de séquence (couche 1 et sommet couche 2), des tessons de céramique et quelques restes de chat témoignent clairement d'éléments intrusifs. En ce qui concerne le renard roux (Vulpes vulpes), le blaireau (Meles meles), le lapin de garenne (Oryctolagus cuniculus) et le chien (Canis familiaris), différents indices permettent de douter de leur contemporanéité avec les vestiges paléolithiques. Des restes de renardeau et de blaireautin sont présents, ce qui témoigne généralement d'une occupation du site par ces carnivores plutôt que d'un apport par l'homme (Mallye, 2007; Mallye, 2011b; Castel et al., 2011). La plupart des restes sont complets et ne portent pas de trace de prédation, ce qui est en fort contraste avec ce qui est observé sur les restes d'ongulés. Certains de ces restes offrent une patine très différente de celle qui est observée sur les restes d'ongulés et de grands carnivores. Enfin, ils sont généralement trouvés dans le même carré et au sein du même décapage de fouille, dénotant une dispersion minimale des restes.

Le lapin est généralement présent dans les sites du Magdalénien final (Jones, 2006). Une mandibule gravée de blaireau a été identifiée dans le site de La Marche (Bourgeois, 2011). Les restes de chien en contexte paléolithique font actuellement l'objet d'un vif débat. Alors 
que certains voient les premiers indices de domestication au début du Paléolithique supérieur (Germonpré et al., 2009, 2012, 2013 et 2015; Ovodov et al., 2011; Crockford et Kuzmin, 2012) pour d'autres auteurs, l'émergence de cette innovation n'est clairement attestée que lors du DMG, il y a environ 15000 ans et serait le fait de groupes magdaléniens (Morey, 2010 et 2014; Napierala et Uerpmann, 2012; Boudadi-Maligne et al., 2012; BoudadiMaligne et Escarguel, 2014).

Concernant l'avifaune, la présence de corneille noire ou de corbeau freux et de la perdrix grise au sommet de la couche 2 (cf. infra) pose aussi question puisque ces espèces affectionnent généralement des environnements tempérés. Sur la base de la synthèse de Tyrberg (1998) et, le cas échéant, en retournant aux données sources, il apparaît que la corneille noire comme le corbeau freux ${ }^{(1)}$ ne sont pas signalés dans des sites du Sud de la France attribués avec certitude au Dryas ancien. Ces différents arguments font douter de l'homogénéité chronologique de cette association faunique qui, de fait, doit être considérée avec réserve pour la reconstitution des biocénoses. La datation directe de ces taxons permettrait de lever définitivement le doute.

Face à ce constat, nous avons vérifié la position spatiale de ces vestiges dans le remplissage (fig. 3) ${ }^{(2)}$. La projection de ces restes dans l'espace de fouille montre que, quelle que soit la travée, ils sont toujours localisés en sommet de séquence, au même niveau que les restes de céramique et dans un espace où la dispersion des vestiges coordonnés est maximale. Ce type de distribution semble caractéristique des sites bioturbés. Il est donc fort probable que le lapin de garenne, le blaireau, le chien, le chat ainsi qu'une partie des restes de renard et d'oiseaux ne soient pas contemporains des dépôts magdaléniens.

Deux dates ${ }^{14} \mathrm{C}$ par méthode classique (comptage des bêta) avaient été obtenues anciennement pour la couche 3 (Lenoir, 1993a, b, c et 2000) : $15700 \pm 430$ BP (Ly 2681) soit 20050-18060 cal. BP à 95,4\% de probabilité, et 15070 $\pm 270 \mathrm{BP}$ (Ly 4222) soit 18870-17700 cal. BP à 95,4\% de probabilité (calibration : OxCal 4.2.4, Bronk Ramsey, 2009), utilisant la courbe IntCal13 (Reimer et al., 2013). Si les ensembles décrits lors de la fouille semblaient plutô relever de lithofaciès que de couches archéologiques, lors de la projection des vestiges, deux nappes de vestiges semblaient s'individualiser à la côte $\mathrm{z}=-205$ (fig. 4). Afin de tester leur réalité temporelle, quatre échantillons ont été sélectionnés pour des datations au radiocarbone par SMA. Les résultats des datations (fig. 4) montrent un ensemble cohérent qui situe l'occupation du RM2 autour de 18900-18600 cal. BP, c'est-à-dire aux commencements du Magdalénien moyen (Langlais, 2010).

L'absence de cohérence des subdivisions faites au moment de la fouille, le caractère très homogène des dates ${ }^{14} \mathrm{C}$ et de l'industrie lithique (Sécher, sous presse, voir infra) rapportées au début du Magdalénien moyen nous ont finalement incités à ne pas tenir compte, pour la synthèse générale, des subdivisions stratigraphiques et à considérer les couches 2 et 3 comme un même ensemble archéologique.

\section{L'INDUSTRIE LITHIQUE}

Cuccédant aux travaux de M. Lenoir sur l'industrie $\checkmark$ lithique (Lenoir, 1993b et c), cette étude a été menée dans le cadre d'un mémoire de master 2 à l'université de Bordeaux (Sécher, 2013). Conditionné par le temps imparti au travail universitaire, un échantillonnage a été réalisé pour l'analyse. Au sein des $11 \mathrm{~m}^{2}$, nous avons opté pour une analyse exhaustive des pièces provenant du carré I23. Ce carré, présentant la plus grande puissance stratigraphique, est le plus riche et le seul dans lequel la couche 3 a été atteinte. Il représente en effet $37 \%$ du matériel coordonné (35\% pour le lithique seul). L'échantillon concerne $46 \%$ des outils, $48 \%$ des armatures et $53 \%$ des nucléus du secteur 2 auquel s'ajoutent les produits bruts et les déchets de débitage. Cet échantillon a été complété a posteriori par un décompte du reste de l'outillage, des armatures et des nucléus (Sécher, thèse en cours). Les premiers résultats confortent les observations faites sur le carré $123^{(3)}$. Les résultats détaillés de l'analyse lithique de I23 ayant déjà fait l'objet d'une publication (Sécher, sous presse), nous en rappelons ici les principaux points.

\section{L'approvisionnement en matières premières siliceuses}

L'examen macroscopique et microscopique - mené en collaboration avec S. Caux - de l'ensemble du corpus d'étude (I23) a permis de déterminer plusieurs matériaux. La Gironde, en particulier l'environnement proche du RM2, est riche en silex de qualités variables disponibles dans les terrasses alluviales et sur certains plateaux voisins. Toutefois, des matériaux régionaux et même d'origine lointaine ont également été mis au jour. Cela permet ainsi de préciser les zones d'approvisionnement et d'avoir un aperçu de l'économie des groupes magdaléniens.

Plus des trois-quarts de l'échantillon étudié sont constitués de matériaux d'origine locale $(<10 \mathrm{~km})$. Il s'agit pour l'essentiel de silex du Sénonien dans leurs variétés grise-noire $(70,3 \%)$ ou blonde $(4,6 \%)$, suivi de silex maastrichtiens $(0,3 \%)$ semblables à ceux du « Bergeracois $»$, et enfin de silex tertiaires $(0,3 \%)$. L'examen des surfaces corticales suggère que ces matières premières ont été principalement récupérées dans des alluvions ou sur les terrasses de la Dordogne à quelques kilomètres seulement du gisement.

Le second groupe est constitué par le silex dit « grain de mil » $(8,2 \%)$. Alors qu'il était connu dans plusieurs séries des Pyrénées et de l'ensemble du Bassin aquitain, son origine des environs de Jonzac, à une cinquantaine de kilomètres au nord du RM2, n'a été confirmée qu'assez récemment (Simonnet et al., 2007). Il fait actuellement l'objet d'une nouvelle caractérisation (Caux, 2013 et en cours).

Un dernier groupe ne correspondant qu'à quelques pièces (une lamelle, une lamelle à dos et une chute de burin dans I23) laisse présumer des liens avec la Chalosse 
(silex du Maastrichtien supérieur à Lepidorbitoides sp. à $200 \mathrm{~km}$ au sud) et la moyenne vallée du Cher (formations du Turonien inférieur à $250 \mathrm{~km}$ au nord). Notons la présence d'une lame retouchée, d'une pièce esquillée et d'une lamelle à dos en silex de Chalosse dans les autres carrés.

Enfin, les silex brûlés représentent $0,6 \%$ du corpus et la part des indéterminés est de $15,4 \%$.

La révision du spectre de matières premières confirme donc un approvisionnement majoritairement local (Lenoir, 1993b et c). Toutefois, la mise en évidence d'une composante de Saintonge non négligeable et de silex plus lointains ouvre de nouvelles perspectives. L'approvisionnement est également marqué par une mobilité plus large qui s'opère au RM2 plutôt du sud au nord avec la zone charentaise. Il y a donc une diversité dans le choix des matières premières mais pour quelle utilisation?

\section{L’outillage : une préférence laminaire}

Dans notre échantillon, l'outillage représente 157 pièces (10,8\% du corpus étudié). Il est préférentiellement fabriqué sur support laminaire $(67,5 \%)$ et à partir de matières premières majoritairement disponibles dans un environnement proche du gisement $(58 \%)$. Le silex « grain de mil » est le deuxième matériau le plus utilisé pour la confection de l'outillage (22,9\%). Les lames sont quasiexclusivement issues de séquences de plein débitage alors que les éclats proviennent essentiellement de la récupération de produits de mise en forme ou d'entretien. Les éclats constituent donc ici des sous-produits de la production lamino-lamellaire.

La composante laminaire provient d'un débitage sur bloc strictement unipolaire et selon une modalité semitournante à tournante. Un plan de frappe principal sert à l'extraction des supports. Il peut être complété par un ou deux plans de frappe nécessaires au maintien des convexités. Les nombreuses néocrêtes et sous-crêtes témoignent du soin apporté à l'entretien du nucléus afin d'optimiser la production. De même, les talons sont fréquemment abrasés ( $40 \%$ des talons des produits laminaires). L'emploi majoritaire du percuteur tendre organique conditionne de fréquents ravivages de plans de frappe comme en témoignent des tablettes. Des éclats provenant des étapes de mise en forme ont été récupérés pour constituer des supports d'appoint. L'importante fragmentation des lames n'a pas permis de réaliser une analyse morphométrique des longueurs. Les rapports largeurs/épaisseurs sont concentrés autour de 14 à $17 \mathrm{~mm}$ de largeur pour 4 à $5 \mathrm{~mm}$ d'épaisseur.

La composition typologique de l'outillage dans l'échantillon est la suivante (tabl. 1) : les lames retouchées-tronquées $\left(30,6 \%\right.$; fig. $\left.5, \mathrm{n}^{\text {os }} 8-10\right)$ devancent les burins (27,5\%; fig. 5, $\left.\mathrm{n}^{\text {os }} 1-5\right)$. Viennent ensuite les éclats retouchés-tronqués $(12,7 \%)$, les grattoirs $(8,3 \%$; fig. $\left.5, \mathrm{n}^{\text {os }} 6-7\right)$, les lamelles retouchées-tronquées $(7,6 \%)$, les éclats laminaires retouchés-tronqués $(4,5 \%)$ et les grattoirs-burins (3,8\%; fig. 5, $\left.\mathrm{n}^{\text {os }} 11-12\right)$ ainsi que les éclats lamellaires retouchés $(2,5 \%)$.

\section{Les lamelles et la fabrication des armatures de chasse}

Les supports lamellaires $(20,2 \%$ du corpus échantillonné; tabl. 2) sont quasi-exclusivement destinés à la fabrication des armatures de chasse (92,8\% des supports lamellaires) comme en témoignent certains stigmates d'impact. Les talons des supports lamellaires sont moins abrasés $(32,2 \%)$ que ceux des lames.

Les modalités de débitage sont diversifiées et issues d'une gestion différentielle de la table et des flancs :

- « pyramidale » : la table lamellaire, installée sur une face étroite, est encadrée par des flancs convergents, elle peut investir de manière semi-tournante l'ensemble du volume par petites séquences frontales qui se décalent au gré des convexités (fig. $6, \mathrm{n}^{\circ} 1$ );

- «prismatique» : la table lamellaire, installée sur une face large, est bordée de flancs perpendiculaires. La progression y est enveloppante à semi-enveloppante (fig. 6, n 2);

- « sur tranche » : la table lamellaire est installée sur la face étroite et exploitée selon une progression strictement frontale (fig. 6, $\mathrm{n}^{\circ} 3$ ). Cette modalité limite la mise en forme du nucléus et permet plus aisément l'extraction de supports (Langlais, 2010);

- association d'une table pyramidale sur la face étroite et d'une table prismatique sur la face large (fig. 6, no 4). Ce dernier type souligne bien une perméabilité dans les modalités opératoires pour des objectifs de production proches voire similaires. L'état d'abandon de ce type de nucléus montre bien une optimisation du débitage du rognon de silex à la fois sur sa face large et sur sa face étroite.

Au-delà de cette apparente diversité de modalités lamellaires, les supports obtenus sont relativement normés avec des gabarits de 8 à $11 \mathrm{~mm}$ de largeur pour 2 à $3 \mathrm{~mm}$ d'épaisseur (fig. 6, nos 5-10; fig. 7). Du fait de l'aménagement du dos, les largeurs des armatures sont nettement réduites et davantage recentrées autour d'une valeur de 4 à $5 \mathrm{~mm}$ (fig. 6, nos 11-24; fig. 7) qui peut constituer une « norme » de fabrication reflétant une possible nécessité fonctionnelle pour l'emmanchement. Par ailleurs, 97\% des armatures présentent au moins une cassure dont environ $7 \%$ sont diagnostiques d'une utilisation comme éléments de projectile. Cette très forte fragmentation des supports pourrait être mis en regard d'une nécessité d'obtenir des fragments de profil rectiligne et donc plus aptes à l'emmanchement. Si l'on considère seulement les armatures ayant au moins une extrémité, les lamelles à dos tronquées représentent au moins $10 \%$ des armatures (NMI : nombre d'armatures tronquées avec au moins une extrémité complète sur le nombre total d'armatures avec au moins une extrémité). Les troncatures ont une délinéation variable (rectiligne à oblique; fig. 6, $\mathrm{n}^{\text {os }}$ 21-24). Pour l'ensemble des armatures, aucune latéralisation préférentielle des dos n'a été observée.

Comme pour la production laminaire, des indices d'entretien des convexités sont présents sur les nucléus mais aussi sous la forme de produits (sous-crêtes, néocrêtes, etc.). Les plans de frappe ont également été régulièrement entretenus par l'extraction de tablettes de ravivage. Parmi ces tablettes, une a été recyclée en burin. 


\begin{tabular}{|c|c|c|c|}
\hline Typologie & Effectifs & Fréquences & Fréquences intra-groupe \\
\hline Lame retouchée-tronquée-appointée & 48 & $30,6 \%$ & \\
\hline Lame retouchée & 37 & $23,6 \%$ & $77,1 \%$ \\
\hline Lame tronquée & 5 & $3,2 \%$ & $10,4 \%$ \\
\hline Lame tronquée retouchée & 3 & $1,9 \%$ & $6,3 \%$ \\
\hline Lame appointée & 1 & $0,6 \%$ & $2,1 \%$ \\
\hline Lame denticulée & 1 & $0,6 \%$ & $2,1 \%$ \\
\hline Lame encochée & 1 & $0,6 \%$ & $2,1 \%$ \\
\hline Burin & 43 & $27,5 \%$ & \\
\hline Burin dièdre d'axe & 9 & $5,7 \%$ & $20,9 \%$ \\
\hline Burin d'angle sur cassure & 9 & $5,7 \%$ & $20,9 \%$ \\
\hline Burin dièdre déjeté & 6 & $3,8 \%$ & $14 \%$ \\
\hline Burin sur troncature oblique & 4 & $2,6 \%$ & $9,3 \%$ \\
\hline Burin fragmenté & 3 & $1,9 \%$ & $7 \%$ \\
\hline Burin multiple & 3 & $1,9 \%$ & $7 \%$ \\
\hline Burin d'angle & 2 & $1,3 \%$ & $4,7 \%$ \\
\hline Burin d'axe & 2 & $1,3 \%$ & $4,7 \%$ \\
\hline Burin double & 1 & $0,6 \%$ & $2,3 \%$ \\
\hline Burin double sur cassure & 1 & $0,6 \%$ & $2,3 \%$ \\
\hline Burin double sur troncature oblique & 1 & $0,6 \%$ & $2,3 \%$ \\
\hline Burin double sur troncature rectiligne & 1 & $0,6 \%$ & $2,3 \%$ \\
\hline Burin sur troncature rectiligne & 1 & $0,6 \%$ & $2,3 \%$ \\
\hline Éclat retouché-tronqué & 20 & $12,7 \%$ & \\
\hline Éclat retouché & 8 & $5,1 \%$ & $40 \%$ \\
\hline Éclat tronqué & 8 & $5,1 \%$ & $40 \%$ \\
\hline Éclat tronqué retouché & 4 & $2,5 \%$ & $20 \%$ \\
\hline Grattoir simple & 13 & $8,3 \%$ & \\
\hline Lamelle retouchée-tronquée & 12 & $7,6 \%$ & \\
\hline Lamelle retouchée & 11 & $7 \%$ & $91,7 \%$ \\
\hline Lamelle tronquée & 1 & $0,6 \%$ & $8,3 \%$ \\
\hline Éclat laminaire & 7 & $4,5 \%$ & \\
\hline Éclat laminaire retouché & 4 & $2,5 \%$ & $57,1 \%$ \\
\hline Éclat laminaire tronqué retouché & 2 & $1,3 \%$ & $28,6 \%$ \\
\hline Éclat laminaire tronqué & 1 & $0,6 \%$ & $14,3 \%$ \\
\hline Grattoir-burin & 6 & $3,8 \%$ & \\
\hline Éclat lamellaire retouché & 4 & $2,5 \%$ & \\
\hline Divers & 4 & $2,5 \%$ & \\
\hline Fragment d'outil & 3 & $1,9 \%$ & $75 \%$ \\
\hline Pièce esquillée & 1 & $0,6 \%$ & $25 \%$ \\
\hline Total général & 157 & $100 \%$ & \\
\hline
\end{tabular}

Tabl. 1 - Inventaire typologique de l'outillage du carré I23 du RM2.

Table 1 - Typological inventory of tools from square I23 of RM2. 

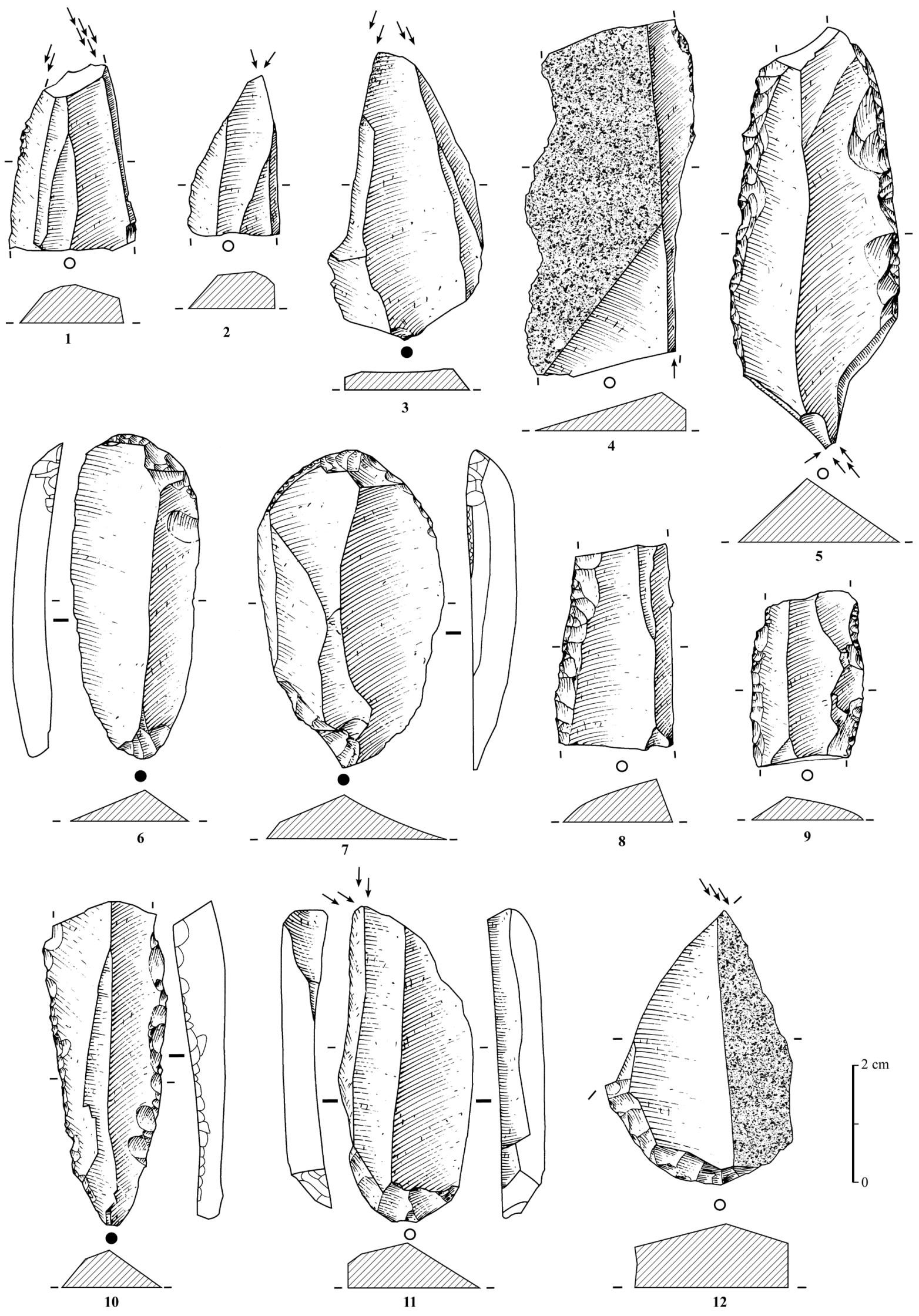

Fig. 5 - Exemples d'outils du carré I23 du RM2. 1-5 : burins; 6-7 : grattoirs; 8-10 : lames retouchées; 11-12 : grattoirs-burins (dessins G. Devilder).

Fig. 5 - Examples of lithic tools from square I23 at RM2. 1-5: burins; 6-7: end-scrapers; 8-10: retouched blades; 11-12: end-scraper/ burin (drawings G. Devilder). 


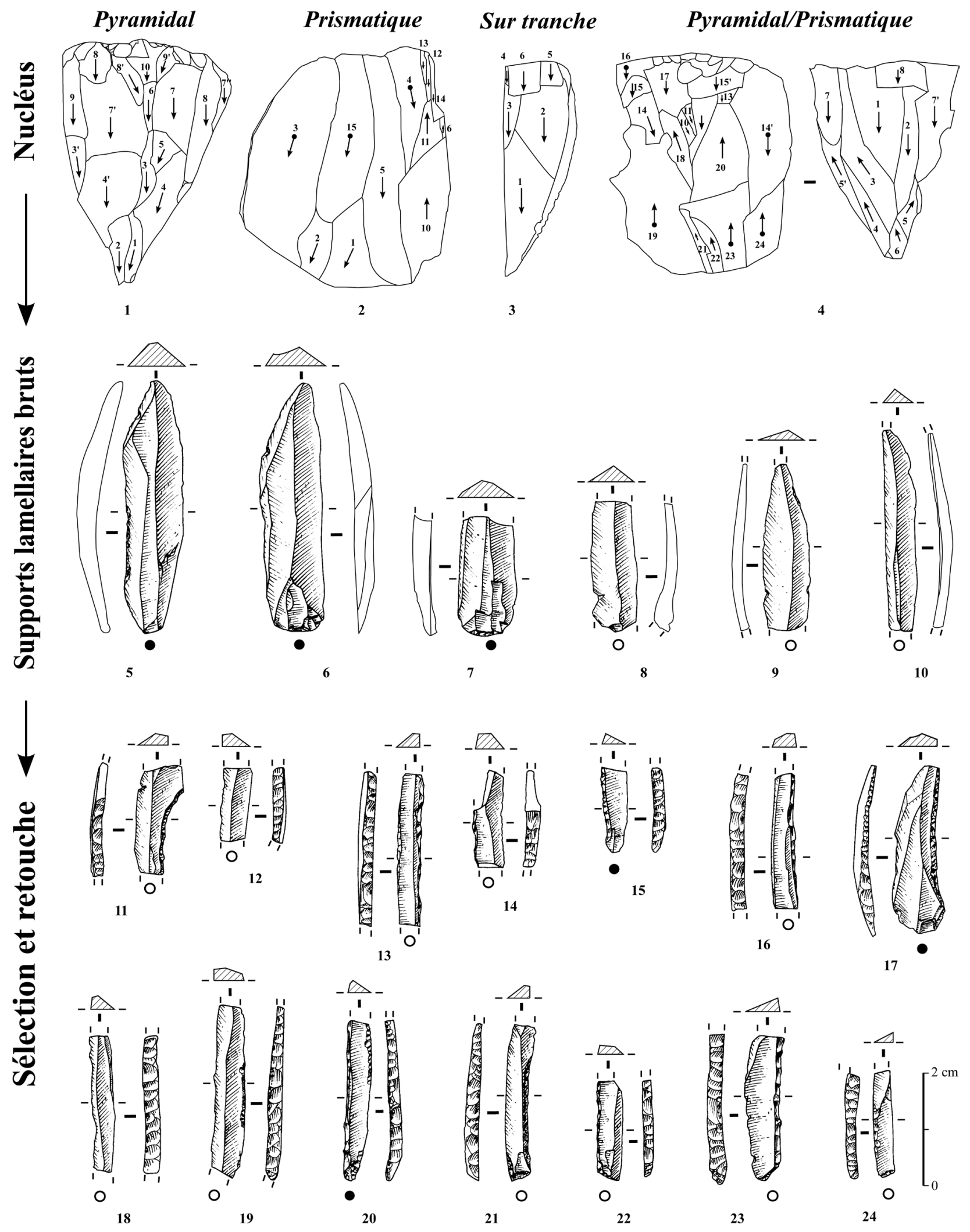

Fig. 6 - Production lamellaire et fabrication des éléments d'armatures lithiques. 1 : nucléus pyramidal; $2:$ nucléus prismatique; $3:$ nucléus sur tranche d'éclat; 4 : nucléus mixte pyramidal et prismatique; 5-10: lamelles brutes; $11:$ lamelle à dos partiel; 12-20: lamelles à dos simple; 21-24 : lamelles à dos tronquées (DAO A. S. ; dessins G. Devilder).

Fig. 6 - Bladelet production and manufacturing products of of microlithic elements. 1: pyramidal core; 2: prismatic core; 3: so-called sur tranche d'éclat' cores; 4: mixed pyramidal and prismatic core; 5-10 : unretouched bladelets; 11: partially backed bladelet; $12-$ 20 : simple backed bladelets; 21-24: truncated-backed bladelets (CAD A. S.; drawings G. Devilder). 


\begin{tabular}{|l|c|c|} 
Typologie & $\begin{array}{c}\text { Effectifs } \\
(\mathrm{NR})\end{array}$ & Fréquences \\
\hline Lamelles à dos simple & 152 & $55,9 \%$ \\
\hline Lamelles à dos retouchées & 43 & $15,8 \%$ \\
\hline Lamelles à dos tronquées & 34 & $12,5 \%$ \\
\hline Lamelles à dos partiel & 16 & $5,9 \%$ \\
\hline $\begin{array}{l}\text { Lamelles à dos tronquées } \\
\text { retouchées }\end{array}$ & 11 & $4,1 \%$ \\
\hline Éclats lamellaires à dos simple & 10 & $3,7 \%$ \\
\hline Éclats lamellaires à dos retouchés & 3 & $1,1 \%$ \\
\hline Lamelles à dos partiel retouchées & 2 & $0,7 \%$ \\
\hline Eclats lamellaires à dos tronqués & 1 & $0,4 \%$ \\
\hline Total & 272 & $100 \%$ \\
\hline
\end{tabular}

Tabl. 2 - Inventaire typologique des armatures de chasse du carré I23 du RM2.

Table 2 - Typological inventory of lithic projectile points from square I23 of RM2.

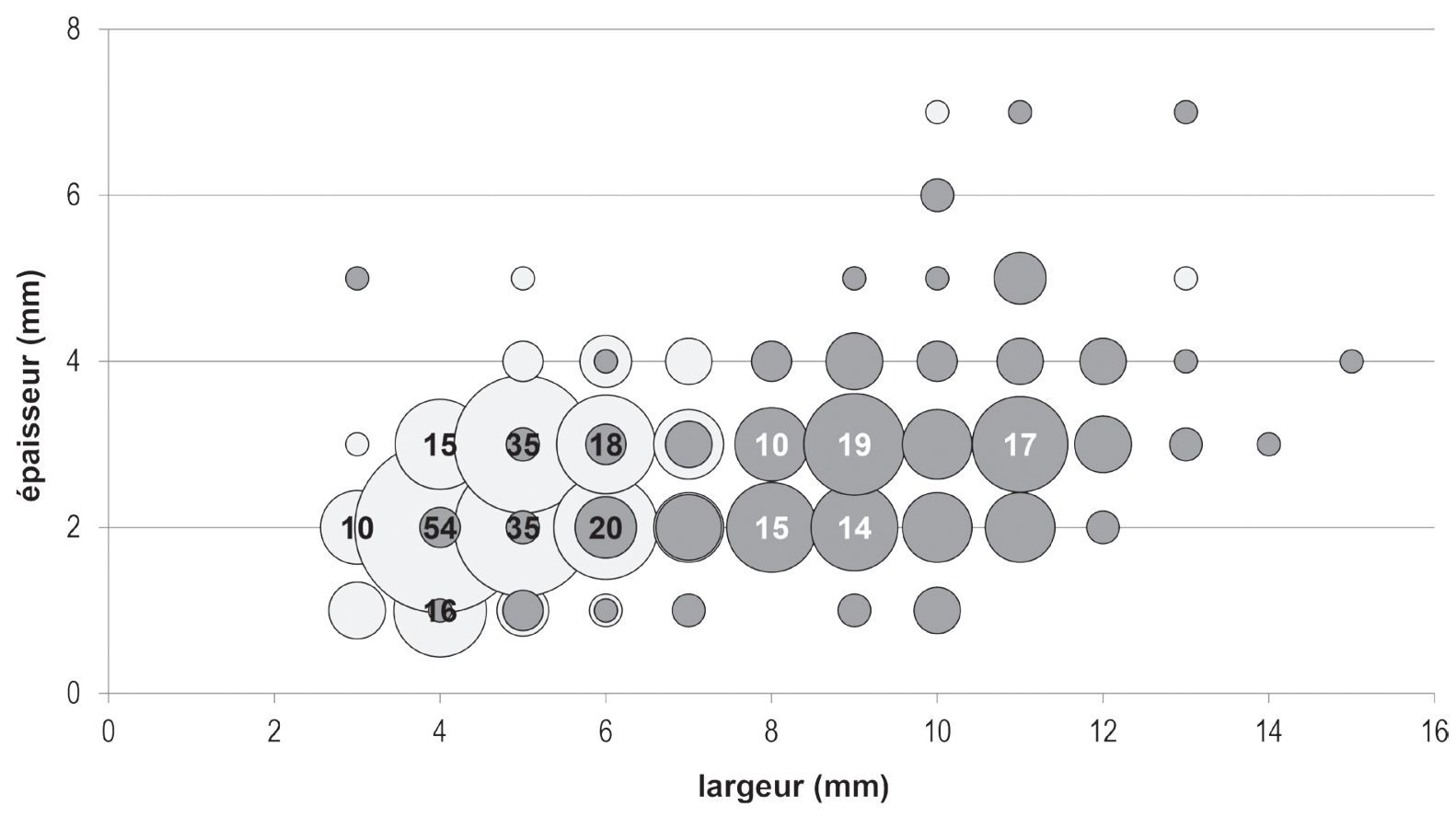

o Armatures

- Supports lamellaires bruts

Fig. 7 - Gabarits des armatures $(\mathrm{n}=274$; nombres en noir $)$ comparés à ceux des supports bruts $(\mathrm{n}=190$; nombres en blanc)

Fig. 7 - Size of elements $(n=274$; black numbers) compared with unretouched bladelets $(n=190$; white numbers).

\section{Comportement techno-économique et gestion du territoire}

Au-delà du seuil morphométrique, la différence entre production laminaire et production lamellaire se fonde sur une double disjonction. La première, conceptuelle et technologique, est illustrée par une séparation des chaînes opératoires et une différenciation dans la gestion volumétrique des nucléus. La seconde est économique et fonctionnelle. En effet, les lames, normalisées, sont vouées à la fabrication de l'outillage (principalement des lames retouchées $s$. $l$. et des burins). Quant aux lamelles, elles sont destinées à la fabrication des armatures de chasse normalisées. Par ailleurs, aucun débitage autonome d'éclats n'a été mis en évidence. Toutefois, des déchets de taille laminaire (éclats, néocrêtes, etc.) ont été récupérés et utilisés de manière secondaire comme appoint pour la fabrication d'outils (environ $20 \%$ des outils de I23).

Il est intéressant de noter que les modes de production de supports lamellaires sont diversifiés (voir supra) pour l'obtention de supports bruts relativement normalisés dont la finalité est quasi-exclusivement l'armature de chasse. Au regard des volumes exploités (blocs, rognons, éclats), nous n'observons pas d'archétypes distincts au niveau des gabarits pouvant être corrélés à une modalité particulière. Toutefois, les armatures reflètent une gamme typologique assez diversifiée : lamelles à dos au tranchant parfois retouché ou à l'extrémité tronquée (rectiligne à oblique). La présence relativement importante de lamelles 
à dos tronquées n'est pas sans rappeler le secteur 1 du Rocde-Marcamps ou Moulin-Neuf (Lenoir, 1983). L'absence de lamelle scalène (bien documentée dans le site voisin de Saint-Germain-la-Rivière; Lenoir, 1983 ; Langlais et al., 2015) et la variation typologique des armatures alimentent la question de particularismes territoriaux tandis que l'outillage présente une relative unité à l'échelle du Magdalénien moyen ancien dans le Sud-Ouest de la France (voir synthèse infra et Langlais et al., soumis).

Les matières premières locales (voir supra), principalement le Sénonien noir, ont fait l'objet d'un débitage sur place. La part du silex « grain de mil » est plus importante dans l'outillage $(22,9 \%)$ et parmi les chutes de burin (32,9\%, contre $25,7 \%$ en Sénonien noir). Il y aurait donc au RM2 un apport de produits en matières de Charente-Maritime (supports laminaires, burins, grattoirs, etc.) qui auraient fait l'objet de nombreuses transformations (retouches et ravivages). Les pièces cassées ou trop réduites ont été abandonnées sur place. Le faible nombre de pièces techniques, de produits corticaux ou d'éclats de débitage en " grain de mil » et en d'autres matières non locales confirme cette tendance. Par ailleurs, quelques pièces témoignent discrètement de liens avec la Touraine et la Chalosse.

Il ressort ainsi de cette analyse une segmentation dans l'espace et le temps des chaînes opératoires laminaires et lamellaires. L'apport de produits finis ou de pré- formes suggère une forte anticipation et une planification des besoins en matériaux. De même, la conception de nucléus lamellaires sur tranche d'éclats permet d'avoir un volume prêt au débitage, facilement transportable et très rapidement utilisable. Cette planification des besoins en matériaux de bonne qualité laisse supposer si ce n'est des expéditions spécialisées, en tout cas une mobilité territoriale du groupe étendue à la zone girondine et charentaise avec des «contacts » sur ses marges nord (Poitou) et sud (Landes).

\section{L'INDUSTRIE EN OS ET BOIS DE CERVIDÉ}

$\mathrm{R}$ M2 a livré soixante-dix-huit pièces travaillées en bois de cervidé et os (tabl. 3). Les pièces d'industrie osseuse ont été isolées au sein de la faune lors de l'étude archéozoologique, les raccords entre fragments ont été systématiquement recherchés et toutes les pièces ont été observées à la loupe binoculaire. Dans l'ensemble, l'industrie osseuse est dans un état de conservation correct, les principaux problèmes étant la présence fréquente de petites zones concrétionnées et l'intensité de la fragmentation post-dépositionnelle; comme souvent, les vestiges en bois de cervidé sont en moyenne moins bien conservés que l'industrie en os.

\begin{tabular}{|c|c|c|c|}
\hline \multirow{12}{*}{ Os } & \multirow{2}{*}{$\mathrm{DD}$} & DD longitudinal par DR & 7 \\
\hline & & DD transversal par sciage & 3 \\
\hline & \multirow{2}{*}{ Supports } & Baguettes & 2 \\
\hline & & Hémicôtes & 4 \\
\hline & \multirow{3}{*}{ Objets finis } & Aiguilles & 4 \\
\hline & & Lissoirs & 3 \\
\hline & & Autres & 2 \\
\hline & \multirow{3}{*}{ Outils non façonnés } & Retouchoirs & 13 \\
\hline & & Retouchoirs-outils d'extrémité & 1 \\
\hline & & Outils d'extrémité & 4 \\
\hline & \multicolumn{2}{|l|}{ Os raclés } & 6 \\
\hline & \multicolumn{2}{|l|}{ Total os } & 49 \\
\hline \multirow{10}{*}{ Bois de cervidé } & \multirow{2}{*}{ DD } & Élagage digitation & 2 \\
\hline & & DD longitudinal par DR & 3 \\
\hline & Supports & Baguettes & 1 \\
\hline & Déchets de façonnage & Cf. « base raccourcie » & 1 \\
\hline & \multirow{3}{*}{ Objets finis } & Bâtons percés & 1 \\
\hline & & Armatures & 5 \\
\hline & & Objets sur baguette indéterminés & 13 \\
\hline & Éclats & & 1 \\
\hline & Bois travaillés & & 2 \\
\hline & Total bois & & 29 \\
\hline \multicolumn{3}{|c|}{ TOTAL INDUSTRIE OSSEUSE } & 78 \\
\hline
\end{tabular}

Tabl. 3 - Composition typotechnologique de l'industrie osseuse du RM2. DD : déchets de débitage; DR : double rainurage.

Table 3 - Typo-technological composition of osseous industry at RM2. DD = manufacturing waste; DR = groove and splinter technique. 


\section{L'industrie en os}

Les quarante-neuf pièces d'industrie en os sont majoritairement produites à partir de côtes et d'os longs d'ongulés. Parmi les pièces qui ont pu être déterminées taxinomiquement, l'antilope saïga, les Bovinés, le cheval et le renne sont les taxons les plus exploités (entre trois et huit pièces pour chacun), comme cela est le cas dans le spectre faunique.

Ces pièces permettent de documenter principalement trois types de production : aiguilles, lissoirs et retouchoirs.

La fabrication d'aiguilles est attestée par six déchets de débitage présentant des traces d'extraction de baguette par double rainurage longitudinal (fig. 8, $\mathrm{n}^{\text {os }} 1$-2). Les blocs exploités sont deux métapodiens de renne et quatre os longs de mammifères de taille petite à moyenne; les baguettes extraites sont larges de 2 à $5 \mathrm{~mm}$. Les pièces sont trop fragmentaires pour livrer des indications sur la productivité des débitages, excepté un déchet montrant l'extraction de deux baguettes parallèles à partir du même bloc (fig. 8, $\mathrm{n}^{\circ} 2$ ). Les produits de ce type de débitage sont présents sous la forme de deux fragments de baguettes osseuses en cours de façonnage et quatre fragments d'aiguilles finies (fig. 8, $\mathrm{n}^{\text {os }} 3-4$ ) de section ovale, larges de 1,5 à $3,5 \mathrm{~mm}$ et épais de 1 à $2,5 \mathrm{~mm}$; seul un exemplaire a conservé une partie de son chas (fig. 8, $\mathrm{n}^{\circ} 4$ ).

La fabrication de lissoirs est documentée par un déchet sur apophyse vertébrale de boviné montrant l'extraction, par double rainurage longitudinal, d'une baguette large de $21 \mathrm{~mm}$ sur une des faces latérales. Quatre fragments d'hémicôtes larges de 14 à $20 \mathrm{~mm}$ - et provenant donc d'ongulés de grande taille - présentent sur chaque bord un pan de rainure, témoignant ainsi du débitage de côtes en deux hémicôtes par rainurage longitudinal bilatéral (fig. 8, no 5). Bien qu'elles soient présentées comme supports dans le tableau 3 , en première approche, ces quatre pièces peuvent être interprétées comme des supports ou comme des déchets, le principe de ce schéma opératoire étant de diviser le bloc osseux en deux moitiés symétriques dont chacune est, a priori, utilisable en tant que support. Les objets finis sont représentés par un probable fragment proximal de lissoir décoré d'incisions (fig. $8, \mathrm{n}^{\circ} 6$ ) et deux fragments mésiaux de lissoirs dont la largeur indique également l'exploitation de côtes de grands ongulés (fig. 8, $\mathrm{n}^{\circ} 7$ ).

RM2 a également livré trois éléments osseux - deux métapodiens de saïga et une côte de cheval - sectionnés par sciage transversal et flexion, ainsi que six fragments d'os d'ongulés de taille petite ou moyenne - un de côte, deux d'os long et trois de métacarpien - présentant des traces de raclage longitudinal qui ne semblent pas se rapporter à des opérations de boucherie. À titre d'hypothèse, nous proposons d'associer ces neuf pièces aux deux schémas opératoires décrits ci-dessus (production d'aiguilles et de lissoirs par double rainurage). Ils relèveraient alors des phases initiales d'exploitation des blocs osseux : nettoyage des blocs par raclage, détachement de blocs secondaires par sciage et flexion. Trois extrémités distales de métacarpiens de saïga présentant des traces de raclage longitudinal sur toutes les faces de la diaphyse pourraient ainsi être de futures matrices d'aiguilles.

L'outillage osseux comprend aussi un nombre important d'outils non façonnés $(n=18)$. Cet ensemble est dominé par une série de quatorze retouchoirs qui présentent des caractères relativement homogènes, signalant probablement une sélection exigeante des supports au sein des vestiges de faune (fig. 8, $\mathrm{n}^{\text {os }} 8-9$ ). En effet, bien que les fragments osseux utilisés soient relativement variés (dix éclats de diaphyse d'os longs d'ongulés de taille moyenne ou grande - saïga, renne, cheval, bovinés -, un éclat de diaphyse de métatarsien de boviné, un éclat de diaphyse de métacarpien de saïga, un fragment de mandibule de cheval, un tronçon de côte de boviné), les objets présentent des dimensions assez stables, suggérant la recherche d'un module spécifique : longueur d'environ 75 à $130 \mathrm{~mm}$ pour dix des douze exemplaires entiers (moyenne 107,8 $\pm 29,1 \mathrm{~mm}$ ) ; largeur d'environ 20 à $40 \mathrm{~mm}$ (moyenne 30,8 \pm 9,7 $\mathrm{mm}$ ); tissu compact épais en général de 4 à $10 \mathrm{~mm}$ (moyenne $6 \pm 2,4 \mathrm{~mm}$ ). L'utilisation de ces retouchoirs semble par ailleurs avoir été peu intense : la plupart ne présentent qu'une plage de stigmates d'utilisation (seuls trois ou quatre en présentent deux) et ces stigmates sont, dans tous les cas, peu ou très peu marqués.

Les autres outils - trois éclats de diaphyse (un tibia de cheval, deux os longs d'ongulés de taille moyenne à grande) et un tronçon de côte de grand ongulé - montrent à l'une des extrémités des traces suggérant une utilisation comme partie active d'outil (émoussé, écrasement, esquillement). De dimensions et de forme variées, ces pièces ont été rassemblées sous l'appellation « outils d'extrémité » en attendant une caractérisation plus précise. Un des retouchoirs présente également, sur une extrémité, des traces d'utilisation similaires.

Enfin, la série comprend deux pièces ne s'inscrivant dans aucun des types de production détaillés ci-dessus. Il s'agit d'un fragment d'ulna d'oiseau raclé et décoré d'incisions transversales (voir infra) et un fragment d'outil indéterminé, façonné par raclage sur une baguette large et épaisse extraite d'un tibia de boviné.

\section{L'industrie en bois de cervidé}

Parmi les vingt-neuf pièces travaillées en bois de cervidé, seul le bois de renne a été identifié de façon certaine; une seule pièce pourrait, sans certitude, être en bois de cerf. Les bois exploités sont essentiellement de gros module (épaisseur moyenne du tissu compact : 5,6 $\pm 1,8 \mathrm{~mm}$, une fois exclus les déchets sur digitation et les fragments d'objets finis longs de moins de $30 \mathrm{~mm}$ ). Les pièces disponibles ne permettent de déterminer ni les modalités d'acquisition des bois (chute ou massacre), ni le nombre minimum de bois introduits sur le site.

Un éclat témoigne du travail de la perche par percussion (fig. 9, no 1), mais ne peut être rattaché à aucun schéma opératoire précis. En dehors de cet unique objet, seules deux opérations techniques sont clairement attestées : l'élagage de digitations par rainurage bifacial 

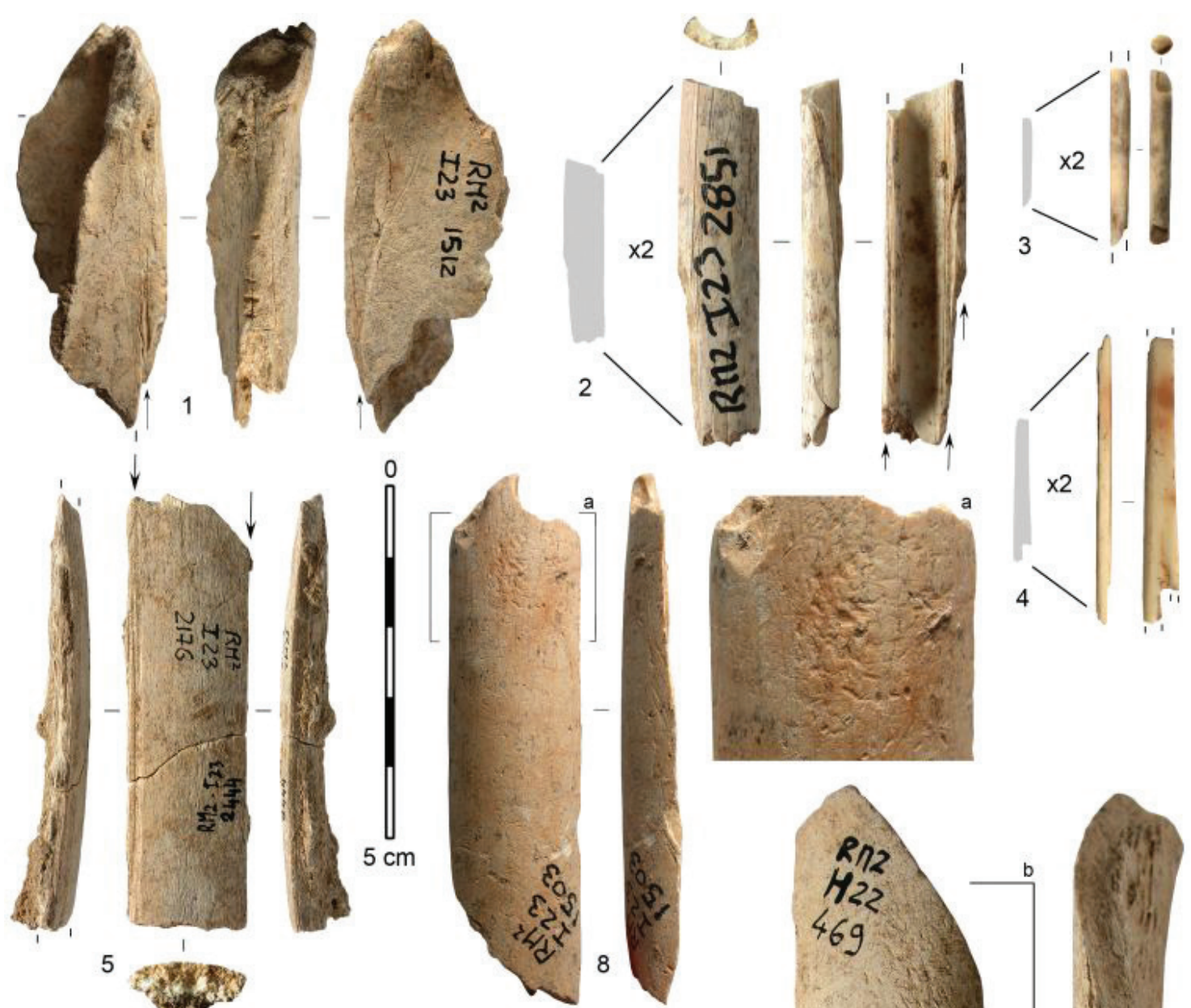

5
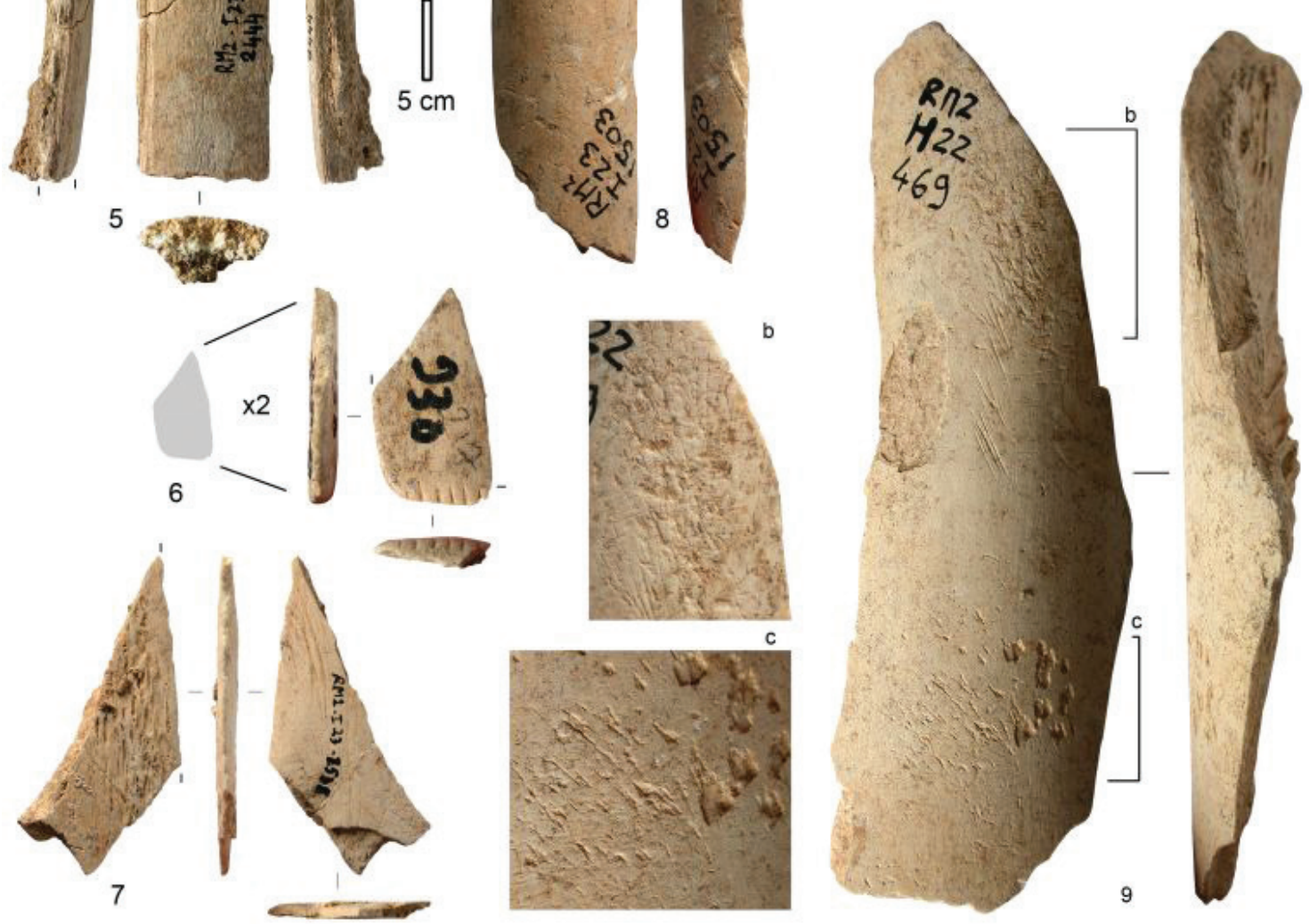

Fig. 8 - Industrie en os du RM2 (les flèches indiquent les pans de rainure). 1 : déchet d'extraction de baguette par double rainurage sur métatarsien de renne; 2 : déchet d'extraction de baguette par rainurage multiple sur os long de petit mammifère; 3-4: fragments mésiaux d'aiguille; 5 : fragment de support ou déchet sur hémicôte, avec traces de double rainurage longitudinal; $6:$ fragment proximal de lissoir décoré; 7 : fragment mésial de lissoir sur hémicôte; 8 : retouchoir sur fémur de saïga et détail de la plage de stigmates d'utilisation (a); 9 : retouchoir sur os long de grand ongulé et détail des deux plages d'utilisation (b, c).

Fig. 8 - Bone industry from RM2 (arrows indicate the grooving traces). 1: manufacturing waste with traces of splinter removal by the groove and splinter technique (reindeer metatarsal); 2: manufacturing waste with traces of multiple splinter removal by the groove and splinter technique (long bone of small mammal); 3-4: mesial needle fragments; 5: fragment of blank or waste product on rib splinter, with traces of groove and splinter technique; 6: proximal fragment of decorated smoother; 7: mesial fragment of smoother on rib splinter; 8: retoucher on saiga femur and detail of the usewear marks (a); 9: retoucher on long bone of large ungulate and detail of the zones bearing usewear marks $(b, c)$ 

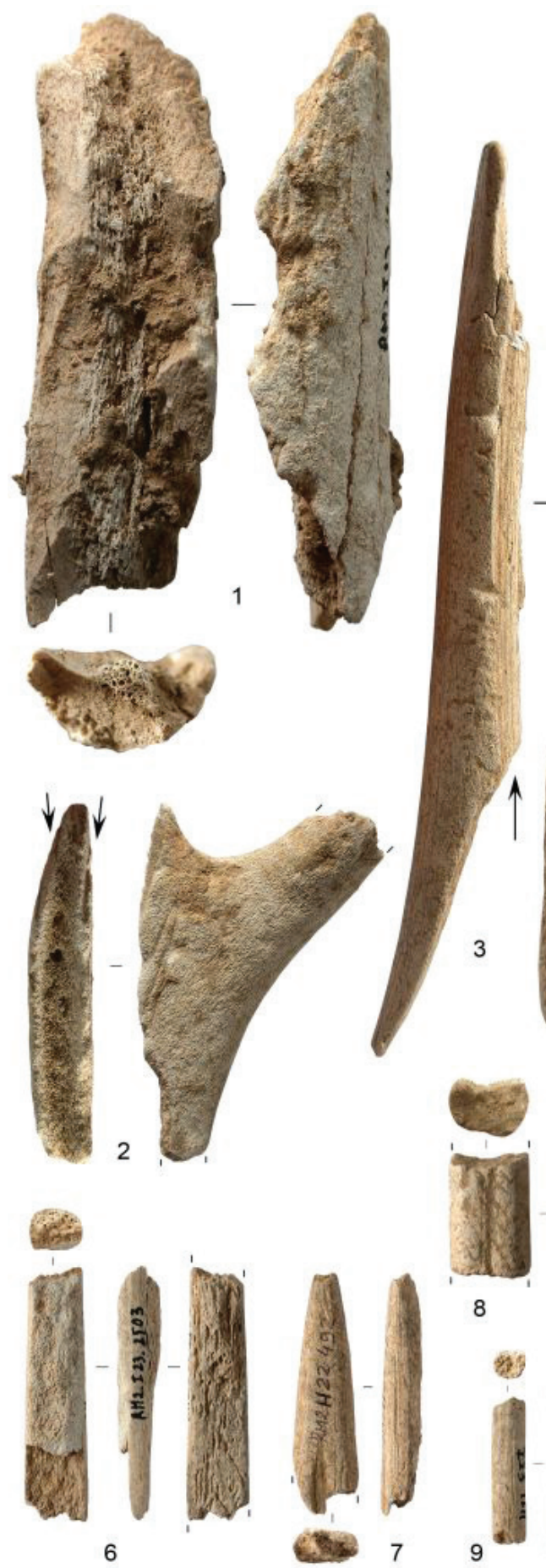

8
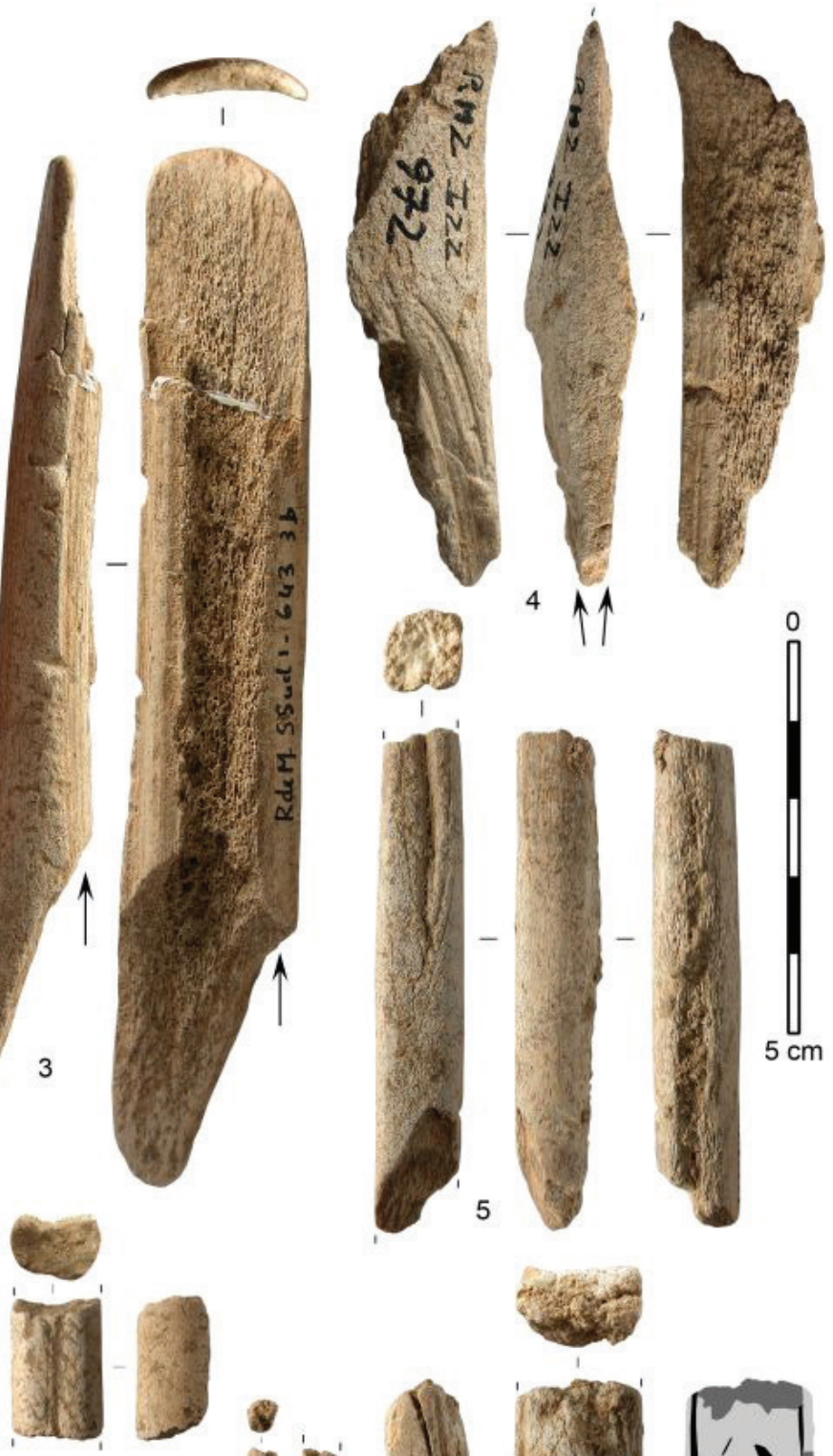

4

$\uparrow \uparrow$

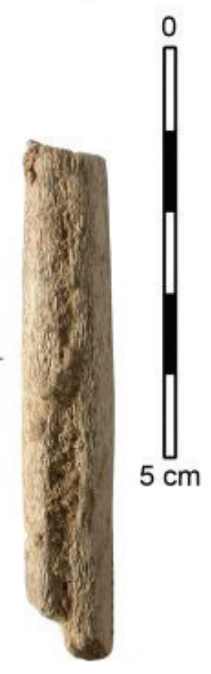

6
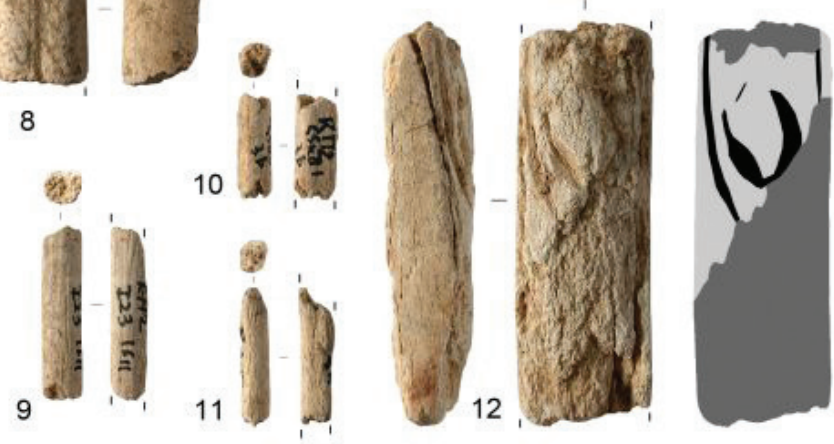

Fig. 9 - Industrie en bois de cervidé du RM2. 1 : éclat sur perche; 2 : déchet d'élagage de digitation par rainurage bifacial opposé (les flèches indiquent les pans de rainure); 3-4 : déchets d'extraction de baguette par double rainurage longitudinal (les flèches indiquent les pans de rainure; le $\mathrm{n}^{\circ} 3$ présente un poli distal indiquant une réutilisation comme outil spatuliforme); 5 : fragment mésial de pointe de projectile avec rainure sur les faces supérieure et inférieure; 6 : fragment mésial de pointe à biseau simple (avec incisions descendantes sur le biseau); 7-8 : fragments de pointe de projectile avec rainure sur la face supérieure; 9-11 : fragments mésiaux de fins outils allongés (les $\mathrm{n}^{\text {os }} 10$ et 11 se rapportent probablement au même objet); 12 : fragment mésial d'objet sur baguette décoré, avec schéma du décor gravé (noir : traits gravés; gris foncé : surface mal conservée).

Fig. 9 - Antler industry from RM2. 1: flake from an antler beam; 2: waste product resulting from the sectioning of an antler tine by bilateral grooving (arrows indicate the grooving traces); 3-4: manufacturing waste with traces of splinter removal by the groove and splinter technique (arrows indicate the grooving traces; number 3 has a distal polish indicating its reuse as a spatulate tool); 5: mesial fragment of projectile point with groove on the upper and lower sides; 6: mesial fragment of single-bevelled point (with downward incisions on bevel); 7-8: point fragments with groove on the upper side; 9-11: mesial fragments of fine elongated tools (numbers 10 and 11 probably come from the same object); 12: mesial fragment of decorated object on splinter, with sketch of the decoration (black: engraved lines; dark grey: poorly preserved surface). 
opposé (deux pièces : fig. $9, \mathrm{n}^{\circ} 2$ ) et le débitage de la perche par double rainurage longitudinal pour la production de baguettes larges de 10 à $20 \mathrm{~mm}$ (trois déchets et un support brut de débitage). Les indications sur la productivité de ces débitages sont rares : un déchet montre une extraction unique (fig. 9, n⿳3 3), tandis qu'un autre présente deux pans de rainure convergents (cf. déchet de type triangle), indiquant probablement l'extraction d'au moins deux baguettes à partir du même tronçon (fig. 9, nº 4).

Les objets finis comprennent un possible fragment distal de bâton percé et dix-huit fragments d'objets sur baguette, essentiellement des armatures de projectile $(n=5)$ ou des fragments compatibles avec cette attribution $(n=6)$. Ces armatures sont de section subquadrangulaire et de calibre assez important (dimensions moyennes des six fragments longs de plus de $30 \mathrm{~mm}$ : largeur 9,7 $\pm 1,8 \mathrm{~mm}$; épaisseur $6,9 \pm 1,9 \mathrm{~mm}$ ). Quatre pièces présentent une rainure longitudinale sur la face supérieure, accompagnée, dans un cas, d'une seconde sur la face opposée (fig. 9, $\mathrm{n}^{\text {os }} 5,7$ et 8). La seule base identifiée est en biseau simple (fig. 9, $\mathrm{n}^{\circ} 6$ ).

Sept autres fragments mésiaux d'objets sur baguette ne semblent pas, d'après leur morphologie et leurs dimensions, se rattacher à la fonction d'armature. Cinq d'entre eux, dont deux se rapportent probablement au même objet, se caractérisent par un calibre réduit $(3,5$ à $5 \mathrm{~mm}$ de largeur et d'épaisseur) et une section circulaire qui évoquent plutôt une production de fins outils allongés (cf. alênes? fig. 9, $\mathrm{n}^{\text {os }}$ 9-11). Un dernier objet, de gros calibre - fragment d'outil intermédiaire? -, présente sur la face supérieure un décor gravé qui n'est malheureusement que très partiellement conservé (fig. 9, n 12).

\section{ÉLÉMENTS DE PARURE ET ASSIMILÉS}

U n total de soixante restes liés à la parure a été découvert au RM2. Il se compose de cinquante-deux coquillages et de huit dents animales (tabl. 4).

\section{Les coquillages}

Parmi les coquillages, les scaphopodes sont les plus nombreux $(n=38)$. Ils regroupent plusieurs espèces de dentales à la surface lisse $(\mathrm{n}=19)$ ou ornée de côtes longitudinales $(n=19)$ dont l'origine fossile ou subactuelle $n$ 'a pas pu être déterminée. En dehors de quatre exemplaires entiers, les coquilles de scaphopodes sont présentes sous forme de tronçons aux dimensions (entre 2 et $23 \mathrm{~mm}$ de longueur) et aux provenances anatomiques variées (six antérieures, deux postérieures, vingt et une mésiales et cinq indéterminées). La présence, parfois simultanée, de stries de dérapage, pans et sillons de sciage $(n=5$ : fig. $10, n^{\text {os }} 1$ et 3$)$ et de fractures en languette $(n=10$ : fig. $10, \mathrm{n}^{\circ} 3$ ) situés sur les extrémités des tronçons atteste un sectionnement volontaire des coquilles par sciage et flexion. Huit tronçons ont été identifiés comme étant des objets finis par la présence de traces de finition $(n=3)$ et d'usure $(\mathrm{n}=8)$. La finition des tronçons de scaphopodes a

\begin{tabular}{|c|c|c|}
\hline & SCAPHOPODE & 38 \\
\hline & GASTEROPODE & 11 \\
\hline & Vitta picta & 4 \\
\hline & Nassarius reticulatus & 3 \\
\hline & Nucella lapillus & 1 \\
\hline & Trivia europea & 1 \\
\hline $\bar{g}$ & Aporrhais pespelecani & 1 \\
\hline & Cyclope neritea & 1 \\
\hline & BIVALVE & 3 \\
\hline & Cardiidae & 2 \\
\hline & Glycymeridae & 1 \\
\hline & DENT & 8 \\
\hline & Incisive de renne & 5 \\
\hline & Incisive de lièvre & 1 \\
\hline & Canine de renard & 1 \\
\hline & Incisive de cheval & 1 \\
\hline $\mathrm{TO}^{\prime}$ & & 60 \\
\hline
\end{tabular}

Tabl. 4 - Décompte des éléments de parure et assimilés du RM2.

Table 4 - Itemized list of personal ornaments and comparable artefacts found at RM2.

consisté à régulariser les bords par abrasion (fig. 10, n ${ }^{\circ}$ ). Les traces d'usure consistent en des émoussés localisés des bords, allant du simple adoucissement à la formation d'une encoche, et des facettes situées au niveau des extrémités (fig. 10, $n^{\circ} 4$ ). Les objets finis mesurent entre 6 et $15 \mathrm{~mm}$ de longueur et proviennent toujours de la partie mésiale de la coquille. Cette récurrence de la position anatomique des objets finis indique un schéma de production consistant à retirer les deux extrémités de la coquille pour créer un élément de parure à partir de la partie centrale. La présence de coquilles entières non travaillées, ainsi que de tronçons provenant des parties antérieure et postérieure (probables déchets de fabrication) suggère une production sur place d'éléments de parure en scaphopodes.

Les coquillages comprennent également onze gastéropodes composés de six espèces : Vitta picta $(\mathrm{n}=4)$; Nassarius incrassatus $(\mathrm{n}=3)$; Nucella lapillus $(\mathrm{n}=1)$; Trivia europea $(\mathrm{n}=1)$; Cyclope neritea $(\mathrm{n}=1)$; et Aporrhais pespelecani $(\mathrm{n}=1)$. Ces gastéropodes ont plusieurs provenances. Les Vitta picta, espèce fossile et fluviatile $\mathrm{du}$ Miocène, ont une origine locale. Elles sont très courantes dans les faluns de la région de Bordeaux. L'origine atlantique est également renseignée par l'espèce actuelle Nucella lapillus. Enfin, l'origine méditerranéenne, située à plus de $350 \mathrm{~km}$, est privilégiée pour l'espèce actuelle Cyclope neritea. Apparue sur les côtes atlantiques il y a trente ans du fait d'introductions biologiques, l'aire de distribution de Cyclope neritea s'avère être exclusivement limitée à la Méditerranée durant le Paléolithique supérieur (Simon-Bouhet, 2006). Les espèces actuelles Nassarius incrassatus, Trivia europea et Aporrhais pespelecani sont présentes sur toutes les côtes françaises. 

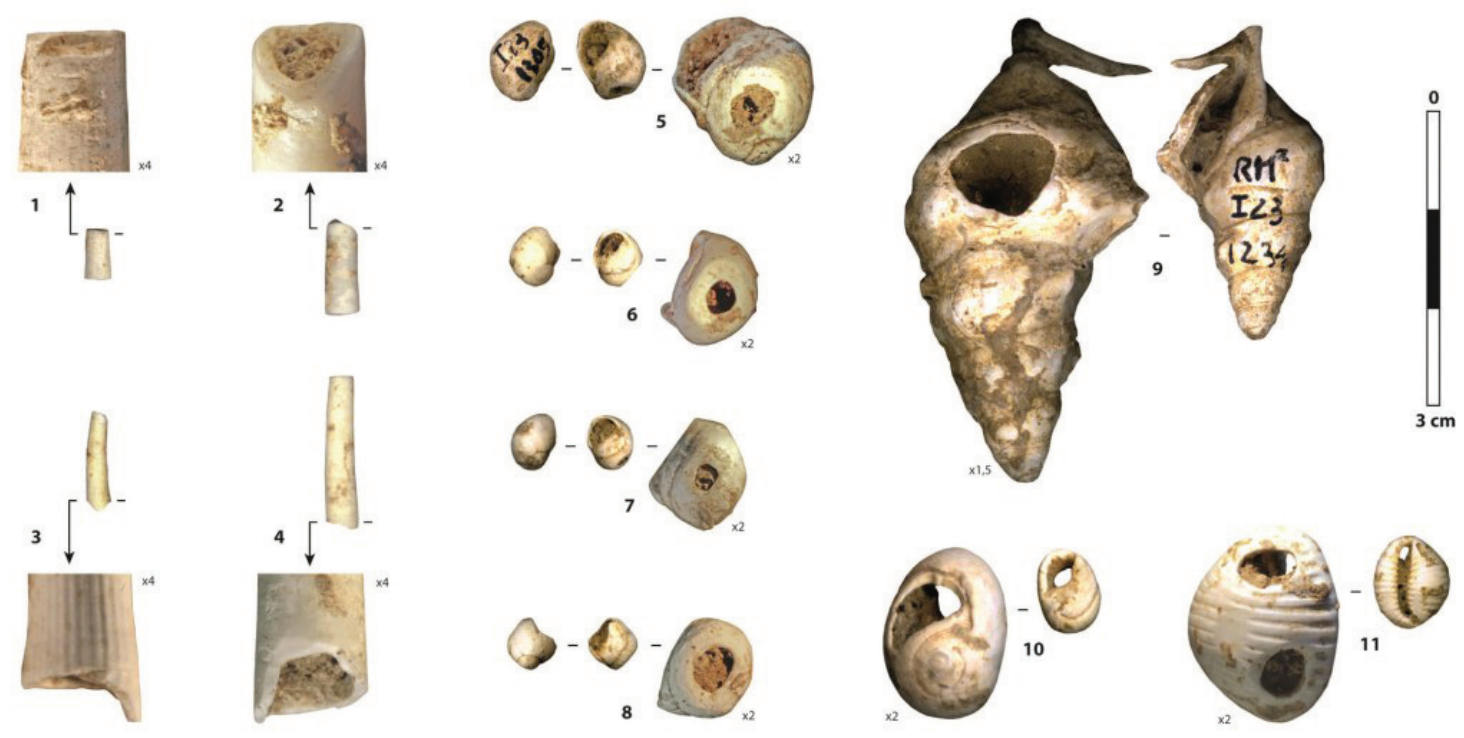

Fig. 10 - Traces de fabrication et d'usure sur les coquillages du RM2. 1-4 : tronçons de scaphopodes travaillés (1-3) et usé (4); 5-8 : Vitta picta percés; 9 : Aporrhais pespelecani percé; 10 : Cyclope neritea percée; 11 : Trivia europea biforée.

Fig. 10-Manufacturing and usewear marks on shells from RM2. 1-4: segments of worked scaphopods (1-3) and worn scaphopod (4); 5-8: pierced Vitta picta; 9: pierced Aporrhais pespelecani; 10: pierced Cyclope neritea; 11: double pierced Trivia europea

Seulement sept gastéropodes présentent des perforations. En raison d'altérations mécaniques et chimiques, la présence d'une perforation n'a pas pu être déterminée sur les Nassarius incrassatus. D'autre part, la Nucella lapillus n'a pas été perforée. Les autres gastéropodes ont été perforés selon trois modalités. Les quatre Vitta picta ont une perforation située sur la face columellaire et réalisée par abrasion (fig. 10, $\mathrm{n}^{\text {os }}$ 5-8). L'Aporrhais pespelecani et la Cyclope neritea ont une perforation située sur la face dorsale et réalisée par percussion (fig. 10, $\mathrm{n}^{\text {os }}$ 9-10). Enfin, la Trivia europea porte deux perforations positionnées sur la face dorsale et réalisées par percussion. Elle présente également des traces d'usure qui consistent en des émoussés du bord supérieur des perforations et des facettes situées sur la face dorsale (entre les deux perforations) et sur la face ventrale (fig. 10, $\mathrm{n}^{\circ} 11$ ).

Enfin, le secteur 2 a livré trois fragments de bivalves appartenant à deux familles : Cardiidae $(\mathrm{n}=2)$ et Glycymerididae $(\mathrm{n}=1)$. Seul le Glycymerididae a conservé une partie de sa perforation. Située au niveau du crochet, celle-ci a été réalisée par abrasion.

\section{Les dents travaillées}

Les huit dents travaillées du RM2 se composent de cinq incisives de renne sciées, d'une incisive de lièvre sciée, d'une canine de renard percée et d'une incisive de cheval décorée.

Les cinq incisives de renne présentent des traces de sciage transversal sur la face vestibulaire de la racine (fig. 11, nos 1-4). Quatre d'entre elles ont la racine sectionnée à 4 ou $5 \mathrm{~mm}$ de la couronne. Le sectionnement a été réalisé par sciage et flexion $(\mathrm{n}=3)$ ou uniquement par flexion $(\mathrm{n}=1)$. Les trois premières incisives portent également un sillon de sciage peu profond situé au niveau du collet, immédiatement sous la couronne. La quatrième incisive présente deux sillons parallèles, également situés au niveau du collet. Les traces de sciage sont plus douteuses sur la cinquième incisive de renne (un sillon de sciage sur le collet?) et le rattachement de cette pièce à la parure reste incertain. Deux incisives présentent également une zone émoussée sur la face vestibulaire qui s'étend depuis le sectionnement de la racine jusqu'au sillon du collet (fig. 11, $\mathrm{n}^{\text {os }} 2$ et 4 ).

Le sectionnement des racines par sciage s'inscrit dans un mode d'obtention des incisives de renne décrit par F. Poplin (1983) : ce type de pièce témoigne de l'extraction simultanée d'une rangée complète d'incisives (les vestiges du Roc de Marcamps ne se rapportent cependant pas à la même série dentaire). En revanche, les sillons, méthodiquement placés au niveau du collet, pourraient avoir participé au système d'attache des incisives. Bien que le fond de ces sillons ne présente pas de trace d'usure, les émoussés observés à proximité sur les racines (probables traces d'usure) pourraient témoigner d'un système d'attache particulier, qui reste néanmoins difficile à établir (sertissage, collage?).

La dent de lièvre est une extrémité apicale d'incisive inférieure gauche. Elle présente des traces de sciage qui ont précédemment été décrites par Slott-Moller (1988) et qui sont comparables à celles observées sur les incisives de renne. En effet, l'incisive de lièvre a été sectionnée par sciage et flexion et porte également un sillon peu profond (fig. 11, no 5).

Le seul exemplaire de dent percée est un fragment d'une canine inférieure de renard qui présente des traces de raclage sur sa racine, ainsi que le reste d'une perforation réalisée par rotation bilatérale. 


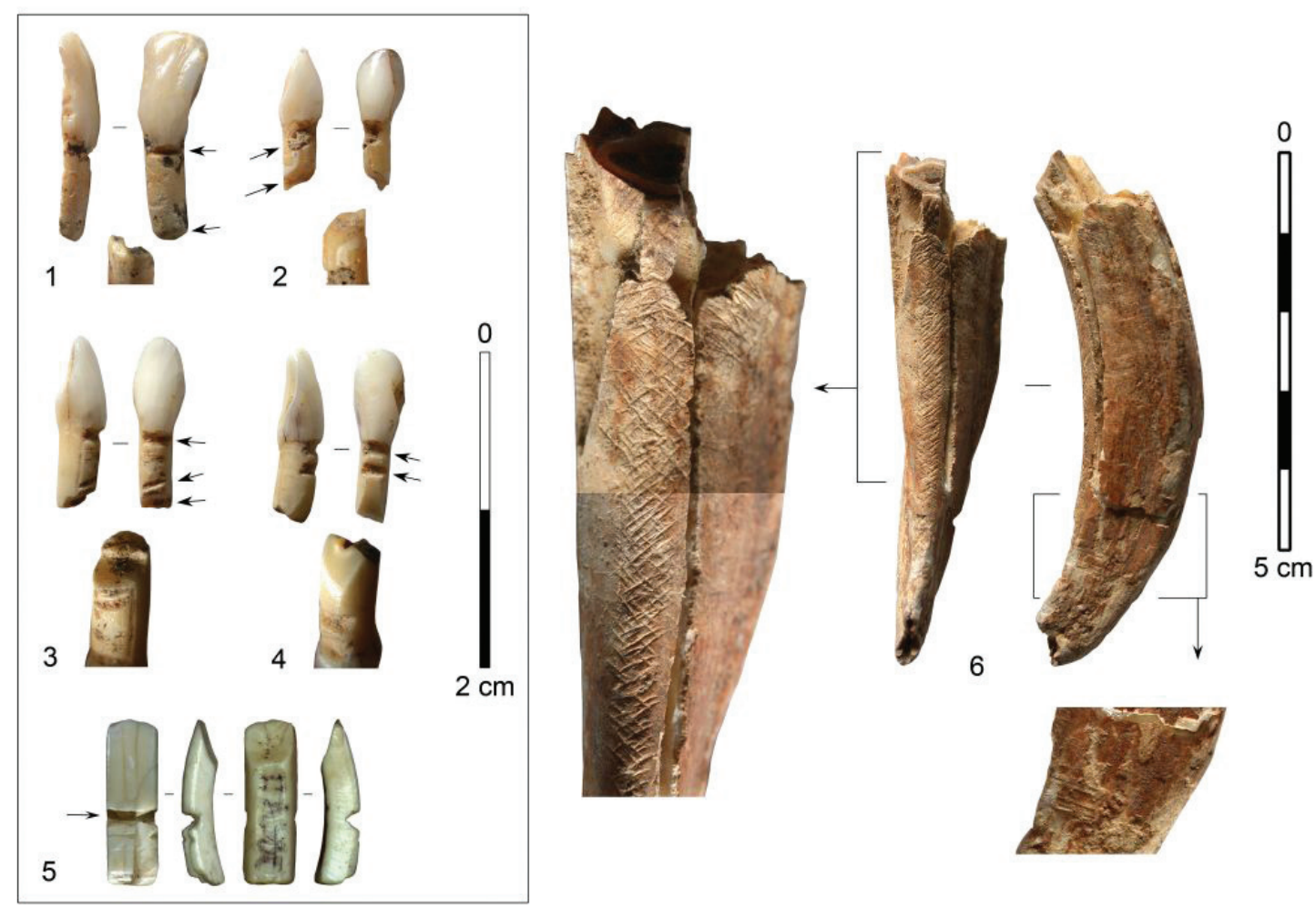

Fig. 11 - Dents travaillées du RM2. 1-4 : incisives de renne sciées, avec détail de l'extrémité apicale sectionnée (les flèches indiquent les traces de sciage); 5 : incisive de lièvre sciée; 6 : incisive de cheval gravée, avec détail du quadrillage sur la face linguale et des incisions transversales sur la face latérale.

Fig. 11 - Worked teeth from RM2. 1-4: cut reindeer incisors, with detail of the sectioned apical extremity (arrows indicate the cutting traces); 5: cut hare incisor; 6: engraved horse incisor, with detail of the grid-pattern decoration on the lingual side and the transversal incisions on the lateral side.

Aux dents sciées et percées s'ajoute une incisive de cheval entière présentant un décor quadrillé disposé sur toute la hauteur de la face linguale, au centre de celle-ci, le long d'une bande large de $3 \mathrm{~mm}$ (fig. 11, $\mathrm{n}^{\circ} 6$; cette bande décorée s'élargit vers l'extrémité occlusale). De courtes incisions transversales sont également visibles sur la face latérale, à 10-15 mm au-dessus de l'apex. La pièce présente par ailleurs une patine rougeâtre qui ne se retrouve pas sur les autres pièces d'industrie osseuse et pourrait suggérer une imprégnation par un pigment. Ici encore, la présence des incisions transversales, qui évoquent un dispositif de suspension, incite à rapprocher - sans certitude - cet objet de la catégorie des éléments de parure.

\section{LES VESTIGES FAUNIQUES}

Cur les $11 \mathrm{~m}^{2}$ fouillés, un total de 4354 restes de faune a été étudié. Ils correspondent aux vestiges coordonnés ainsi qu'aux restes déterminables issus des refus de tamis. Les restes indéterminés des refus de tamis n'ont pas été systématiquement quantifiés. La détermination des ongulés a été effectuée au laboratoire «TRACES » (Toulouse); celle des grands carnivores, de la mésofaune et de l'avifaune au laboratoire « PACEA » (Bordeaux) ainsi qu'au Muséum national d'historie naturelle (Paris) pour les oiseaux. Les pièces non déterminables taxinomiquement ont été enregistrées par classe de taille (mammifère de grande taille, de moyenne taille, de petite taille, etc.). Que ce soit pour le NMI (nombre minimum d'individus) ou le NME (nombre minimum d'éléments), les nombres minimaux de combinaison ont été calculés en prenant en compte l'âge et la taille. Les traces susceptibles de nous renseigner sur l'histoire taphonomique ont été observées sur les pièces déterminées anatomiquement et taxinomiquement avec une loupe grossissante de $\times 10$ à $\times 30$ ou un stéréomicroscope. Pour l'identification des traces, nous avons retenu les critères couramment utilisés en taphonomie (White, 1992; Lyman, 1994; Fischer, 1995, etc.). Pour l'interprétation des traces de boucherie, différents référentiels actualistes ont été pris en compte (Binford, 1981; Laroulandie, 2000; Nilssen, 2000; Mallye, 2007 et 2011a; Llovera et al., 2009; Val et Mallye, 2011; Costamagno, 2012).

\section{Spectre faunique et implications paléoenvironnementales}

Le spectre faunique est riche (tabl. 5). Pour les ongulés, l'absence de taxons domestiques dans l'intégralité de la séquence et les similitudes dans l'abondance relative des espèces présentes nous a conduits à considérer toutes les couches identifiées à la fouille comme un ensemble homogène. Si l'on tient compte du nombre minimal d'individus, 

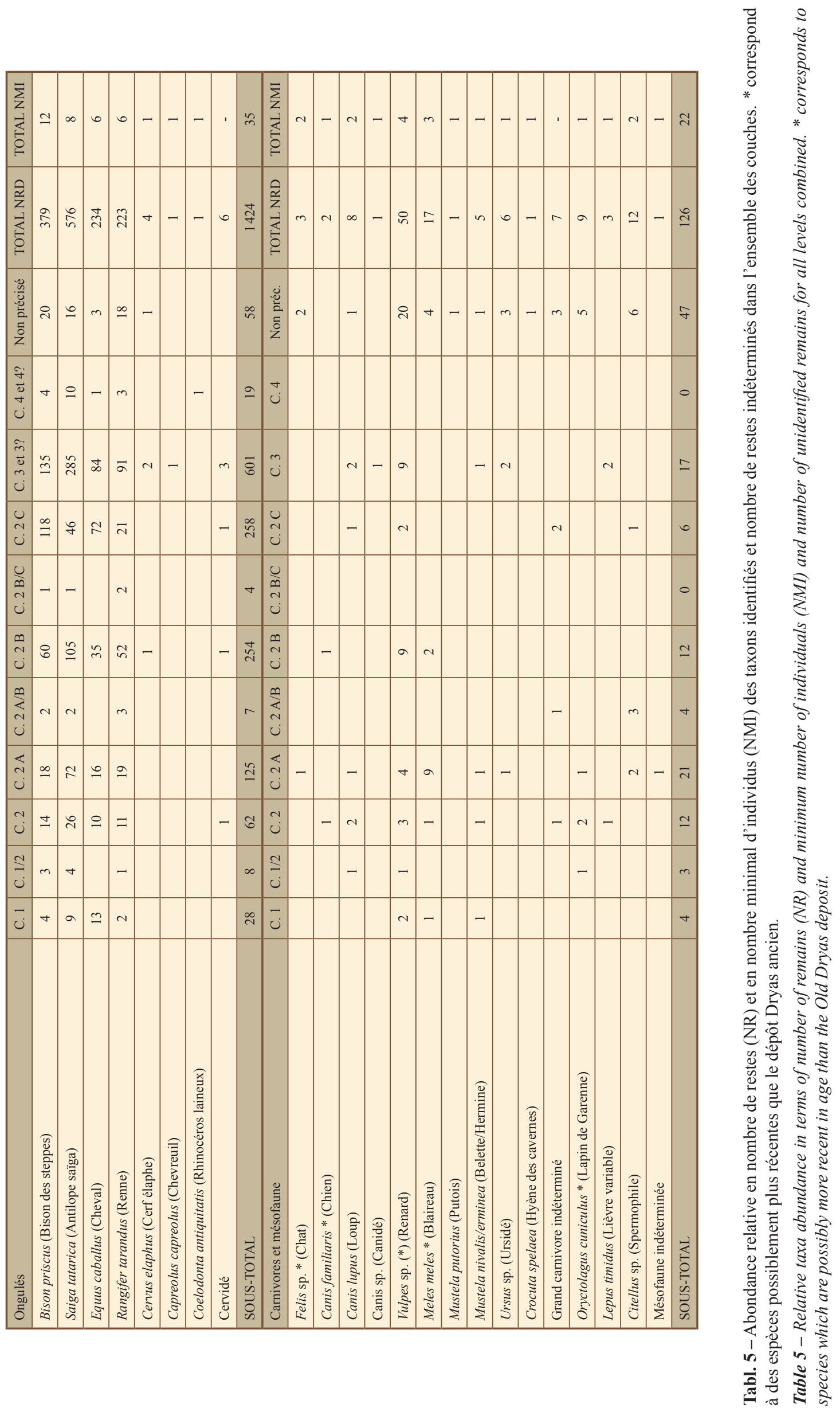

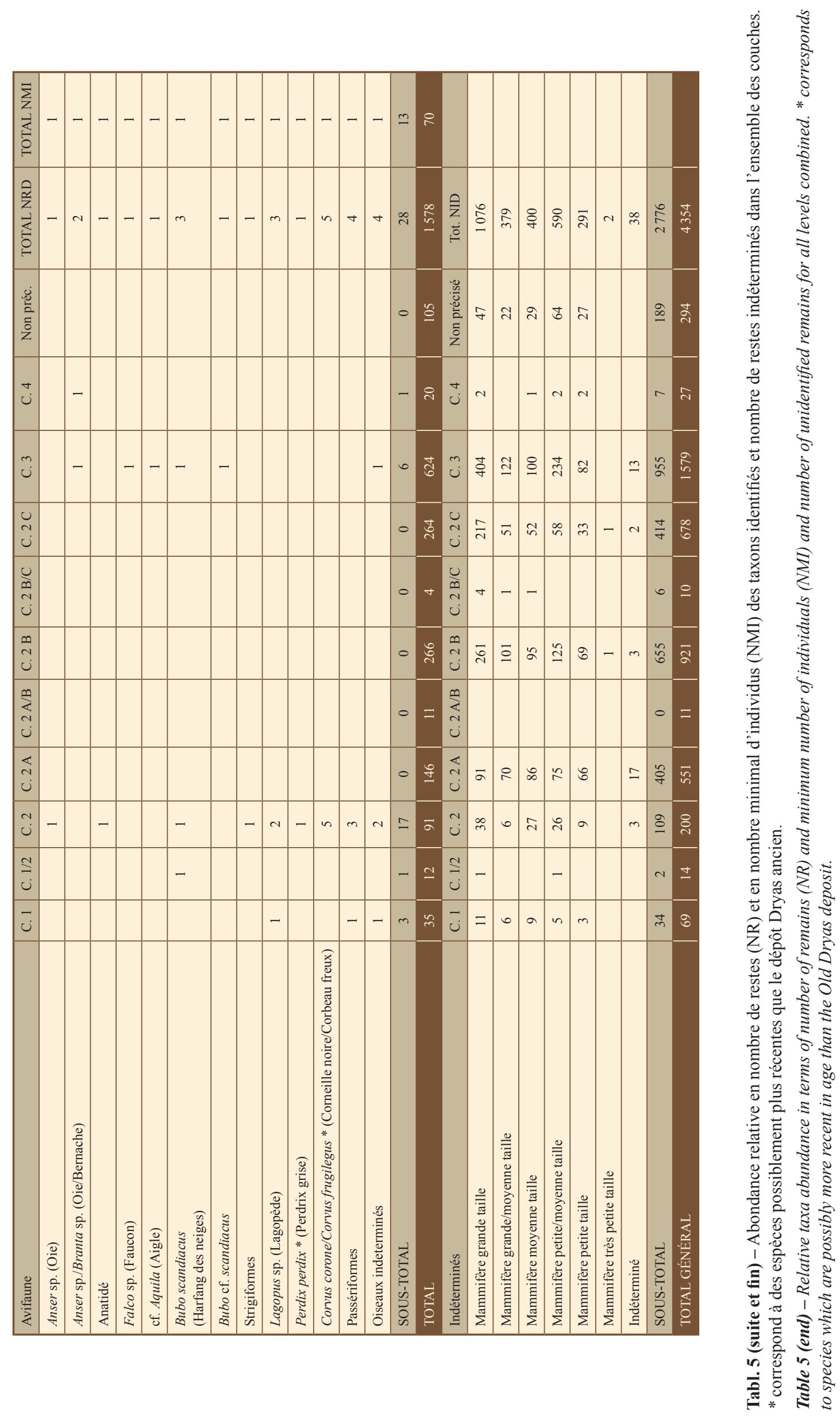
plus représentatif que le pourcentage du nombre de restes osseux et dentaires d'animaux initialement présents, le bison (Bison priscus) constitue l'ongulé majoritaire, avec douze individus. Viennent ensuite l'antilope saïga (Saiga tatarica) et le cheval (Equus caballus), représentés respectivement par un minimum de huit et six individus. Les cervidés sont également attestés, avec la présence de six rennes (Rangifer tarandus), un cerf (Cervus elaphus) et un chevreuil (Capreolus capreolus). Enfin, un fragment de prémolaire de rhinocéros (Coelodonta antiquitatis) a également été déterminé au sein de la couche 4, qui d'après les projections, s'intègre dans la couche 3 . En termes paléoécologiques, ce spectre faunique témoigne de conditions froides et steppiques dans un environnement ouvert, ce qui concorde avec l'ensemble de datations qui situent l'occupation vers 18000-19000 cal. BP, au commencement de l'épisode climatique d'Heinrich 1 (19000-14600 cal. BP : Stanford et al., 2011).

Les grands carnivores et la mésofaune sont représentés par divers taxons. Nous avons identifié un peu moins d'une centaine de restes se rapportant à des carnivores de toute taille. À cela s'ajoute une trentaine de restes qui se rapportent principalement aux léporidés et aux écureuils terrestres. Tous ces taxons, bien que diversifiés, sont toujours minoritaires par rapport aux ongulés, que cela soit en nombre de restes (NR) ou en nombre minimal d'individus (NMI). On trouve ainsi, par ordre d'importance décroissante, le renard roux (Vulpes vulpes), le spermophile (Citellus superciliosus), le loup (Canis lupus), l'ours (Ursus sp.), la belette ou l'hermine (Mustela sp.) et le lièvre variable (Lepus timidus). Enfin, un reste d'hyène des cavernes (Crocuta spelaea) a été identifié.

La présence d'hyène et de rhinocéros laineux, représentés par deux restes dentaires au RM2, amène quelques réflexions. En France, peu de gisements de la fin du Pléistocène ont livré des restes d'hyène des cavernes (Stuart et Lister, 2007; Discamps, 2011). Ces occurrences doivent donc être prises avec prudence. RM2 étant situé non loin de la grotte des Fées qui fut occupée par les hommes et par les hyènes, l'idée d'un apport de ces quelques restes par les Magdaléniens est tout à fait envisageable.

Il est difficile de discuter des conditions environnementales à partir de la présence des carnivores tant ils sont capables de s'adapter à des environnements variés. En revanche, la présence de spermophile dans cet ensemble dénote un environnement ouvert de type steppe, et la présence de lièvre variable témoigne de conditions assez froides.

Les vestiges fauniques ont également livré vingt-huit restes aviaires. Ils appartiennent à un minimum de cinq ordres comprenant des Ansériformes, des rapaces nocturnes et diurnes, des Galliformes et des Passériformes. Certaines espèces, comme les lagopèdes et la chouette harfang, fréquentent actuellement des environnements découverts et froids.

\section{Étude taphonomique}

Les ossements du RM2 présentent de bons à très bons états de surface; près de $80 \%$ des restes d'ongulés ont des surfaces lisibles entièrement ou aux trois-quarts. Seuls 5\% apparaissent totalement illisibles. Les principales altérations post-dépositionnelles ayant affecté les surfaces osseuses des restes d'ongulés, de carnivores et de mésofaune sont d'origine climato-édaphique, particulièrement le concrétionnement $-23,8 \%$ du nombre de restes total d'ongulés, de carnivores et de mésofaune - et les fissurations longitudinales - 22,3\% (tabl. 6). La desquamation touche seulement $15 \%$ des restes; les cupules de dissolution sont trouvées de manière très anecdotique $(\mathrm{NR}=4)$. Les traces biologiques non humaines sont également présentes, majoritairement sous forme de vermiculations $(16,8 \%)$, qui sont à mettre en relation avec l'activité des racines végétales. Des traces de carnivores ont aussi été relevées (fig. 12) sur près de $3 \%$ du nombre de restes total; parmi elles, plusieurs pièces digérées ont été observées. L'impact des carnivores paraît néanmoins modéré sur les carcasses animales.

\section{Les restes d'ongulés}

Le principal agent accumulateur des ossements d'ongulés est l'homme, comme en attestent les nombreuses traces de découpe ainsi que la morphologie des bords de fracture et les traces de percussion qui témoignent d'une fracturation anthropique sur os frais (Villa et Mahieu, 1991).

Sous l'effet des processus post-dépositionnels et selon leur densité, les ossements sont plus ou moins destinés à disparaître (Lyman, 1985 et 1994; Lam et al., 2003). Au préalable de toute analyse des modalités de transport et de traitement des carcasses, il convient donc d'identifier un éventuel problème de conservation différentielle. Les proportions squelettiques des ongulés les mieux représentées sont ainsi analysées à partir des pourcentages MAU (Minimum Animal Unit : Binford, 1978) et sont testées grâce aux indices de densité osseuse. Les indices établis par Lam et al. (1999) pour le cheval et le renne sont utilisés. Aucun indice n'étant disponible pour l'antilope saïga, nous avons repris ceux qui sont disponibles pour le renne. Pour les Bovinés, nous avons eu recours à ceux de Kreutzer (1992). Le test non paramétrique du coefficient de corrélation $\mathrm{r}_{s}$ de rang de Spearman a été appliqué pour les données de chaque espèce.

Les tests statistiques confrontant le pourcentage MAU et les indices de densité indiquent des corrélations relativement faibles pour les Bovinés et le cheval, au seuil de significativité de $5 \%$ (fig. 13). Il apparaît ainsi difficile de conclure à un problème de conservation différentielle des ossements de grands ongulés. De fait, si on ne prend en compte que les extrémités articulaires des os longs (cheval : 18\% du NME total et Bovinés : 14\% du NME total), il n'y a pas de relation statistiquement significative entre l'abondance relative de ces portions et leur densité respective (cheval : $r_{s}=0,165$ ddl 10; bovinés : $r_{s}=0,230$ ddl 10). En outre, la présence de restes de fœtus et de très jeunes individus pour ces deux ongulés irait dans le sens d'une bonne conservation des ossements. En revanche, pour l'antilope saïga et le renne, la corrélation est plus forte et apparaît comme très significative $(p<0,01)$ pour 


\begin{tabular}{|c|c|c|c|c|c|c|c|c|}
\hline & \multicolumn{4}{|c|}{ TRACES BIOLOGIQUES NON ANTHROPIQUES } & \multicolumn{4}{|c|}{ TRACES Climato-ÉDAPHIQUES } \\
\hline & Racines & Carnivores & Digestion & Rongeurs & Concrétionnement & $\begin{array}{c}\text { Fissurations } \\
\text { longitudinales }\end{array}$ & Desquamation & Dissolution \\
\hline Bison priscus & 66 & 8 & 1 & 1 & 138 & 111 & 83 & - \\
\hline Saiga tatarica & 93 & 14 & 10 & 1 & 105 & 104 & 68 & - \\
\hline Equus caballus & 46 & 10 & - & - & 72 & 64 & 44 & - \\
\hline Rangifer tarandus & 31 & 2 & 1 & - & 40 & 49 & 32 & 1 \\
\hline Cervus elaphus & 2 & - & 2 & - & - & 1 & 1 & - \\
\hline Felis sp. & 1 & - & - & - & - & - & - & - \\
\hline Canis familiaris & - & - & - & - & - & - & - & - \\
\hline Canis lupus & 1 & 1 & 1 & - & - & 3 & 1 & - \\
\hline Canis sp. & - & - & - & - & - & - & - & - \\
\hline Vulpes sp. & 4 & 2 & 1 & - & 9 & 6 & 4 & 1 \\
\hline Meles meles & 8 & - & - & - & 4 & 2 & 4 & 1 \\
\hline Mustela putorius & - & - & - & - & - & - & - & - \\
\hline Mustela nivalis/erminea & - & 3 & 3 & - & - & - & - & - \\
\hline Ursus sp. & - & - & - & - & - & 4 & - & 1 \\
\hline Crocuta spelaea & - & - & - & - & - & - & - & - \\
\hline Grand carnivore indéterminé & 2 & - & - & - & - & 1 & 1 & - \\
\hline Oryctolagus cuniculus & 4 & - & - & - & - & - & 2 & - \\
\hline Lepus timidus & - & 1 & 1 & - & - & - & - & - \\
\hline Citellus sp. & 1 & 4 & 4 & - & - & - & - & - \\
\hline Mésofaune indéterminé & - & - & - & - & - & - & - & - \\
\hline TOTAL & 259 & 45 & 24 & 2 & 368 & 345 & 240 & 4 \\
\hline$\%$ restes avec traces & 20,1 & 3,5 & 1,9 & 0,2 & 28,6 & 26,8 & 18,6 & 0,3 \\
\hline$\%$ du nombre total de restes & 16,8 & 2,9 & 1,6 & 0,1 & 23,8 & 22,3 & 15,5 & 0,3 \\
\hline
\end{tabular}

Tabl. 6 - Processus taphonomiques ayant affecté la surface des restes d'ongulés, de carnivores et de mésofaune (en nombre de restes).

Table 6 - Taphonomic processes responsible for surface damage of ungulate, carnivore and small fauna remains (expressed in number of remains).
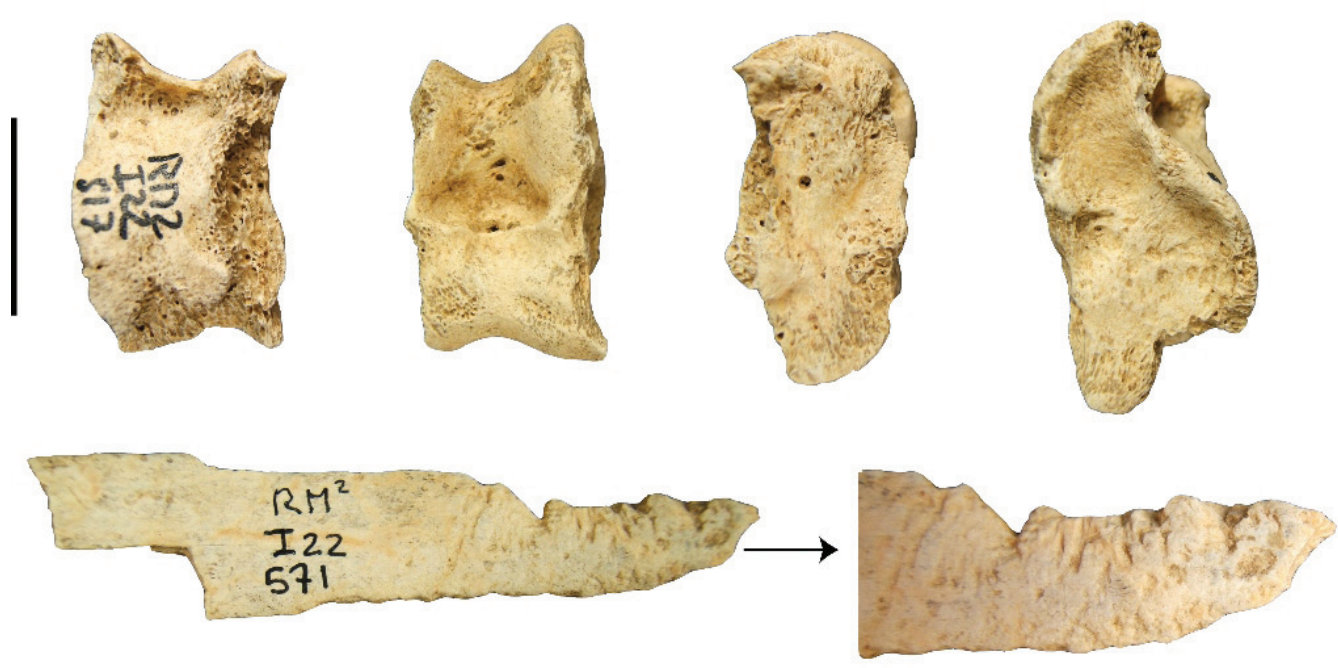

Fig. 12 - Traces de carnivores (en haut : digestion sur un talus d'antilope saïga, en bas : mâchonnement sur un fragment de côte d'ongulé de grande taille, grossissement $\times 2$ ). L'échelle représente $2 \mathrm{~cm}$.

Fig. 12 - Carnivore marks (top: digestion on a saiga antelope astragalus, bottom: chewing marks on a rib fragment of a large-sized ungulate - magnification $\times 2$ ). The scale represents $2 \mathrm{~cm}$. 

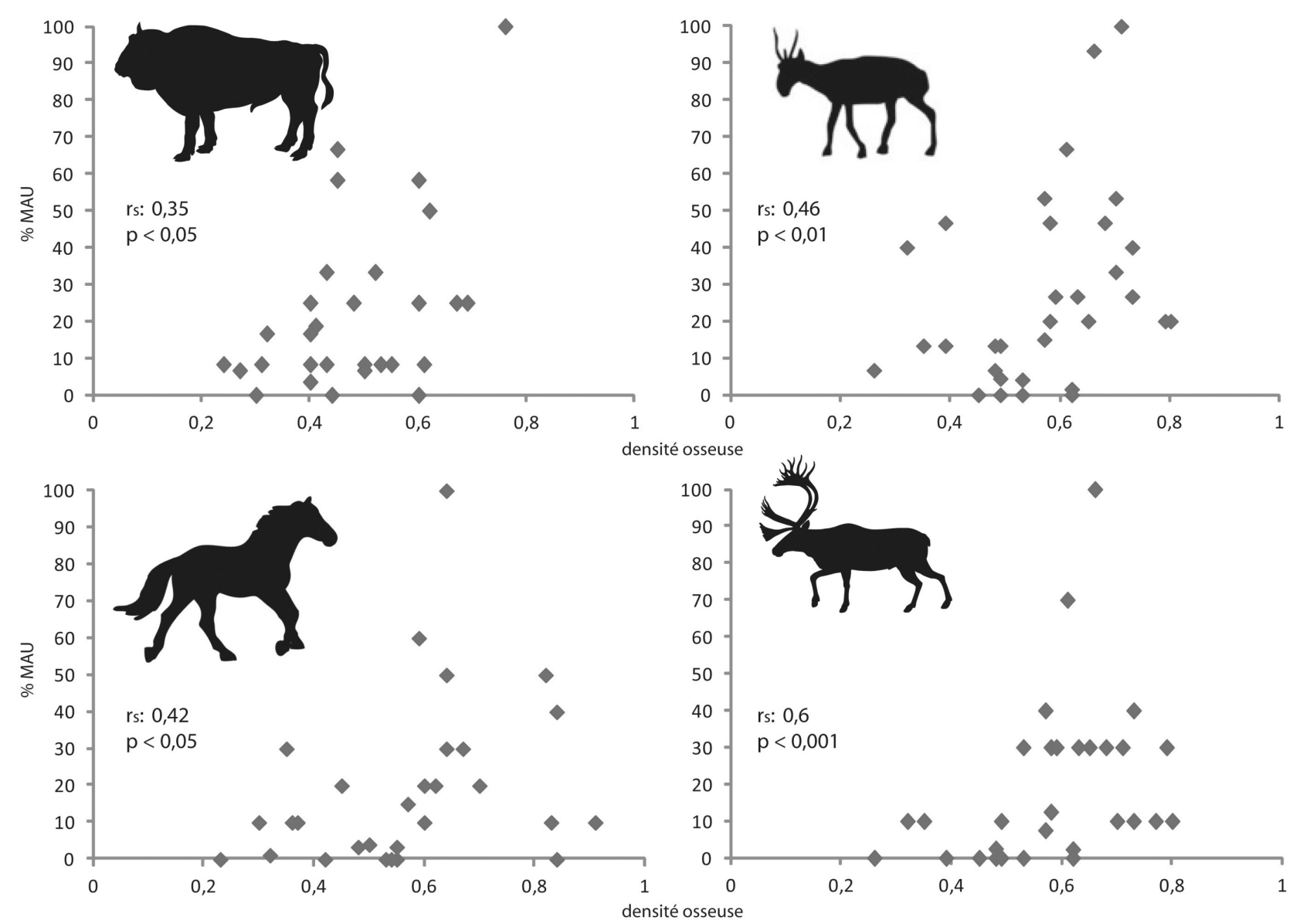

Fig. 13 - Représentation des éléments squelettiques (\% MAU) des ongulés en fonction de la densité osseuse.

Fig. 13 - Representation of ungulate skeletal elements (\% MAU) based on bone density.

la première, et hautement significative $(\mathrm{p}<0,001)$ pour le second. En ne tenant compte que des portions articulaires d'os longs (antilope saïga : $28 \%$ du NME total et renne : $26 \%$ du NME total), la corrélation reste significative au seuil de $5 \%$ pour le renne $\left(\mathrm{r}_{\mathrm{s}}=0,784 \mathrm{ddl} 10\right)$ et devient non significative pour l'antilope saïga $\left(\mathrm{r}_{\mathrm{s}}=0,367 \mathrm{ddl} 10\right)$. Pour les ongulés de taille moyenne, la densité ne semble pas être le seul facteur à l'origine de la représentation différentielle des éléments squelettiques.

\section{La mésofaune et les grands carnivores}

Les traces de prédation sont extrêmement rares sur le matériel étudié. En ce qui concerne les carnivores, seul le renard porte des traces d'exploitation par l'homme $(n=2)$. Les restes de loup, pour la plupart complets, sont exempts de toute trace de prédation. Le squelette d'ours se résume à une première phalange sans aucune trace et les autres restes sont des dents complètes ou fragmentaires. Aucune trace n'a été observée sur la mandibule de putois décrite par Slott-Moller (1988). Des traces anthropogéniques ont été relevées sur deux restes de lièvre alors que sur le troisième, des traces de digestion sont clairement identifiées. Parmi les douze restes de spermophile, quatre présentent des traces de digestion et seulement deux sont complets.
La plupart des diaphyses d'os longs du spermophile présentent des bords de fracture dont la morphologie est typique de la fracturation sur os frais.

En somme, les preuves directes d'un apport par les magdaléniens ne sont trouvées que chez le renard et le lièvre. Pour ce dernier, deux hypothèses peuvent être avancées; il est possible en effet que l'échantillon étudié corresponde à deux individus dont l'un serait apporté par l'homme et le second par un prédateur non-humain (rapace? renard?). Il est aussi possible que le reste semidigéré résulte du charognage d'amas de boucherie in situ. Le statut du loup est également énigmatique : alors que les restes d'ongulés sont en large majorité fragmentés, les restes de loup sont quasiment tous complets et exempts de toute trace. Dès lors il est difficile d'expliquer leur présence dans ce site archéologique où les activités de boucherie sont pleinement documentées (cf. infra). Ces vestiges n'en sont pas moins intéressants et posent la question des relations entre l'homme et le loup quelques millénaires avant la domestication avérée de ce carnivore (Boudadi-Maligne et Escarguel, 2014; Morey, 2014). En effet, bien que les canidés de RM2 correspondent très certainement au loup, la présence non anecdotique de traces de carnivores (voir tabl. 6 et fig. 12), pourrait suggérer un contact entre loups et groupes humains dès le Magdalé- 
nien moyen. Pour l'ours, la découverte d'un lot important de restes dentaires pourrait être, dans le même cas que les dents d'hyène et de rhinocéros, le résultat d'un ramassage par les Magdaléniens dans les grottes environnantes.

La petite collection aviaire livre de rares indices directs permettant d'identifier les agents responsables de la présence des restes d'oiseaux au sein du dépôt archéologique. Parmi ces traces, une scapula d'oie (Anser sp.) montre dans sa partie distale des impacts bilatéraux résultant vraisemblablement de la manducation par un carnivore de petite taille. Aucun argument ne permet de dire s'il s'agit plutôt de charognage sur place d'un ossement introduit par un autre prédateur ou d'un transport par cet agent. Deux pièces supplémentaires portent des marques résultant de l'activité des chasseurs-cueilleurs magdaléniens (voir infra).

\section{Exploitation des ongulés}

\section{Profils de mortalité et saisons d'abattage des ongulés}

L'étude des profils de mortalité a été menée pour les quatre principaux ongulés selon les classes d'âge établies à partir des séquences d'éruption et d'usure dentaire connues pour plusieurs référentiels (bison : Frison et al., 1976; Soulier, 2013; antilope saïga : Costamagno, 1999 et 2001; cheval : Bignon, 2008; Soulier, 2013; renne : Miller, 1974). Les profils sont représentés sous la forme de diagrammes ternaires (Stiner, 1990 et 1994; Steele et Weaver, 2002; Weaver et al., 2011) adaptés à chaque taxon selon Discamps (2011) pour les bisons, chevaux et rennes et Costamagno (1999 et 2001) pour l'antilope saïga.

Pour les bisons, il apparaît que les chasses ont été menées majoritairement sur des individus adultes dans la force de l'âge (dix individus sur douze). Les deux individus restants, âgés de moins d'un an et demi, ont été prélevés au sein du harem natal (fig. 14). Quatre restes osseux représentant deux jeunes individus pourraient leur correspondre. Le faible nombre d'extrémités articulaires mesurables n'a pas permis d'aborder la question du sexratio. Toutefois, la présence des deux jeunes individus et d'un fragment de pelvis de fœtus atteste la présence de femelles. Cette composition démographique pourrait traduire une organisation sociale du type mixed group, qui correspond au groupe familial composé de femelles, de mâles, de nouveau-nés et de juvéniles (Soper, 1941 ; Fuller, 1960).

Pour les autres ongulés (antilope saïga : sept individus sur huit; cheval : cinq individus sur six; renne : six individus sur six), les projections par diagrammes ternaires des profils de mortalité mettent en évidence, à partir des restes mandibulaires parfois couplés aux dents isolées, des courbes dites « catastrophiques », indiquant une absence de sélection des proies abattues selon leur âge. Toutefois, en raison de NMI peu élevés, les ellipses de confiance s'étendent sur toutes les aires, hormis celle des «vieux dominants» pour les rennes et les chevaux. Comme pour les bisons, le faible nombre d'extrémités articulaires mesurables n'a pas permis d'aborder la question du sexratio. Nous pouvons seulement suspecter l'abattage de deux saïgas mâles (présence de deux fragments de crânes avec les chevilles osseuses gauches attenantes) ainsi que de deux juments en raison de l'existence d'ossements de deux fœtus. Aucune canine de cheval - dent se trouvant systématiquement chez les mâles, beaucoup plus rarement chez les femelles - n'a été identifiée.

Les indications saisonnières proviennent de trois sources: les restes de fœtus, l'éruption dentaire ainsi que la cémentochronologie. Pour cette dernière méthode, seuls trois des taxons (Bovinés, antilope saïga et renne) ont été étudiés; faute de temps, le cheval a été provisoirement écarté des analyses. Un croisement des données interobservateur ainsi qu'une analyse avec insertion d'une lame lambda ont été utilisés afin de limiter les risques d'erreurs. Les modifications taphonomiques ont été systématiquement enregistrées : météorisation (fissurations transversales ou décollement du cément : Pike Tay, 1991; Lieberman, 1993), modifications microbiennes (Geusa et al., 1999) et remobilisations post mortem de l'enregistrement saisonnier sous forme de recristallisation ou de déstructuration pouvant imiter les structures biogéniques (Stutz, 2002a et b; Rendu et al., 2012). Une lame mince a été considérée comme illisible quand un même résultat ne pouvait être obtenu sur différentes portions de la dent. De plus, si les remobilisations post mortem touchaient les derniers dépôts, les échantillons ont été systématiquement écartés. Au final, pour RM2, treize échantillons sur vingt et un analysés se sont avérés lisibles.

Pour le bison, la période de rut ayant lieu entre fin juillet et fin août (Soper, 1941; Fuller, 1960; Bowyer et al., 2007; Roden et al., 2011) et celle des mises bas en mai (Soper, 1941; Roden et al., 2005), une femelle gravide a pu être abattue en hiver ou au printemps et les deux jeunes individus, âgés d'environ 6-7 mois, durant les mois de novembre-décembre, c'est-à-dire au commencement de la mauvaise saison. Ces indications, fondées sur des méthodes classiques, sont en accord avec celles obtenues à partir des analyses cémentochronologiques qui indiquent l'abattage de quatre individus au cours de la mauvaise saison, et un individu durant la bonne saison (fig. 15) sur un total de neuf dents analysées.

Pour l'antilope saïga, la présence de deux individus âgés de 3 à 6 mois d'après les stades d'éruption dentaire, indiquerait un abattage entre les mois d'août et de novembre soit à la bonne saison ou à la fin de la bonne saison, la mise bas ayant lieu autour du mois de mai (Costamagno, 1999). Les analyses cémentochronologiques menées sur trois autres individus (sur six) livrent d'autres occurrences saisonnières : deux durant la mauvaise saison et un autre au début de la bonne saison (fig. 15). Toutefois, il convient de souligner que la moitié des dents d'antilope saïga se sont avérées illisibles du fait de problèmes de conservation mais aussi de singularités liées au mode de dépôt du cément pour cette espèce (très forte proportion du cément cellulaire qui a la particularité de se remodeler au cours de la vie de l'individu : Lieberman, 1993). À ces problèmes vient s'ajouter l'absence de test 

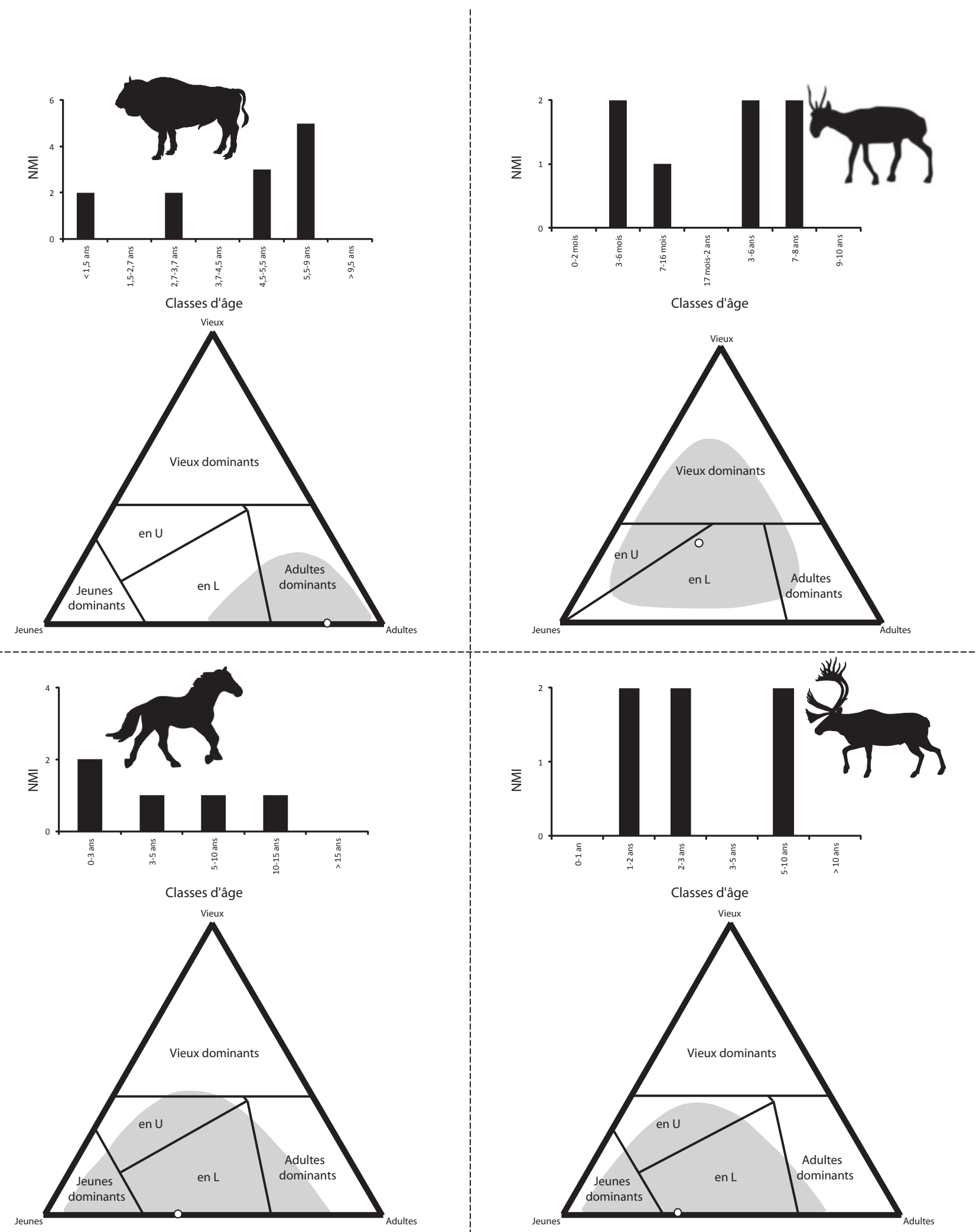

Fig. 14 - Profils de mortalité des principaux ongulés du RM2. En haut : profil de mortalité; en bas : diagramme ternaire (le cercle correspond au profil de mortalité et la zone grisée à l'ellipse de confiance au seuil de $95 \%$ ).

Fig. 14 - MMortality profiles of the main ungulates at RM2. Top: mortality profile; bottom: triangular graph (the circle corresponds to the mortality profile and the grey zone corresponds to the $95 \%$ confidence ellipse). 


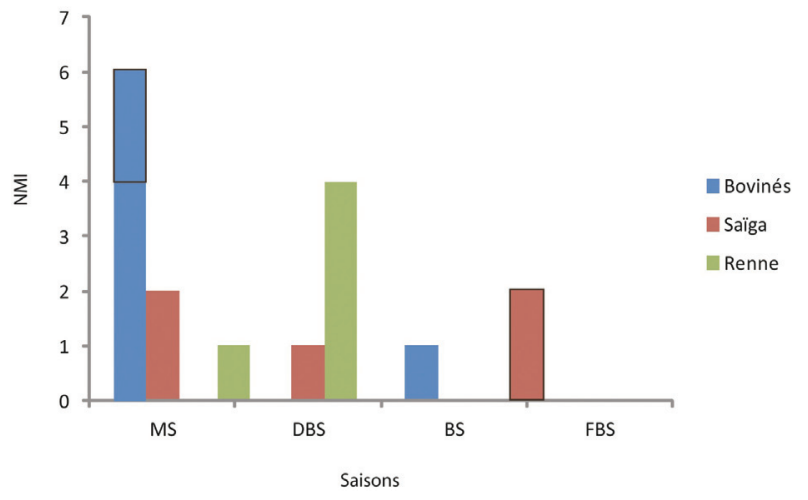

Fig. 15 - Données saisonnières à partir des méthodes classiques (en encadré noir) et de la cémentochronologie. MS : mauvaise saison; DBS : début de la bonne saison; BS : bonne saison; FBS : fin de la bonne saison.

Fig. 15 - Seasonal data based on classical methods (black box) and cementum approach. $M S=$ cold season, $D B S=$ beginning of warm season, $B S=$ warm season, $F B S=$ end of warm season.

de la méthode sur des échantillons actuels dont la saison de mort est connue. Ces difficultés ont déjà été rencontrées et soulignées par les deux analystes sur la série de Saint-Germain-la-Rivière (Costamagno, 1999; Langlais et al., 2015). Les résultats cémentochronologiques sur l'antilope saïga sont donc, d'une manière générale, à considérer avec prudence.

Pour le renne, aucun individu de moins d'un an n'est présent. En outre, nous n'avons identifié ni de bois de chute ni de massacre parmi les trente-deux fragments de boi. Aucune donnée saisonnière n'est donc disponible à partir du matériel. Les analyses cémentochronologiques livrent en revanche des indications pour cinq des six individus identifiés. À l'inverse des bisons, les rennes ont été abattus majoritairement au début de la bonne saison, un seul individu indique soit la mauvaise saison soit le début de la bonne saison (fig. 15). Un léger dépôt lumineux sur l'extérieur de cette dernière dent empêche de déterminer si le dernier dépôt est un annulus ou une zone ayant tout juste commencé sa croissance.

Enfin, les indications saisonnières pour le cheval sont sporadiques : seule la présence de deux fœtus et de deux très jeunes individus apporte quelques informations. La mise bas connaissant un pic en avril et mai (Berger, 1986; Waring, 2003; Bignon, 2008), l'abattage d'au moins quatre individus (dont deux femelles) a pu se produire durant l'hiver, le printemps ou l'été.

\section{Transport des carcasses et produits recherchés}

Afin d'évaluer les stratégies nutritives mises en œuvre par les groupes magdaléniens, plusieurs indices ont été utilisés : le (S) FUI (standardized food utility index), l'indice de moelle osseuse (marrow index) et, pour le renne, la teneur en acide oléique (UMI). Pour le bison, les indices (S) FUI et de moelle proviennent des travaux de Emerson (1990); pour le cheval, de Outram et Rowley-
Conwy (1998). Pour le renne, les valeurs du (S) FUI et de moelle sont issues des travaux de Metcalfe et Jones (1988), celles de la teneur en acide oléique de Morin (2007). À défaut de référentiel pour l'antilope saïga, nous avons utilisé les données disponibles pour Antilocaprina americana (O'Brien et Libert, 2014). Nos résultats sont comparés à ceux de ces référentiels à partir de la corrélation du rang de Spearman (logiciel PAST, version 3.0, (C) Hammer et al., 2001). La faiblesse des échantillons et l'étendue limitée de la fouille constituent un facteur limitant les interprétations qui, de fait, doivent être considérées avec précaution.

Pour le bison, les os longs (plus particulièrement ceux du membre postérieur) et les éléments crâniens (notamment les rochers) sont surreprésentés (fig. 16). Pour le cheval, les os longs sont également bien représentés alors qu'au niveau du crâne, l'absence de restes crâniens et de rochers ainsi que la présence en nombre important d'os hyoïdes et de mandibules sont remarquables. Pour ces deux grands ongulés, les éléments du squelette axial post-crânien apparaissent peu abondants (entre 1 et $7 \%$ du MAU) hormis le sacrum et les vertèbres caudales pour le cheval (entre 10 et $20 \%$ du MAU). Les os courts (carpiens, tarsiens, malléole et patella) et les bas de pattes (métapodes, phalanges et sésamoïdes), présents dans des proportions équivalentes, sont moins abondants que les os longs riches en viande. Des problèmes de conservation différentielle pouvant être écartés au vu des analyses de densité, les carcasses des bisons et des chevaux semblent donc avoir été transportées le plus souvent incomplètes au campement, après une première étape de boucherie sur le site d'abattage. Toutefois, il n'est pas exclu que certaines carcasses aient été transportées complètes.

Concernant la quantité et la qualité de la viande, l'analyse statistique pour le (S) FUI indique une corrélation positive mais statistiquement non significative pour le bison, et négative pour le cheval (fig. 16). Chez ces deux espèces, les éléments du squelette axial post-crânien (côtes et vertèbres thoraciques pour le bison; vertèbres thoraciques, pelvis et vertèbres cervicales) figurent parmi les plus riches en viande, expliquant cette faible corrélation. La rareté du squelette axial post-crânien sur le site ne constitue pourtant pas un argument en faveur d'un désintérêt pour la viande puisque les filets ont pu très facilement être prélevés sur le lieu d'abattage puis introduits sur le site. Néanmoins, même en excluant les vertèbres et les côtes, les coefficients de corrélation, bien que nettement plus hauts $\left(r_{\mathrm{s}}=0,703 \mathrm{ddl} 9\right.$ pour le cheval; $r_{s}=0,675$ ddl 8 pour les bovinés), restent toujours statistiquement non significatifs. Il semble donc que la viande n'ait pas été la seule ressource qui ait motivé les modalités de transport des carcasses des gros ongulés. Les relations hautement significatives pour le bison et significatives pour le cheval entre l'abondance relative des éléments squelettiques et la quantité de moelle indiquent qu'en complément à la viande, la recherche de la moelle osseuse est le facteur clé présidant au transport des carcasses des grands animaux. 

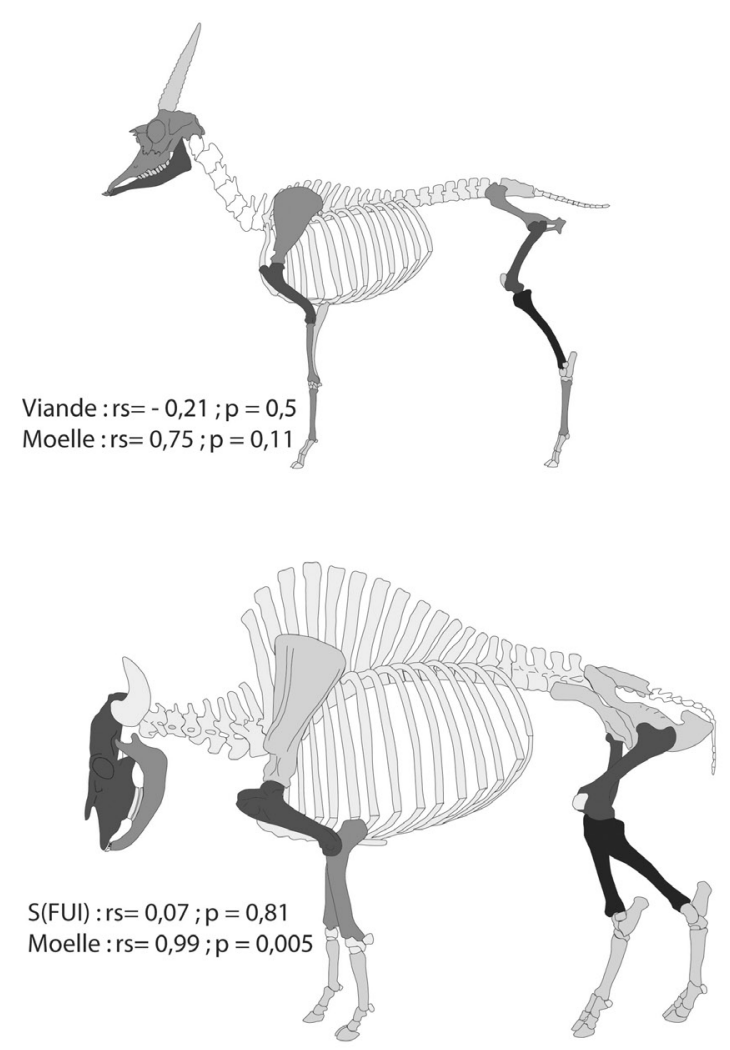

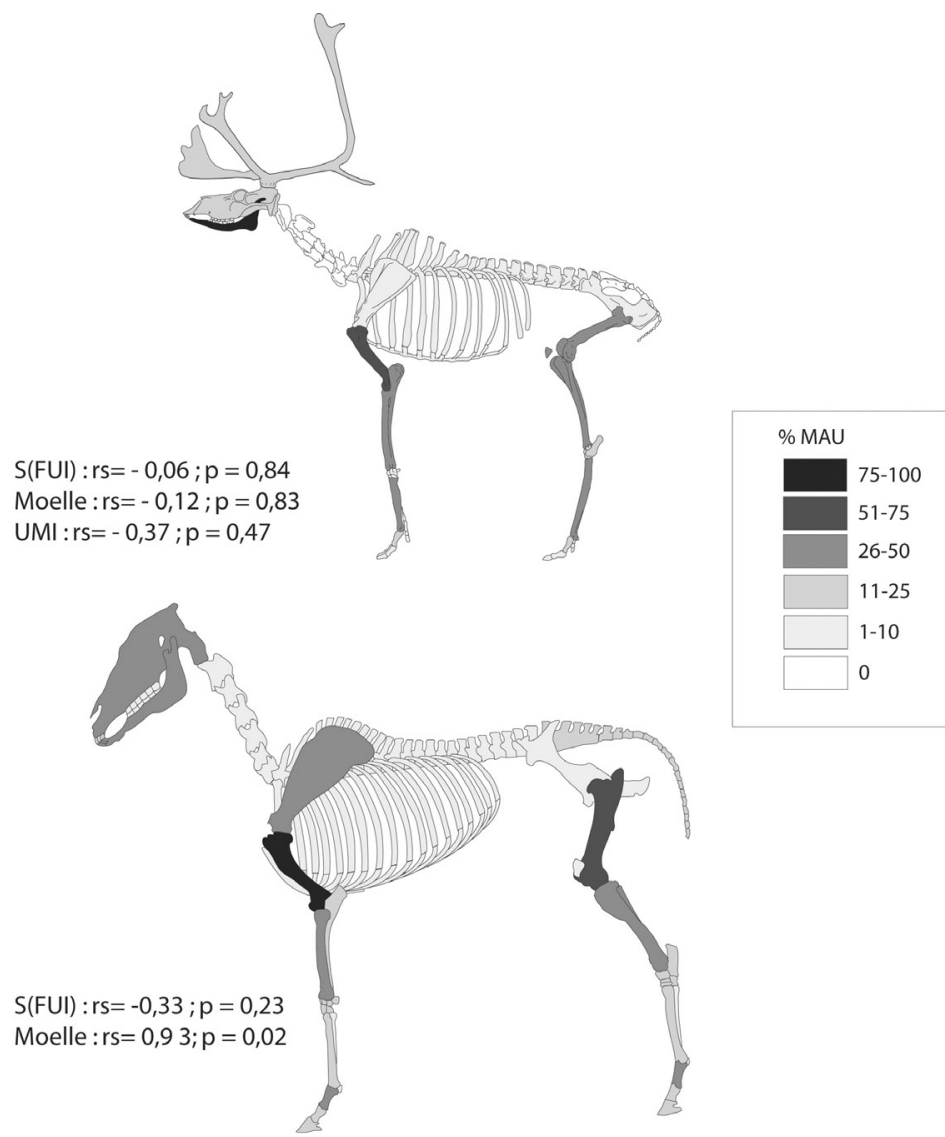

Fig. 16 - Représentation squelettique des ongulés du RM2 selon le pourcentage MAU et coefficients de corrélation de Spearman pour le (S) FUI, la quantité de viande, l'indice de moelle et la teneur en acide oléique.

Fig. 16 - Ungulate skeletal representation at RM2 based on \%MAU and Spearman's rank correlation coefficient for (S) FUI, meat quantity, marrow index and oleic acid content.

Pour les plus petits ongulés, là encore, les os longs et les restes crâniens, particulièrement les mandibules, apparaissent comme les éléments anatomiques les plus abondants (fig. 16). Relativement aux gros ongulés, les extrémités des pattes et particulièrement les métapodes sont mieux représentées. Le déficit en bois, crânes et dents supérieures est particulièrement marqué pour le renne. Seulement quelques côtes et vertèbres ont été déterminées pour cette espèce; elles sont également quasiment absentes pour l'antilope saïga. D'après les analyses sur la densité, la conservation différentielle pourrait avoir affecté plus profondément les ongulés de taille moyenne. La rareté du squelette axial post-crânien pourrait ainsi s'expliquer par ce biais mais on ne peut exclure l'hypothèse, comme pour les gros ongulés, de l'abandon des éléments du tronc sur le site d'abattage. Les coefficients de corrélation entre le pourcentage MAU et les indices de viande sont très faibles $\left(r_{s}=-0,06\right.$ ddl 14 pour le renne; $r_{\mathrm{s}}=-0,21$ et $-0,117 \mathrm{ddl} 12$ pour l'antilope saïga selon que l'on prend en compte le poids de viande ou le rendement calorifique). Du fait d'une potentielle introduction de la viande du squelette axial sous forme de filets ou d'un problème de conservation différentielle, on ne peut pour autant conclure que la viande n'était pas un facteur de choix pour les Magdaléniens. Néanmoins, en excluant ces parties, le coefficient reste toujours négatif, tant pour le renne $\left(r_{s}=-0,026, d d l 9\right)$ que pour l'antilope saïga $(r=-0,084$ ddl 9 pour le poids de viande). Pour cette dernière espèce, la prise en compte du rendement calorifique par rapport au coût de traitement augmente le coefficient qui reste statistiquement non significatif $\left(r_{s}=0,304\right.$ ddl 9). Par ailleurs, il n'y a pas de relation statistiquement significative entre l'abondance des os longs de renne et les indices de moelle $(r=-0,123$ ddl 6 pour le marrow index; $\mathrm{r}_{\mathrm{s}}=-0,37 \mathrm{ddl} 6$ pour la teneur en acide oléique). Sous réserve que ces profils soient représentatifs de l'ensemble du site, on peut donc en conclure que les membres de renne ont été introduits complets, la rareté des phalanges pouvant alors être liée à la récupération des peaux. Pour l'antilope saïga, les coefficients de corrélation sont plus forts $\left(\mathrm{r}_{\mathrm{s}}=0,754 \mathrm{ddl} 6, \mathrm{p}>0,05\right)$ mais restent néanmoins non significatifs.

\section{Activités de boucherie}

De nombreuses traces de boucherie (stries et points d'impact) ont été observées sur les ossements d'ongulés : pour les stries, de $25 \%$ à $33 \%$ du nombre de restes total selon les espèces et, pour les points d'impact, de 12 à $17,5 \%$ (tabl. 7). Pour une description détaillée de ces 


\begin{tabular}{|l|c|c|c|c|c|}
\multicolumn{1}{l|}{ NRD } & $\begin{array}{c}\text { NRD } \\
\text { cut }\end{array}$ & $\begin{array}{c}\% \text { NRD- } \\
\text { cut }\end{array}$ & $\begin{array}{c}\text { NRD } \\
\text { percu }\end{array}$ & $\begin{array}{c}\% \text { NRD } \\
\text { percu }\end{array}$ \\
\hline Bison & 379 & 95 & 25,1 & 62 & 16,4 \\
\hline Saïga & 576 & 154 & 26,7 & 77 & 13,4 \\
\hline Cheval & 234 & 77 & 32,9 & 41 & 17,5 \\
\hline Renne & 219 & 54 & 24,7 & 27 & 12,3 \\
\hline
\end{tabular}

Tabl. 7 - Nombre de restes d'ongulés portant des stries de boucherie et des impacts de percussion par taxon.

Table 7 - Number of ungulate remains bearing cutmarks and percussion marks, per taxon.

traces, nous renvoyons à une publication future (Kuntz et al., en préparation).

Des représentations schématiques des différentes activités menées sur les carcasses ont ensuite été effectuées (fig. 17).

Pour le bison, les stries observées sur plusieurs restes mandibulaires attestent le dépouillement de la tête. Sur les os des membres, les traces, longitudinales et obliques, sont principalement présentes sur les métapodes et les phalanges et indiquent que la peau a été incisée au plus près des extrémités. Le décharnement constitue l'activité qui a laissé le plus de traces sur les ossements, particulièrement les plus charnus. Le retrait de la langue est visible sur plusieurs restes mandibulaires et os hyoïdes. Les traces en lien avec la désarticulation apparaissent plus ténues. La séparation entre la mandibule et le reste du crâne est attestée, ainsi que la désarticulation du coude et de la cheville. Enfin, les métapodes ont pu être séparés des phalanges et également certaines phalanges entre elles. Les traces relatives au retrait des tendons sont assez rares. Aucun os long n'a été retrouvé complet. Les ossements ont été intensément fracturés pour la récupération de la moelle. Cette activité concerne tant les mandibules que les os longs et les phalanges, particulièrement les proximales (tabl. 8). Plusieurs d'entre elles montrent une fracture longitudinale qui a fendu la phalange en deux dans son axe médian. D'après Jin et Mills (2011), ce type de fracture indique, chez les gros ongulés, une désarticulation préalable des phalanges, ce que nous avons constaté dans le matériel osseux du RM2.

Pour l'antilope saïga, les stries en lien avec les activités de retrait de la peau sont nombreuses. Comme pour le bison, elles se situent principalement sur les os crâniens et les extrémités des pattes. Le décharnement affecte près de la moitié des ossements portant des stries de boucherie.

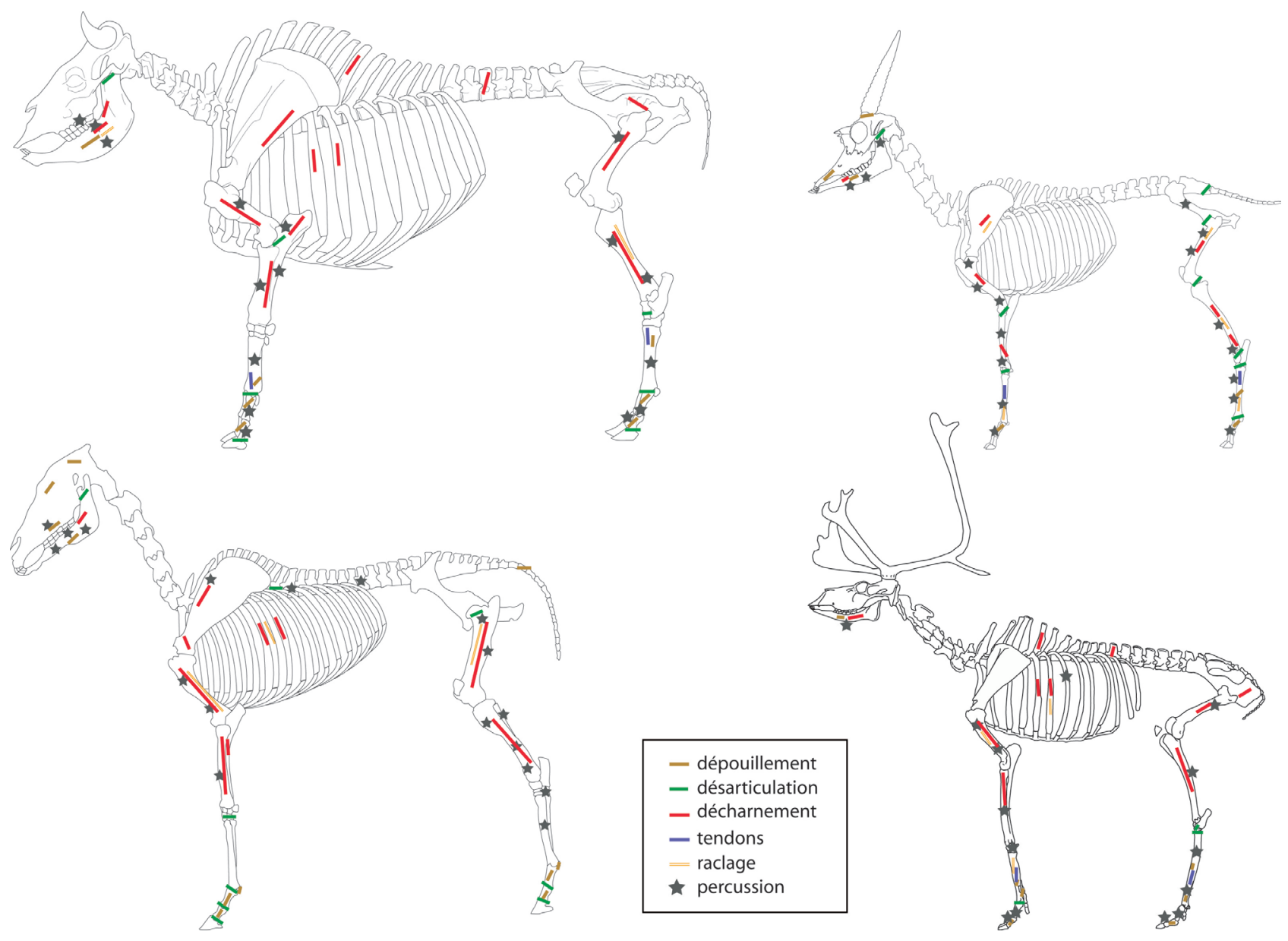

Fig. 17 - Représentation schématique des activités de boucherie (stries et impacts de percussion) pour les quatre principaux ongulés. Fig. 17 - Simplified diagram of butchery activity (cutmarks and percussion impacts) for the four main ungulates. 


\begin{tabular}{|l|c|c|c|c|c|}
\multicolumn{1}{c|}{} & Bison & Saïga & Cheval & Renne & $\%$ NRD percu \\
\hline Phalange proximale complète & $1 / 28$ & $5 / 17$ & $4 / 8$ & $0 / 7$ & 16,4 \\
\hline Phalange mésiale complète & $6 / 9$ & $8 / 9$ & $3 / 4$ & $0 / 5$ & 13,4 \\
\hline
\end{tabular}

Tabl. 8 - Phalanges proximale et mésiale complètes par rapport au nombre total de phalanges pour chaque ongulé.

Table 8 -Complete proximal and mesial phalanges relative to total number of phalanges for each ungulate.

Cette activité a été particulièrement intense sur les os longs charnus. Un seul fragment de mandibule atteste le retrait de la langue. Les traces de désarticulation sont présentes sur une grande partie du squelette. La mandibule a été séparée du reste du crâne au niveau des condyles mandibulaires. La queue a été découpée à proximité d'une vertèbre sacrée. Le démembrement est visible au niveau du coude, du poignet, du bassin, du genou et de la cheville. Une extrémité distale de métatarsien témoigne en outre de la séparation de cet élément avec une phalange proximale. Contrairement au bison, les phalanges d'antilope saïga n'ont semble-t-il pas été isolées les unes des autres. Des traces de prélèvement des tendons ont en revanche été observées sur plusieurs fragments de métapodes. Des diaphyses d'os longs portent des traces de raclage qui témoignent probablement de la préparation de la surface osseuse en vue d'une fracturation pour la récupération de la moelle. Les traces de percussion apparaissent en effet nombreuses sur les restes d'antilope saïga, particulièrement sur les os longs. Quelques restes mandibulaires ainsi que quelques phalanges proximales, majoritairement incomplètes (tabl. 8), portent aussi ce type de traces.

Les restes de chevaux sont ceux qui enregistrent le plus fort pourcentage d'ossements striés et fracturés (tabl. 7). Le dépouillement est visible sur plusieurs éléments crâniens, sur les sésamoïdes et les deux premières phalanges ainsi que sur une vertèbre caudale. La peau semble avoir été incisée très bas car aucun métapode ne porte de trace caractéristique de cette activité. Comme pour les autres ongulés évoqués précédemment, le décharnement est l'activité qui a laissé le plus de traces, majoritairement sur les os longs mais également sur quelques côtes et scapulas. Le prélèvement de la langue est attesté sur un fragment d'os hyoïde. Hormis une extrémité proximale de fémur, aucun os long ou élément de ceintures (scapulaire ou pelvienne) ne porte de trace de désarticulation, les extrémités articulaires des os longs de chevaux étant relativement peu nombreuses. Comme pour les autres ongulés, la mandibule a toutefois été séparée du crâne. Le poignet a pu être désarticulé à différents niveaux, certains métacarpiens ont été séparés des phalanges et ces dernières ont été désarticulées les unes des autres. Sur une phalange distale, des stries pourraient correspondre à la récupération de sabots, dont l'étui peut être utilisé pour la confection de colle de kératine ou être consommé (références in Soulier, 2013). Aucune trace caractéristique du sectionnement des tendons n'a été observée sur les métapodes de chevaux. En revanche, plusieurs diaphyses et quelques côtes portent des traces de raclage. Les impacts de percussion sont nombreux et touchent les maxillaires et mandibules ${ }^{(4)}$, les os longs ainsi que le bord externe d'une scapula, une extrémité proximale de côte et une vertèbre lombaire. Dans ces deux derniers cas, la percussion a pu se produire lors d'une activité de désarticulation. Enfin, deux restes (une extrémité distale d'humérus et une phalange proximale) sont fendus.

Pour le renne, des stries de dépouillement s'observent également sur les mandibules ainsi que sur les extrémités des pattes. Le décharnement a été pratiqué sur les os longs charnus ainsi que sur quelques côtes et vertèbres et un fragment d'os pelvien. La langue a été prélevée sur au moins deux individus. La désarticulation est attestée seulement au niveau des extrémités distales des métacarpiens et du massif tarsien. Les extrémités articulaires, particulièrement des métapodes, sont pourtant relativement bien représentées. Plusieurs diaphyses de métapodes portent des traces caractéristiques d'un sectionnement des tendons. Comme pour le cheval, une phalange distale a livré des stries évoquant la récupération du sabot. Une diaphyse d'humérus et une diaphyse de métacarpien portent des traces de raclage. Hormis les os longs et les mandibules qui attestent un prélèvement de la moelle, d'autres éléments osseux (côte, carpiens, phalanges) portent des impacts de percussion. Les phalanges de renne ont semble-t-il été abondamment fracturées car les pièces complètes sont rares (tabl. 8). Ces éléments ont de toute évidence été brisés en vue d'une récupération de la moelle.

Au-delà de la recherche de la moelle contenue dans les cavités médullaires, la graisse présente dans les tissus spongieux était-elle utilisée par les chasseurs-cueilleurs du RM2? Que ce soit sous forme de combustible, comme ressource alimentaire ou technique, l'exploitation de la graisse engendre une fragmentation importante des éléments ou portions spongieuses en lien avec un traitement anthropique (Théry-Parisot et al., 2005; Costamagno et Rigaud, 2014) ou des processus de combustion et des phénomènes post-dépositionnels (Costamagno et al., 2009). Il en résulte le plus souvent une sous-représentation de ces portions spongieuses détruites car plus fragiles ou difficiles à déterminer du fait de leur petite taille (Outram, 2005 ; Costamagno, 2013). Comparativement à des sites comme le Noisetier ou les Pradelles (Costamagno et Rigaud, 2014) où les fragments d'extrémités articulaires correspondent à moins de $10 \%$ des fragments d'os longs, au RM2, la situation est plus contrastée. En effet, ce pourcentage est très variable selon les éléments squelettiques, variant entre 5 et $18 \%$ pour les os du stytopode (humérus, fémur) et du zeugopode (radius, tibia) et aux 
alentours de $40 \%$ pour les métapodes (fig. 18). Un problème de conservation différentielle ayant été écarté, ces différences témoignent très certainement d'un traitement différentiel de ces parties. La présence de quelques os courts ou extrémités d'os longs avec des pans de fracture rectilignes témoigne d'une fracturation intentionnelle de ces parties qui pourraient avoir été utilisées comme combustible ou comme ressource alimentaire ou technique après concassage ou confection de bouillon gras. Parmi les restes déterminés ou coordonnés, les os brûlés représentent moins de $6 \%$ des vestiges. Ce pourcentage est difficile à interpréter car, lors d'une combustion intentionnelle, la fragmentation est telle que la majeure partie des fragments brûlés sont indéterminables (Costamagno et al., 2010). Au sein des restes non déterminés du tamisage, les os brûlés bien que présents ne sont jamais dominants. Parmi les restes étudiés en détail, les pièces brûlées sont majoritairement carbonisées, moins de 10\% présentent des traces de combustion peu intenses et près de $50 \%$ sont des portions spongieuses alors que parmi les restes non brûlés, les portions spongieuses correspondent à moins de $30 \%$ des vestiges. Une partie des portions spongieuses pourrait donc avoir été utilisée comme combustible mais sans une étude quantitative de restes indéterminés issus des refus de tamis, il n'est pas possible d'exclure une récupération de la graisse par bouillon ou concassage.

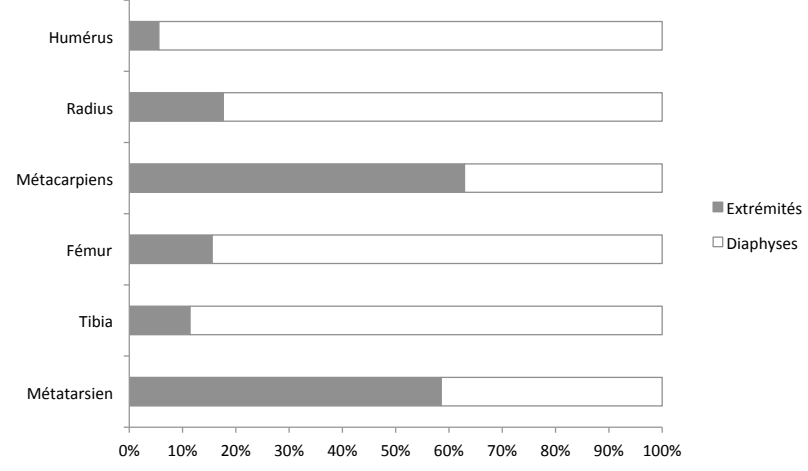

Fig. 18 - Pourcentage d'extrémités articulaires d'os longs relativement aux fragments de diaphyses.

Fig. 18 - Percentage of long bone articular surfaces in relation to diaphysis fragments.

\section{Exploitation de la mésofaune et de l'avifaune}

À côté des ongulés, qui constituent l'essentiel des ressources animales exploitées par les chasseurs-cueilleurs, se trouvent quelques éléments provenant de petits animaux à poils et à plumes.

Deux pièces de renard portent des traces d'exploitation. La première est une portion de mandibule droite qui présente sur sa face linguale à l'aplomb des molaires de fines stries obliques. Ces stries peuvent être mises en relation avec le retrait de la langue. Sur la face vestibulaire, aucune strie typique du décharnement n'a été observée. Le deuxième reste est une troisième phalange sur laquelle ont été identifiées des stries obliques au niveau de la surface articulaire proximale. Elles renvoient à la désarticulation de ces phalanges au moment du dépouillement de la carcasse. Enfin, un fragment de canine inférieure a été transformé en élément de parure (voir supra). Sa position spatiale, très élevée dans le remplissage et à proximité des éléments de céramique pose un certain doute quant à son attribution au Magdalénien.

Deux restes de lièvre présentent des traces d'activité humaine. Il s'agit tout d'abord d'un fragment distal de diaphyse d'une ulna gauche qui porte une fine strie oblique sur sa face latérale ainsi que des traces de chauffe ou de brûlure distale (sensu Vigne et Marinval-Vigne, 1983). La première de ces traces renvoie au prélèvement de la viande autour de l'avant-bras et la seconde indique que cette portion anatomique a été placée à proximité d'une source de chaleur très probablement au moment de la cuisson. Le second reste est une incisive inférieure gauche qui a été utilisée comme élément de parure (voir supra).

Seules deux pièces témoignent de l'exploitation des oiseaux. La première est un fragment proximal de coracoïde de lagopède, Lagopus sp., qui porte un faisceau de stries de boucherie (fig. 19, $\mathrm{n}^{\circ} 1$ ). Situées sur la face antérieure de l'os, juste sous l'articulation humérale, ces stries indiquent la désarticulation de l'aile ou la découpe des muscles de cette zone de la carcasse. La seconde pièce est un fragment de corps d'ulna à la circonférence incomplète qui a été utilisé comme matière première (fig. 19, $n^{\circ} 2$ ). Ses dimensions et sa morphologie générale (en particulier des apophyses anconales) permettent de le rapprocher d'un aigle, cf. Aquila. Cet os long a été raclé puis décoré de deux rangées d'incisions transversales régulièrement espacées. Son état fragmentaire gène l'attribution typologique de cette pièce mais le support (os long de grand oiseau) comme le décor rappellent les objets tubulaires connus au Magdalénien classique (Chauvet, 1910; Saint-Périer, 1947; Allain, 1950; Chollot, 1964; Laroulandie, 2000). Remis dans leur contexte chronoculturel régional, de discrets éléments se rapportant à la chouette harfang contribuent, en l'absence de traces directes, à discuter de l'agent accumulateur. L'intérêt des hommes pour ce rapace, et notamment pour ses griffes, est bien connu au Magdalénien supérieur dans le Bassin aquitain (Laroulandie, 2009) et a également été décrit récemment dans le Magdalénien inférieur et moyen du site voisin de Saint-Germain-la-Rivière (Laroulandie in Langlais et al., 2015). Dans tous les cas, les stries de désarticulation, qui sont des épiphénomènes (Laroulandie, 2000, p. 129), s'observent seulement sur une partie du stock osseux et les griffes sont généralement moins affectées que les pénultièmes phalanges. Au RM2, la chouette harfang est représentée par un faible nombre de restes mais il s'agit uniquement de griffes ( $\mathrm{NR}=4)$. Au vu du contexte, et bien que des preuves irréfutables manquent, il est envisageable que ces griffes soient en lien avec l'activité des occupants magdaléniens. 


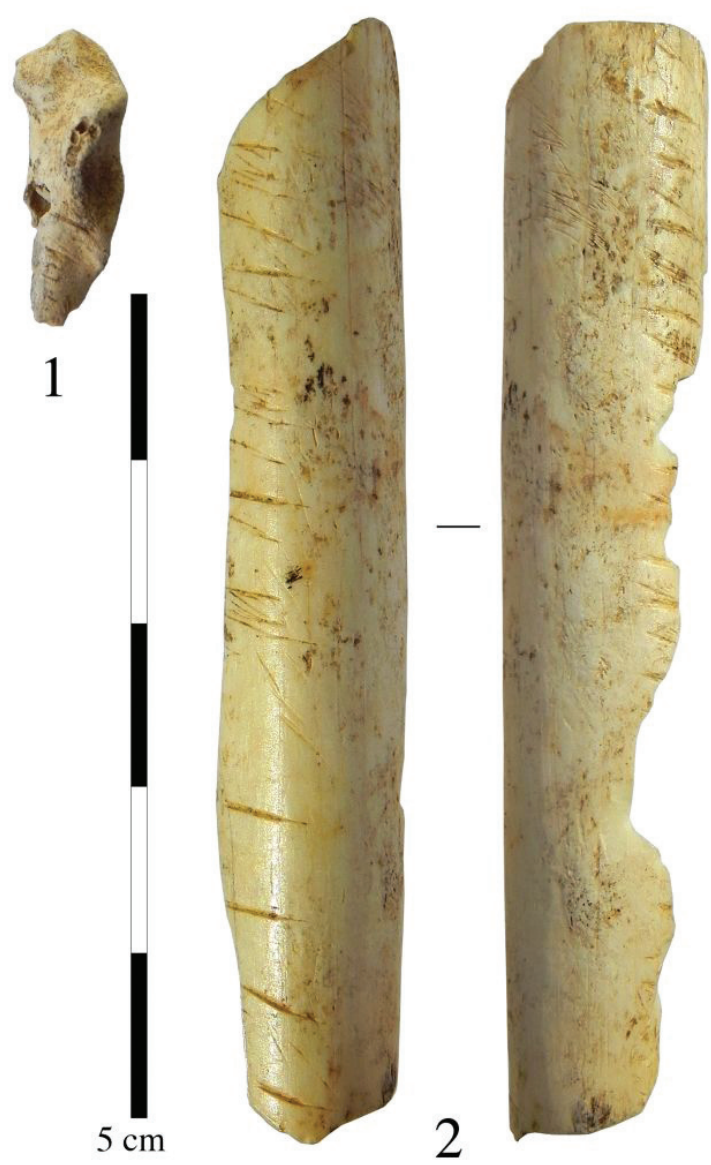

Fig. 19 - Ossements d'oiseaux modifiés. 1 : fragment proximal de coracoïde gauche de lagopède portant des stries de découpe; 2 : fragment de corps d'ulna de grand oiseau (cf. Aquila) raclé et décoré d'incisions. L'échelle représente $5 \mathrm{~cm}$.

Fig. 19 - Modified bones of birds. 1: Proximal fragment of left coracoid of Ptarmigan with cutmarks; 2: fragment of an ulna shaft belonging to a large bird (cf. Aquila) scraped and decorated with incisions. The scale represents $5 \mathrm{~cm}$.

\section{SYNTHÈSE ET DISCUSSION}

L es nouvelles données obtenues sur le site du RM2 livrent de précieuses informations sur les comportements techno-économiques des groupes humains durant le Magdalénien moyen ancien. Les quatre dates obtenues sur des vestiges de renne et d'antilope saïga confirment les deux datations plus anciennes et placent l'occupation autour de 18900-18600 cal. BP, comme cela est avéré pour d'autres gisements girondins attribués à cette phase : secteur 1 du Roc de Marcamps, RM1 (Lenoir, 1993a et b; Barshay-Szmidt et al., en préparation), couche 2 de Moulin-Neuf, MN (Barshay-Szmidt et al., en préparation); ou encore l'ensemble supérieur de Saint-Germain-la-Rivière, SG (Langlais, 2010 et Langlais et al., 2015). Si RM2 s'inscrit bien chronologiquement dans cet ensemble, peut-on préciser sa relation avec les dits « faciès» présents dans deux gisements voisins - « Magdalénien à pointes de Lussac-Angles » reconnu aux Fées (Langlais et al., soumis) et " Magdalénien à navettes » bien connu dans les anciennes collections du Roc de Marcamps (en particulier la série Maziaud) - mais aussi avec les sites de SG et de MN?

$\mathrm{Au}$ RM2, les vestiges osseux documentent l'exploitation de plusieurs espèces animales durant diverses périodes de l'année. En termes de nombre minimal d'individus, le spectre faunique diffère des autres sites girondins hormis RM1. Dans ce dernier, bison et saïga sont les gibiers majoritaires (Slott-Moller, 1988). Au RM2, le bison constitue le gibier dominant alors qu'il est très peu représenté à $\mathrm{SG}(\mathrm{NMI}=2:$ Costamagno in Langlais et al., 2015) et au MN (NMI = $3:$ Costamagno, 2000) où c'est l'antilope saïga qui est majoritaire (quarantetrois individus à $\mathrm{SG}$ et dix-huit individus à $\mathrm{MN}$ ); alors qu'au RM2, elle constitue le gibier secondaire. Le harfang des neiges apparait en seconde position à SG et a été consommé par les groupes humains; au RM2, il n'est représenté que par un seul individu qui ne porte pas de trace évidente d'exploitation par l'homme. Dans ces trois gisements, chevaux et rennes sont présents dans des proportions relativement équivalentes.

Au RM2, la chasse aux ongulés s'est majoritairement déroulée au cours de la mauvaise saison et au début de la bonne saison. Une complémentarité saisonnière semble émerger entre le bison et le renne : les bovinés, représentés majoritairement par des adultes, ont surtout été chassés à la mauvaise saison (de même que certains des chevaux) alors que les rennes, dont le profil de mortalité traduit une courbe catastrophique, ont plutôt été abattus au début de la bonne saison. L'antilope saïga, dont le profil de mortalité reflète également une population naturelle, aurait été acquise à plusieurs périodes de l'année. Dans les autres gisements girondins, les chasses aux antilopes saïgas semblent également s'être déroulées durant la mauvaise saison et au début de la bonne (MN : Costamagno, 1999 et 2001) ainsi qu'à la pleine bonne saison (SG : Costamagno, 1999; Langlais et al., 2015). Au RM1, une fréquentation plus ou moins continue a été mise en évidence, avec une activité plus soutenue en automne et en hiver (Slott-Moller, 1988).

Durant la période hivernale, les bisons sont généralement répartis en petits groupes et sont peu mobiles en raison du couvert neigeux. Au début de la mauvaise saison, les peaux sont de très bonne qualité, les femelles sont en bonne condition physique et les mâles ont renouvelé une partie de la graisse perdue durant le rut (Peck, 2004). La traque de ce gibier en hiver, a fortiori des individus adultes, a donc probablement permis aux Magdaléniens du RM2 de disposer d'une importante masse carnée et graisseuse ainsi que de peaux de bonne qualité

Pour le renne, au vu des données saisonnières du RM2 (début de la bonne saison), il paraît étonnant de ne pas avoir, au sein des vestiges osseux, de restes de nouveaunés ou de très jeunes individus âgés de quelques mois. Les femelles gestantes étant affaiblies après la mise bas, les chasses ont pu être menées préférentiellement sur des femelles non gestantes ou des individus mâles. Malheureusement, aucune information sur le sex ratio n'est dispo- 
nible en raison d'effectifs trop réduits pour entreprendre des analyses de mélanges (Kuntz, 2011) et du faible nombre de bois, tant dans les restes de faune que dans les vestiges techniques. Malgré tout, dans l'économie du bois de renne, les quelques bois de renne travaillés du RM2 montrent une sélection orientée vers les bois de gros module, appartenant probablement à des individus mâles adultes. Dans les autres séries du Roc de Marcamps, cette préférence pour les bois de gros module va de pair avec une productivité élevée des débitages (deux à cinq baguettes extraites de chaque bois); mais nous n'avons pas d'éléments pour le vérifier au RM2. Alors que les collections anciennes du Roc de Marcamps ont livré cinquante-deux bases de bois (cinquante et un de chute, un de massacre) de module généralement gros, avec des traces d'extractions multiples de baguettes sur la perche $\mathrm{A}$, et que trois déchets similaires sur base de bois de gros module (deux chutes, un massacre) proviennent de RM1, la rareté des indices de travail du bois de renne au RM2 est assez frappante. S'agit-il d'un biais d'échantillonnage ou d'un réel contraste dans les activités pratiquées? La seconde hypothèse pourrait être privilégiée si on considère les données saisonnières. Au début de la bonne saison, période durant laquelle la majorité des rennes du RM2 ont été abattus, soit les sujets sont dépourvus de bois (femelles gestantes et jeunes mâles et femelles), soit le bois est encore recouvert de velours (femelles non gestantes et mâles : Murray, 1993). Des contraintes techniques liées à la qualité du bois (non minéralisé) directement accessible pourraient donc expliquer en partie ce faible investissement dans le travail du bois de renne de la part des groupes magdaléniens du RM2.

Que ce soit au RM2 ou dans les autres sites girondins du Magdalénien moyen ancien, l'exploitation alimentaire des ongulés a été intensive (Costamagno, 1999, 2001 et 2003; Costamagno in Langlais et al., 2015; Kuntz et al., en préparation). Au RM2, les bisons et les chevaux semblent avoir été transportés le plus souvent incomplets au campement, après une première étape de boucherie sur le site d'abattage. Au sein de l'industrie en os, les restes de grands ongulés - cheval, Bovinés - occupent une place dominante dans les supports (production de lissoirs, retouchoirs, etc.), hormis pour la fabrication d'aiguilles. Pour les antilopes saïga et les rennes, les analyses de densité ne permettent pas de conclure à un transport complet des carcasses ou encore à un abandon du squelette axial post-crânien sur le site d'abattage mais, pour le renne, il est envisageable que les membres aient été introduits complets. Pour les quatre principaux ongulés, la moelle a été un produit particulièrement recherché en complément de la viande. Certains fragments osseux ont servi de retouchoirs. La fréquence relativement importante de cet outillage non façonné est d'ailleurs inhabituelle pour une série magdalénienne. Mais les autres séries du Roc de Marcamps n'ayant pas bénéficié de conditions aussi favorables à leur identification (récolte sélective de la faune dans les fouilles anciennes, pas de recherche systématique lors de l'étude archéozoologique du secteur 1, etc.), il est difficile de savoir si cette abondance de retou- choirs est une spécificité du secteur 2. Il existe cependant des analogies locales : la série de la couche 2 de MN et l'ensemble supérieur des fouilles Trécolle à SG, dont l'industrie en os comprend également d'assez abondants outils non façonnés (retouchoirs et outils d'extrémité).

Concernant le travail des peaux et en particulier la couture, les aiguilles à chas sont rares au RM2 et leur production occupe une place relativement restreinte par rapport aux autres sites considérés. Les collections anciennes du Roc de Marcamps ont notamment livré vingt-six « matrices d'aiguilles » typiques - des déchets sur extrémité proximale ou distale de métapodien (le plus souvent d'antilope saïga) portant des départs de rainures qui indiquent l'extraction de trois ou quatre baguettes sur chaque bloc (Pétillon, observation personnelle). Dans le contexte du Magdalénien moyen ancien régional, ce schéma opératoire est également attesté à $\mathrm{MN}$, à la grotte des Fées et dans l'ensemble supérieur de SG (Costamagno, 1999; Pétillon in Langlais et al., 2015). L'absence de matrices et la rareté des aiguilles au RM2 - alors que la matière première, telle des métapodiens de saïga et de renne, est disponible - est-elle le reflet d'un biais d'échantillonnage ou l'indice d'une différence dans les activités pratiquées entre les deux secteurs du Roc de Marcamps (et entre RM2 et d'autres sites)? Un argument irait plutôt dans le sens de la seconde hypothèse, à savoir un contraste réel : les fouilles Lenoir du secteur 1 ont livré un ensemble d'industrie osseuse qui, bien qu'il ne soit pas plus abondant que celui du secteur 2 (une soixantaine de pièces), comporte pourtant une matrice à aiguilles.

La parure du RM2 s'inscrit dans les pratiques ornementales du début du Magdalénien moyen. La forte proportion des scaphopodes correspond à une tendance générale pour cette période (Taborin, 1993). Les incisives de renne sciées sont communes au Magdalénien supérieur (Poplin, 1983; Berganza et Arribas, 2010) et au début du Magdalénien moyen (la Garenne, RM, peutêtre les pièces de Raymonden et Laugerie-Haute attribuées au « Magdalénien III »: Poplin, 1983); les indices de leur existence dans la phase récente du Magdalénien moyen (fouilles Péquart au Mas d'Azil, fouilles Bouvier à la Madeleine : Poplin, 1983) et au Magdalénien inférieur (le Petit Cloup Barrat, c. 4 : Chauvière in Ducasse et al., 2011) sont moins nombreux et demanderaient à être étayés. La parure du RM2 montre plusieurs similarités avec les autres séries du Roc de Marcamps. Les incisives de renne sciées sont également bien représentées au RM1 (trois exemplaires) et dans les collections anciennes du Roc de Marcamps avec huit exemplaires ainsi que deux incisives de cheval décorées (dont une rappelle la pièce du RM2). La forte proportion de dentales se retrouve au RM1 (fouilles Lenoir : 43 exemplaires) et dans les collections anciennes (141 exemplaires) où la présence conjointe de coquilles entières, déchets de fabrication et objets finis semble également indiquer des activités de production et de réfection. La composition et les modalités de perforation des gastéropodes (15 au RM1 fouilles Lenoir; 20 dans les collections anciennes) s'inscrivent dans les tendances observées au RM2. Plus abondantes 
et diversifiées, les autres séries du Roc de Marcamps contiennent aussi quelques spécimens de gastéropodes absents du secteur 2 (Nassarius reticulatus, Nassarius gibbosulus, Phalium saburon, Granulolabium plicatum, Turritella sp., Littorina obstusata, Colus gracilis, Oliva dufresnei, Cyraea), de nombreux bivalves (6 au RM1 fouilles Lenoir; 151 dans les collections anciennes), des fossiles (trois dents de requin et une boucle cutanée de raie dans les collections anciennes), des dents percées (deux incisives de jeunes bovinés, une canine d'ours et une crache de cerf dans les collections anciennes) et deux pendeloques (collections anciennes : une pendeloque-spatule sur côte et une pendeloque quadrangulaire biforée et ornée de stries parallèles). À l'inverse, RM2 contient des objets qui n'ont pas été découverts ailleurs dans le gisement (la Trivia europea biforée, la Nucella lapillus, la canine de renard percée et l'incisive de lièvre sciée).

Au final, bien que la zone fouillée soit restreinte par rapport à l'étendue probable du gisement et que la stratigraphie, sur un mètre de dépôts, corresponde certainement à un cumul de plusieurs occupations, le croisement des données permet malgré tout d'avancer des hypothèses sur la fonction du RM2. Les résultats des études typotechnologiques des industries lithique (présence de déchets de taille, d'outils du fonds commun et de nombreux ravivages de burin notamment), osseuse (présence de déchets de débitage et d'objets finis) et de la parure (fabrication sur place des objets en coquillage) ainsi que sur les stratégies de chasse (spectre faunique diversifié, alternance saisonnière de la chasse aux rennes et aux bovinés, abattage à proximité du site et exploitation intensive des carcasses) s'accordent en effet pour proposer l'hypothèse d'une fonction résidentielle du RM2, occupé une grande partie de l'année sans que l'on puisse concrètement conclure du caractère continu ou répété des installations.

L'étude de l'industrie lithique confirme l'attribution du gisement au Magdalénien moyen comme l'avait proposé M. Lenoir. Rappelons qu'aucune microlamelle à dos et tranchant convexe, signant un Magdalénien inférieur, n'a été retrouvée. Les traits techniques et économiques du Magdalénien moyen définis entre Rhône et Èbre sont en effet déjà présents (Langlais, 2007b et 2010) avec un sous-système technique articulé autour des lames et des lamelles; des objectifs de production disjoints (une chaîne de production laminaire pour l'outillage et une autre lamellaire pour l'armement de chasse); une stabilité de la production laminaire (débitage unipolaire, modalité semi-tournante, optimisation des longueurs); une diversité des modalités de débitage lamellaire et, enfin, une normalisation des supports associée à une forte productivité.

Les matières premières de Saintonge, à une cinquantaine de kilomètres au nord du gisement, tiennent une place économique importante notamment dans la réalisation de l'outillage. Elles sont même les plus nombreuses dans le cas des chutes de burin. Il y a donc un apport de supports laminaires et d'outils sur le gisement. Ces derniers sont en partie abandonnés fortement réaffûtés.
Quelques pièces indiquent des liens avec le Sud du Sable des Landes (comme MN) et la moyenne vallée du Cher (rappelant SGR, MN et les Fées : Langlais et al., soumis). $\mathrm{Au} \mathrm{RM} 2$, la complémentarité entre matières premières locales et allochtones témoigne d'un schéma de mobilité ou d'échanges complexe qui reste difficile à interpréter en terme de mobilité résidentielle ou spécialisée. Ce réseau d'approvisionnement ou d'échange de matières premières sur de grandes distances se retrouve en effet dans tout le Magdalénien moyen ancien de Gironde (par ex. MN, RM1, Fées : Langlais et al., soumis). L'actualisation et la confrontation des données lithologiques mais aussi et surtout le croisement avec l'ensemble des autres registres d'activités doivent encore être précisés afin de discuter des schémas de mobilité sur le territoire aquitain (Sécher, en cours).

En l'état actuel des connaissances sur les équipements lithiques des premiers temps du Magdalénien moyen, l'outillage normalisé présente généralement une faible variation régionale et a vocation à circuler sur de vastes espaces sous la forme de supports polyfonctionnels (Langlais, 2007a). À l'échelle macrorégionale, il y a une certaine stabilisation des schémas opératoires laminaires sous-tendus par une exigence en matière première de grands modules et de bonne qualité. En revanche, les armatures semblent signer des traditions variées : une première dans laquelle la lamelle scalène est un véritable morphotype normalisé (par ex. latéralisation préférentielle : Langlais, 2008) comme à SG; et une seconde arborant une composante de lamelles à dos tronquées se démarquant des précédentes (délinéation des troncatures variable, absence de latéralisation préférentielle). Cette seconde composante se retrouve tant dans des séries du « Magdalénien à navettes » (par ex. RM1 : Lenoir, 1993a) que dans le « Magdalénien à pointes de Lussac-Angles » aquitain (par ex. Les Fées : Langlais et al., soumis; Isturitz : Langlais, 2007b). RM1, RM2 et MN (Lenoir, 1983) sont également attribuables à cette tradition de lamelles à dos tronquées.

À l'échelle de la Gironde, différents faciès ou traditions s'imbriquent sans que l'on puisse actuellement préciser la nature de ces interactions. L'uniformité du système laminaire coexistant avec différents morphotypes d'armatures permet d'ouvrir une réflexion sur l'identité culturelle du (des) groupe(s) du Magdalénien moyen sur le territoire aquitain et ses marges ainsi que les mécanismes évolutifs sous-jacents (Sécher, thèse en cours). Au-delà de l'Aquitaine, nous rappelons que le corpus des armatures du RM2, marqué par l'absence de lamelles scalènes et la présence de lamelles à dos tronquées, fait écho aux séries du « Magdalénien à navettes » comme la Garenne (Jacquot, 2002 ; Taylor, 2003) ou Arlay (David, 1996; Cupillard et Welté, 2006) mais également aux séries du « Magdalénien à pointes de Lussac-Angles » comme le Taillis des Coteaux, niveau IIg ( Primault et al., 2007; Astier, 2014), la Marche (Pradel, 1959; Airvaux et al., 2012) ou le Roc-aux-Sorciers (Chehmana et Beyries, 2010). De même, dans les séries du Massif central (par ex. Enval, Sol de la Grange, E4, etc.) s'expriment une pluralité dans 
les modes de production lamellaires allant de pair avec une stabilité de la production laminaire (Angevin et Surmely, 2013 et 2014). Les séries aujourd'hui disponibles dans cette région ne sont actuellement rapportées ni au « Magdalénien à navettes » ni au « Magdalénien à pointes de Lussac-Angles ».

Dans l'industrie en os du RM2, le fragment de lissoir décoré d'incisions évoque une pièce très similaire dans les séries anciennes du Roc de Marcamps ainsi que dans la collection de la grotte des Fées (qui a livré des pointes de Lussac-Angles mais aucun artéfact typique du « Magdalénien à navettes »). Parmi les armatures en bois de renne du RM2, le seul type de base attesté (en biseau simple) est également le type dominant dans les séries anciennes et dans le secteur 1 (fouilles Lenoir). Cette place dominante des pointes à biseau simple au Roc de Marcamps nous éloigne d'autres sites du Magdalénien à navettes, comme La Garenne (Allain et al., 1985), où les pointes à biseau double sont les plus fréquentes (Chauvière et Rigaud, 2008, graph. 1). Les armatures du Roc de Marcamps sont également différentes de celles de l'ensemble supérieur des fouilles Trécolle à SG (Langlais et al., 2015). Soulignons aussi que les pointes de LussacAngles comme les pointes bivalves (composées de deux baguettes demi-rondes accolées) sont absentes de tous les secteurs du Roc de Marcamps. Enfin, toujours dans l'industrie en bois de cervidé, la production de fins outils à section circulaire (alênes ?) est également attestée à $\mathrm{MN}$ et évoque certaines productions du Magdalénien inférieur (présentes notamment dans l'ensemble inférieur de SG : Langlais et al., 2015).

Rappelons par ailleurs que les collections d'industrie osseuse issues des fouilles anciennes du Roc de Marcamps, très abondantes (plus de 1600 pièces conservées au musée d'Aquitaine), ont livré plusieurs types de pièces qui sont absentes du secteur 2 mais permettent des rapprochements avec d'autres sites. On compte ainsi une vingtaine de navettes, similaires à celles de la Garenne et des autres sites du « Magdalénien à navettes » (Allain et al., 1985); trois crochets de propulseur de type $2 \mathrm{du}$ premier groupe (sensu Cattelain, 2004 : Langlais et al., soumis), un sous-type également présent dans des sites ayant livré non pas des navettes mais des pointes de Lussac-Angles (El Mirón : González Morales et Straus, 2009; Isturitz : P. Cattelain, communication personnelle) ou les deux types d'objets (le Placard : Cattelain, 2004); et deux os hyoïdes travaillés (un percé, un sectionné et décoré) évoquant les pendeloques en os hyoïde connues dans plusieurs sites du Magdalénien moyen (Langlais, 2007b, p. 421 et 448 ; 2010, p. 280-283).

Dans plusieurs gisements attribués au début du Magdalénien moyen, les incisives de renne sciées sont aménagées d'une perforation. C'est le cas dans l'ensemble supérieur de SG (Vanhaeren et d'Errico, 2003) et également, à une échelle extra-régionale, aux Peyrugues (Rodière, 1996) ou encore à Lafaye et Plantade (Ladier et Welté, 1993; Ladier et al., 1994). Les exemplaires du Roc de Marcamps se distinguent des autres gisements du Sud-Ouest français par l'installa- tion de sillons plutôt que d'une perforation, particularité que l'on retrouve également à l'abri Vidon (Campmas et al., 2011) et à La Garenne (Peschaux, en cours). L'utilisation de reste dentaire de léporidé comme objet de parure a par ailleurs été décrit à Gazel (Sacchi, 2003) mais dans ce cas, il s'agit d'incisive percée. Dans le même registre, des incisives de marmotte sciées ont été identifiées dans le Magdalénien supérieur de Monruz (Müller, 2013). Le sciage d'incisive de lièvre dans le Magdalénien moyen n'est, à notre connaissance, pas documenté par ailleurs.

Les parures du RM2 et de la Garenne sont également comparables dans la composition et les modalités de fabrication des coquillages. Le site de La Garenne a fourni de nombreux scaphopodes, des Vitta picta et des Nucella lapillus perforés par abrasion sur la face columellaire et ventrale, ainsi que quelques spécimens de Cylope neritea et Aporrhais pespelecani perforés par percussion sur la face dorsale (Taborin et Tymula, 2009; Peschaux, en cours). La ressemblance entre les parures de ces deux sites rapprocherait le Roc de Marcamps, y compris RM2, du «Magdalénien à navettes ». En revanche, l'incisive de cheval gravée du RM2 (et la pièce similaire provenant des collections anciennes) évoque celles du « Magdalénien à pointes de Lussac-Angles » (la Marche, les Fadets, le Roc-aux-Sorciers, Montgaudier : Airvaux, 2011). Celle du RM2 ne leur est pas strictement identique, mais on retrouve le choix du support (incisive de cheval), le choix de l'emplacement du décor (face linguale), le motif de quadrillage et l'insistance sur la partie de la face linguale la plus proche de la face occlusale. Il ne s'agit donc pas strictement du même type de pièce, mais une influence qui lierait des sites « à pointes de Lussac-Angles » avec un site « à navettes » peut ainsi être envisagée.

Certains traits techno-économiques témoignent finalement d'une forte anticipation des besoins allant dans le sens d'un réseau étendu d'interactions sociales. Au cours du Magdalénien moyen ancien, nous assistons à une diffusion des systèmes de productions lithiques et osseux qui semble unifier tant le Sud-Ouest que l'ensemble de son territoire culturel étendu. En définitive, la réévaluation du RM2 permet de souligner l'existence d'un fonds commun du Magdalénien moyen ancien, fonds commun qui transcende les variations exprimées en faciès ou en traditions différentes. Si le site du RM2 ne peut pas être rattaché exclusivement au « Magdalénien à navettes » ou $\mathrm{au}$ « Magdalénien à pointes de Lussac-Angles » bien qu'il en soit contemporain, plusieurs rapprochements sont proposés tant avec le secteur 1 et les sites «à navettes » (parures en coquillages et en dents) qu'avec les séries « à Lussac-Angles » (lissoirs, incisives décorées). Ces éléments montrent clairement des interactions entre ces dits faciès. Ceci doit conduire à s'interroger sur la pertinence de l'utilisation de ces faciès pour définir des « cultures exclusives » qui finalement se recouvrent chronologiquement et géographiquement, notamment en Gironde qui sans doute occupe une place privilégiée au cœur de fortes interactions sociales. 
Remerciements : Nous tenons à remercier le projet « Magdatis » (ANR 2011 BSH3 0005) et Michel Lenoir grâce à qui cette étude pluridisciplinaire a été rendue possible, ainsi que Solène Caux pour la détermination des matières premières lithiques et Gauthier Devilder pour les dessins lithiques.

\section{NOTES}

(1) Le corbeau freux est signalé à Rochereil en Dordogne (détermination Astre, 1950). Une révision de ce matériel par V. Laroulandie dans le cadre d'un projet collectif de recherches (PCR) dirigé par P. Paillet montre que les ossements appartiennent en fait au lagopède.
(2) La plupart des objets ayant été trouvés dans les refus de tamis, nous avons attribué à ces restes les valeurs moyennes en abscisses et en ordonnées des carrés intéressés et pour l'altitude, la moyenne des objets ayant été coordonnés précédemment au tamis.

(3) Si l'on considère l'ensemble des carrés du secteur 2, l'outillage est dominé par les burins $(26 \%)$ et les lames retouchées-tronquées $(25,4 \%)$. Les armatures sont majoritairement représentées par les lamelles à dos simple $(51,3 \%)$ parfois retouchées $(22 \%)$ ou tronquées $(18,3 \%)$. La sélection des supports est concordante avec celles mises en évidence dans I23 tant technologiquement que lithologiquement.

(4) La fracturation des mandibules est aussi attestée grâce à la présence de dents jugales au fût fendu.

\section{RÉFÉRENCES BIBLIOGRAPHIQUES}

Airvaux J. (2011) - Les incisives de chevaux gravées du Magdalénien moyen de Lussac-Angles, Préhistoire du SudOuest, 19, 2, p. 137-195.

Airvaux J., Brou L., Primault J. (2012) - Les outils sur lames tronquées et amincies du Magdalénien moyen de LussacAngles, Préhistoire du Sud-Ouest, 20, 2, p. 143-178.

Allain J. (1950) - Un appeau magdalénien, Bulletin de la Société préhistorique française, 47, 3-4, p. 181-192.

Allain J., Desbrosse R., KozŁowski J. K., Rigaud A. (1985) - Le Magdalénien à navettes, Gallia Préhistoire, 28, p. 37-124.

Angevin R., Surmely F. (2014) - Les temps du Magdalénien dans le Massif central et ses marges septentrionales : structure paléohistorique, mutations culturelles et expressions techniques entre $15000 \mathrm{BP}$ et $11500 \mathrm{BP}$, in J. Jaubert, N. Fourment et P. Depaepe (dir.), Transitions, ruptures et continuité en Préhistoire, 2. Paléolithique et Mésolithique, actes du $27^{\mathrm{e}}$ Congrès préhistorique de France (Bordeaux - Les Ezyies, 31 mai-5 juin 2010), Paris, Société préhistorique française, p. 449-462.

Angevin R., Surmely F. (2013) - Le Magdalénien moyen et la trajectoire historique des sociétés du $\mathrm{XVI}^{\mathrm{e}}$ millénaire av. J.-C. en France centrale, Comptes rendus Palevol, 12, 1 , p. $57-68$

Astier A. (2014) - Comportements techniques au Magdalénien moyen sur le site du Taillis des Coteaux (Vienne). Analyse technologique de l'industrie lithique : niveau EG-IIg, mémoire de master I, université Toulouse II, 201 p.

Astre G. (1950) - Faune magdalénienne et azilienne de Rochereil (Dordogne), Bulletin de la Société d'histoire naturelle de Toulouse, 85, p. 151-171.

Barshay-Szmidt C., Pétillon J.-M., Costamagno S., Laroulandie V., Langlais M., Mallye J.-B., HenryGambier D., Boudadi-Maligne M., Kuntz D. (en préparation) - The Chronology of the Middle and Late Magdalenian in the Western Aquitaine/Pyrenean Region of France (ca. 19-14 Ky cal. BP). New Extensive Focused AMS ${ }^{14} \mathrm{C}$ Dating of the MAGDATIS Project and Overall Trends, Quaternary International.

Berganza E., Arribas J. L. (2010) - Dientes de herbívoros serrados e incisos de la cueva de Santa Catalina (Lekeitio, Bizkaia), Munibe, 61, p. 57-70.
Berger J. (1986) - Wild Horse of the Great Basin, Chicago, University of Chicago Press, $326 \mathrm{p}$.

Bignon O. (2008) - Chasser les chevaux à la fin du Paléolithique dans le Bassin parisien. Stratégie cynégétique et mode de vie au Magdalénien et à l'Azilien ancien, Oxford, Archaeopress (British Archaeological Reports, International Series 1747), $170 \mathrm{p}$.

BINFORD L. R. (1978) - Nunamiut Ethnoarchaeology, New York, Academic Press, 509 p.

BINFORD L. R. (1981)-Bones: Ancient Men and Modern Myths, New York, Academic Press, 320 p.

Boudadi-Maligne M., Mallye J.-B., Langlais M., BARShaY-Szmidt C. (2012) - Des restes de chiens magdaléniens à l'abri du Morin (Gironde, France). Implications socio-économiques d'une innovation zootechnique, Paléo, 23, p. 39-54.

Boudadi-Maligne M., Escarguel G. (2014) - A Biometric Re-evaluation of Recent Claims for Early Upper Palaeolithic Wolf Domestication in Eurasia, Journal of Archaeological Science, 45, p. 80-89.

Bourgeors G. (2011) - Étude paléontologique et archéozoologique d'une mandibule décorée de Blaireau (Meles meles) du site de la Marche (Vienne, France), in A. Gardeisen et C. Chandezon (coord.), Ve Rencontres archéozoologiques (Lattes, 17 juin 2011).

Bowyer R. T., Bleich V. C., Manteca X., Whiting J. C., Stewart K. M. (2007) - Sociality, Mate Choice, and Timing of Mating in American Bison (Bison bison): Effects of Large Males, Ethology, 113, p. 1048-1060.

Bronk RAMsey C. (2009) - Bayesian Analysis of Radiocarbon Dates, Radiocarbon, 51, p. 337-360.

Campmas E., Daujeard C., Lenoir M., Ajas A., Baillet M., Bourgeon L., Delvigne V., Robert B., Teyssandier J., Armand D., Rigaud S. (2011) - Nouvelles données sur le Magdalénien de l'Entre-deux-Mers : la faune de l'abri Vidon (Juillac, Gironde), Préhistoire du Sud-Ouest, 19, 1, p. 3-18.

Castel J.-C., Mallye J.-B., Oppliger J. (2011) - Les petits carnivores dans leur abris temporaires : choix des espèces et caractéristiques taphonomiques. Implications pour l'archéologie, in V. Laroulandie, J.-B. Mallye et C. Denys (dir.), 
Taphonomie des petits vertébrés : référentiels et transferts aux fossiles, actes de la table ronde du réseau thématique pluridisciplinaire « Taphonomie » (Talence, 20-21 octobre 2009), Oxford, Archaeopress (BAR, International Series 2269), p. 77-91.

Cattelain P. (2004) - Un propulseur inédit de la grotte du Placard (Vihonneur, Charente, France), Notae praehistoricae, 24, p. 61-67.

Caux S. (2013) - A New Piece Within a Larger Puzzle: Characterization of « Grain de Mil » Flint from the CharenteMaritime: a Central Resource for the Reconstruction of Paleolithic Territories in Southwestern France, in A. García, J. García, A. Maximiano et J. Ríos-Garaizar (dir.), Debating Spatial Archaeology. Landscape and spatial analysis in Archaelogy, actes du colloque international (Santander, 8-9 juin 2012), Santander, Instituto internacional de investigaciones prehistóricas de Cantabria, p. 143-152.

CAux S. (en cours) - Le silex dit " grain de mil » : caractérisation, techno-économie et circulation au début du Paléolithique supérieur dans le Bassin d'Aquitaine, thèse de doctorat, université Bordeaux I.

Chauvet G. (1910)-Os, ivoires et bois de renne ouvrés de la Charente. Hypothèses paléthnographiques, Angoulême, E. Constantin (Bulletin de la Société archéologique et historique de la Charente), $191 \mathrm{p}$.

Chauvière F.-X., Rigaud A. (2008) - Le travail du bois de renne à la Garenne (Saint-Marcel, Indre) : entre conceptions préhistoriennes et techniques magdaléniennes ou comment séparer ébauches et déchets des pointes vraies?, Préhistoire du Sud-Ouest, 16, p. 173-183.

Chehmana L., Beyries S. (2010) - L'industrie lithique du Roc-aux-Sorciers (collection Rousseau), in J. Buisson-Catil et J. Primault (dir.), Préhistoire entre Vienne et Charente, Hommes et sociétés du Paléolithique, Chauvigny, Association des publications chauvinoises (Mémoire, 38), p. $453-$ 460 .

Chollot M. (1964)-Musée des Antiquités nationales. Collection Piette. Art mobilier préhistorique, Paris, Éd. des musées nationaux, $480 \mathrm{p}$.

Costamagno S. (1999) - Stratégies de chasse et fonction des sites au Magdalénien dans le Sud de la France, thèse de doctorat, université Bordeaux I, $495 \mathrm{p}$.

Costamagno S. (2000) - Stratégies d'approvisionnement et traitement des carcasses au Magdalénien : l'exemple de Moulin-Neuf (Gironde), Paléo, 12, p. 77-95.

Costamagno S. (2001) - Exploitation de l'antilope saïga au Magdalénien en Aquitaine, Paléo, 13, p. 111-128.

Costamagno S. (2003) - L'exploitation des Ongulés au Magdalénien dans le Sud de la France, in S. Costamagno et V. Laroulandie (dir.), Mode de vie au Magdalénien : les apports de l'archéozoologie, actes du XIV $\mathrm{X}^{\mathrm{e}}$ Congrès de 1'UISPP (Liège, 2-8 septembre 2001), Oxford, Archaeopress (British Archaeological Reports, International Series, 1144), p. 73-88.

Costamagno S. (2012) - Des stries de boucherie aux sous-systèmes techniques de transformation et de consommation des ressources animales : apports de l'approche expérimentale, mémoire d'habilitation à diriger des recherches, université Bordeaux I, $146 \mathrm{p}$.

Costamagno, S. (2013) - Bone Grease Rendering in Mousterian Contexts: the Case of Noisetier Cave (Fréchet-Aure,
Hautes-Pyrénées, France), in J. L. Clark et J. D. Speth (dir.), Zooarchaeology and Modern Human Origins: Human Hunting Behavior during the Later Pleistocene, Springer, Dordrecht, p. 209-225.

Costamagno S., Thery-Parisot I., Castel J.-C., Brugal J.-P. (2009) - Combustible ou non? analyse multifactorielle et modèles explicatifs sur les ossements brûlés paléolithiques, in I. Théry-Parisot, S. Costamagno et A. Henry (dir.), Gestion des combustibles au Paléolithique et au Mésolithique : nouveaux outils, nouvelles interprétations, actes du $X V^{e}$ Congrès de l'IUSPP (Lisbonne, 4-9 septembre 2006), Oxford, Archaeopress (British Archaeological Reports, International Series 1914), p. 69-84

Costamagno S., Théry-Parisot I., Kuntz D., Bon F., MenSAN R. (2010) - Impact taphonomique d'une combustion prolongée sur des ossements utilisés comme combustible, P@lethnologie, 2, p. 173-187.

Costamagno S., Rigaud J.-P. (2014) - L'exploitation de la graisse au Paléolithique, in S. Costamagno (dir.), Histoire de l'alimentation humaine : entre choix et contraintes, actes du $138^{\mathrm{e}}$ congrès du CTHS (Rennes, avril 2013), Paris, CTHS, p. 134-152.

Couste R. (1959) - Les subdivisions du Magdalénien de la Gironde, in Actes du $82^{\circ}$ Congrès national des sociétés savantes, section d'archéologie (Bordeaux, 24-26 avril 1957), Paris, Impr. nationale, p. 27-33.

Crockford S. J., Kuzmin Y. V. (2012) - Comments on Germonpré et al., Journal of Archaeological Science, 36, 2009 "Fossil dogs and wolves from Palaeolithic sites in Belgium, the Ukraine and Russia: osteometry, ancient DNA and stable isotopes", and Germonpré, Lázkičková-Galetová, and Sablin, Journal of Archaeological Science 39, 2012 "Palaeolithic dog skulls at the Gravettian Předmostí site, the Csech Republic”, Journal of Archaeological Science, 39, p. 2797-2801.

Cupillard C., Welté A.-C. (2006) - Le Magdalénien de la grotte "Grappin » à Arlay (Jura, France) : nouveaux regards, L'Anthropologie, 110, 4, p. 624-683.

DAvid S. (1996) - La fin du Paléolithique supérieur en FrancheComté : environnement, cultures, chronologie, Gallia Préhistoire, 38, 1, p. 111-248.

Demars P.-Y., LaurenT P. (1989) - Types d'outils lithiques du Paléolithique supérieur en Europe, Paris, Éd. du CNRS (Cahiers du Quaternaire, 4), $196 \mathrm{p}$.

Discamps E. (2011) - Hommes et hyènes face aux recompositions des communautés d'Ongulés (MIS 5-3). Éléments pour un cadre paléoécologique des sociétés du Paléolithique moyen et supérieur ancien d'Europe de l'Ouest, thèse de doctorat, université Bordeaux I, 437 p.

Ducasse S., Castel J.-C., Chauvière F.-X., Langlais M., Camus H., Morala A., Turq A. (2011) - Le Quercy au cœur du Dernier Maximum Glaciaire. La couche 4 du Petit Cloup Barrat et la question de la transition badegoulomagdalénienne, Paléo, 22, p. 101-154.

Emerson A. M. (1990) - Archaeological Implications of Variability in the Economic Anatomy of Bison bison, thèse de doctorat, Washington State University, Pullman (Wash.), $896 \mathrm{p}$.

Fisher J. W. (1995) - Bone Surface Modifications in Zooarchaeology, Journal of Archaeological Method and Theory, 2, 1, p. 7-68. 
Frison G. C., Wilson M., Wilson D. J. (1976) - Fossil Bison and Artifacts from an Early Altithermal Period Arroyo Trap in Wyoming, American Antiquity, 41, 1, p. 28-57.

Fuller W. A. (1960) - Behaviour and Social Organization of the Wild Bison of Wood Buffalo National park, Canada, Arctic, 13, 1, p. 3-19.

Germonpré M., Sablin M. V., Stevens R. E., Hedges R. E. M., Hofreiter M., Stiller M., Després V. R. (2009) - Fossil Dogs and Wolves from Palaeolithic Sites in Belgium, the Ukraine and Russia: Osteometry, Ancient DNA and Stable Isotopes, Journal of Archaeological Science, 36, $\mathrm{p}$ 473-490.

Germonpré M., LÁZKiČKovÁ-Galetová M., SABlin M. V. (2012) - Palaeolithic Dog Skulls at the Gravettian Predmostí Site, the Czech Republic, Journal of Archaeological Science, 39, p 184-202.

Germonpré M., Sablin M. V., Després V. R., Hofreiter M., LázkičKová-Galetová M., Stevens R. E., Stiller M. (2013) - Palaeolithic Dogs and the Early Domestication of the Wolf: a Reply to the Comments of Crockford and Kuzmin (2012), Journal of Archaeological Science, 40, p 786792.

Germonpré M., LázkičKová-Galetová M., Losey R. J., RäIKkönen J., SAblin M. V. (2015) - Large Canids at the Gravettian Predmostí Site, the Czech Republic: The Mandible, Quaternary International, 359-360, p. 261-279.

Geusa G., Bondioli L., Capucci E., Cipriano A., Grupe G., Savoré C., Macchiarelli R. (1999) - Osteodental Biology of the People of Portus Romae (Necropolis of Isola Sacra, 2nd-3rd Cent. AD). II. Dental Cementum Annulations and Age at Death Estimates, CD-ROM.

González Morales M. R., Straus L. G. (2009) - Extraordinary Early Magdalenian Finds from El Mirón Cave, Cantabria (Spain), Antiquity, 83, p. 267-281.

Hammer O., Harper D. A. T., Ryan P. D. (2001) - PAST: Paleontological Statistics Software Package for Education and Data Analysis, Palaeontologia Electronica, 4, 1, p. 1-9.

JACQUOT E. (2002) - À la recherche de l'identité culturelle des Magdaléniens de la grotte Blanchard à la Garenne (Indre). Étude technologique des microlithes et de leur mode de production, mémoire de maitrise, université Paris I, $110 \mathrm{p}$.

Jin J. J. H., MiLLs E. W. (2011) - Split Phalanges from Archaeological Sites: Evidence of Nutritional Stress?, Journal of Archaeological Science, 38, 8, p. 1798-1809.

Jones E. L. (2006) - Prey Choice, Mass Collecting, and the Wild European Rabbit (Oryctolagus cuniculus), Journal of Anthropological Archaeology, 25, p. 275-289.

Kreutzer L. A. (1992) - Bison and Deer Bone Mineral Densities: Comparisons and Implications for the Interpretation of Archaeological Faunas, Journal of Archaeological Science, 19, p. 271-294.

Kuntz D. (2011) - Ostéométrie et migration(s) du renne (Rangifer tarandus) dans le Sud-Ouest de la France au cours $d u$ dernier Pléniglaciaire et du Tardiglaciaire (2150013000 cal. BP), thèse de doctorat, université Toulouse II, $467 \mathrm{p}$.

Kuntz D., Costamagno S., Feyfant L., Martin F. (en préparation) - Food Exploitation of the Ungulates during the Magdalenian in the Entre-Deux-Mers (Gironde, France), Quaternary International.
LACORRE F. (1938) - La grotte des Fées à Marcamps (Gironde) ou Roc de Marcamps (fouilles du groupe de préhistoriens de la Société linnénne), Procès verbaux de la Société linnéenne de Bordeaux, 90, p. 35-51.

Ladier E., Welte A.-C. (1993) - Les objets de parure de la vallée de l'Aveyron. Fontalès, abri de Bruniquel (Plantade, Lafaye, Gandil), Paléo, 5, p. 281-317.

Ladier E., Welte A.-C., Lambert G. (1994) - Les objets de parure de la vallée de l'Aveyron. Le Courbet, BruniquelMontastruc et autres abris; documents inédits, Paléo, 6, p. 197-231.

Lam Y. M., Chen X., Pearson O. M. (1999) - Intertaxonomic Variability in Patterns of Bone Density and the Differential Representation of Bovid, Cervid, and Equid Elements in the Archaeological Record, American Antiquity, 64, 2, p. 343362.

Lam Y. M., Pearson O. M., Marean C. W., Chen X. (2003) - Bone Density Studies in Zooarchaeology, Journal of Archaeological Science, 30, 12, p. 1701-1708.

LANGLAis M. (2007a)-Des identités qui se cherchent... Apports des industries lithiques à la question de l'origine du Magdalénien moyen dans le Sud-Ouest européen, Bulletin de la Société préhistorique française, 104, 4, p. 759-770.

Langlais M. (2007b) - Dynamiques culturelles des sociétés magdaléniennes dans leurs cadres environnementaux : enquête sur 7000 ans d'évolution de leurs industries lithiques entre Rhône et Èbre, thèse de doctorat, universités Toulouse II et Barcelone, 548 p.

LANGLais M. (2008) - Chronologie et territoires au Magdalénien entre le Rhône et l'Ebre : l'exemple des armatures lithiques, in J.-M. Pétillon, M.-H. Dias-Merino, P. Cattelain, M. Honegger, C. Normand et N. Valdeyron (dir.), Recherches sur les armatures de projectile du Paléolithique supérieur au Néolithique, actes du XV $\mathrm{V}^{\circledR}$ Congrès de l'IUSPP (Lisbonne, 4-9 septembre 2006), P@lethnologie, 1, p. 220249.

LANGLAIS M. (2010) - Les sociétés magdaléniennes de l'isthme pyrénéen, Paris, CTHS (Documents préhistoriques, 26), $337 \mathrm{p}$.

Langlais M., Laroulandie V., Costamagno S., Pétillon J.-M., Mallye J.-B., Lacrampe-Cuyaubère F., BoudadiMaligne M., Barshay-Szmidt C., Masset C., Pubert E., Rendu W., Lenoir M. (2015) - Premiers temps du Magdalénien en Gironde : réévaluation des fouilles Trécolle à Saint-Germain-la-Rivière (France), Bulletin de la Société préhistorique française, 112, 1, p. 5-58.

Langlais M., Pétillon J.-M., Sécher A. (soumis) - Les débuts du Magdalénien moyen dans le Sud-Ouest français. Témoignages croisés des équipements lithiques et osseux, in L. Chehmana, R. Malgarini, M. Poltowicz-Bobak et C. Bourdier (dir.), L'essor du Magdalénien : aspects culturels, symboliques et techniques des faciès à navettes et à Lussac-Angles, actes de la séance de la Société préhistorique française (Besançon, 17-19 octobre 2013), Paris, Société préhistorique française.

Laroulandie V. (2000) - Taphonomie et archéozoologie des oiseaux en grotte : applications aux sites paléolithiques du Bois-Ragot (Vienne), Combe Saunière (Dordogne) et de La Vache (Ariège), thèse de doctorat, université Bordeaux I, $396 \mathrm{p}$. 
Laroulandie V. (2009) - De la plume à l'œuf : exploitation des ressources aviaires au Magdalénien dans le Sud de la France, in L. Fontana, A. Bridault et F.-X. Chauvière (dir.), In Search of Total Animal Exploitation. Case Studies from the Upper Palaeolithic and Mesolithic, actes du XV Congrès de l'UISPP (Lisbonne, 4-9 septembre 2006), Oxford, Archaeopress (British Archaeological Reports, International Series, 2040), p. 71-89.

LenoIr M. (1983) - Le Paléolithique des basses vallées de la Dordogne et de la Garonne, thèse de doctorat, université Bordeaux I, $702 \mathrm{p}$.

LenoIR M. (1993a) - Un gisement magdalénien en Gironde : le Roc de Marcamps à Prignac et Marcamps, Bulletin de la Société linnéenne de Bordeaux, 21, 2, 3, p. 87-108.

Lenoir M. (1993b) - Le gisement du Roc de Marcamps (Prignac et Marcamps, Gironde), Les cahiers du Vitrezais, p. 1-13.

LENOIR M. (1993c) - Un gisement magdalénien en Gironde : le Roc de Marcamps à Prignac-et-Marcamps, Bulletin de la Société linnéenne de Bordeaux, 21, 4, p. 109-145.

LenoIR M. (2000) - La Préhistoire ancienne en Gironde : apport des recherches récentes, Gallia Préhistoire, 42, p. 57-84.

Lieberman D.E. (1993) - Life History Variables Preserved in Dental Cementum Microstructure, Science, 261, p. 11621164.

Lloveras L., Moreno García M., Nadal, J. (2009) - Butchery, Cooking and Human Consumption Marks on Rabbit (Oryctolagus cuniculus) Bones: An experimental Study, Journal of Taphonomy, 7, p. 179-201.

Lyman R. L. (1985) - Bone Frequencies: Differential Transport, In Situ Destruction, and the MGUI, Journal of Archaeological Science, 12, p. 221-236.

Lyman R. L. (1994)-Vertebrate Taphonomy, Cambridge (Mass.), Cambridge University Press, 524 p.

Mallye, J.-B. (2007)-Les restes de blaireau en contexte archéologique : taphonomie, archéozoologie et éléments de discussion des séquences préhistoriques, thèse de doctorat, université Bordeaux I, 547 p.

Mallye J.-B. (2011a)-Réflexion sur le dépouillement des petits carnivores en contexte archéologique : apport de l'expérimentation, Archeofauna, 20, p. 7-25.

Mallye J.-B. (2011b) - Badger (Meles meles) Remains within Caves as an Analytical Tool to Test the Integrity of Stratified Sites: The Contribution of Unikoté Cave (Pyrénées-Atlantiques, France), Journal of Taphonomy, 9, p. 15-36.

Metcalfe D., Jones K. T. (1988) - A Reconsideration of Animal Body-part Utility Indices, American Antiquity, 53, 3, p. 486-504.

Miller F. L. (1974) - Biology of the Kaminuriak Population of Barren Ground Caribou, 3. Taiga Winter Range Relationships and Diet, Ottawa, Canadian Wildlife Service Reports, $42 \mathrm{p}$.

Morey D. F. (2010) - Dogs: Domestication and the Development of a Social Bond, New York, Cambridge University Press, $356 \mathrm{p}$.

Morey D. F. (2014) - In Search of Paleolithic Dogs: A Quest with Mixed Results, Journal of Archaeological Science, 52, p. 300-307.
Morin E. (2007) - Fat Composition and Nunamiut Decisionmaking: A New Look at the Marrow and Bone Grease Indices, Journal of Archaeological Science, 34, 1, p. 69-82.

MÜller W. (2013) - Le site magdalénien de Monruz 3. Acquisition, traitement et consommation des ressources animales, Hauterive, Office du patrimoine et de l'archéologie de Neuchâtel (Archéologie neuchâteloise, 49), 309 p.

Murray N. A. (1993) - The Behavioural Ecology of Reindeer (Rangifer tarandus) during the Last Glaciation in Britain and its Implications for Human Settelment, Subsistence and Mobility, thèse de doctorat, university of Edinburgh, Édimbourg, $364 \mathrm{p}$.

Napierala H., Uerpmann H.-P. (2012) - A 'New' Paleolithic Dog from Central Europe, International Journal of Osteoarchaeoly, 22, p. 127-137.

NilsSEn P. J. (2000) - An Actualistic Butchery Study in South Africa and its Implications for Reconstructing Hominid Strategies of Carcass Acquisition and Butchery in the Upper Pleistocene and Plio-Pleistocene, thèse doctorat, university of Cape Town, Le Cap, 649 p.

O'BRIEN M., LIEBERT T. A. (2014) - Quantifying the Energetic Returns for Pronghorn: A Food Utility Index of Meat and Marrow, Journal of Archaeological Science, 46, p. 384-392.

Outram, A. K. (2005) - Distinguishing Bone Fat Exploitation from other Taphonomic Processes: What Caused the High Level of Bone Fragmentation at the Middle Neolithic Site of Ajvide, Gotland, in J. Mulville et A. K. Outram (dir.), The Zooarchaeology of Fats, Oils, Milk and Dairying, actes du colloque de 1'ICAZ (Durham, août 2002), Oxford, Oxbow Books, p. 32-43.

Outram A. K., Rowley-Conwy P. (1998) - Meat and Marrow Utility for Horse (Equus), Journal of Archaeological Science, 25, p. 839-849.

Ovodov N. D., Crockford S. J., Kuzmin Y. V., Higham T. F. G., Hodgins G. W. L., Van Der Plicht J. (2011) - A 33,000-Year-Old Incipient Dog from the Altai Mountains of Siberia: Evidence of the Earliest Domestication Disrupted by the Last Glacial Maximum, PLoS one, 6, 7, p. 1-7.

Peck R. T. (2004) - Bison Ethology and Native Settlement Patterns during the Old Women's Phase on the Northwestern Plains, Oxford, Archaeopress (British Archaeological Reports, International Series 1278), 147 p.

Peschaux C. (en cours) - Étude diachronique des éléments de parure durant le Dernier Maximum Glaciaire. Une autre approche de la variabilité sociale et culturelle entre le Solutréen, le Badegoulien et le début du Magdalénien, thèse de doctorat, université Paris I.

Pike-TAY A. (1991) - Red Deer hunting in the Upper Paleolithic of South-West France: A study of seasonality, Oxford, Archaeopress (British Archaeological Reports, International Series, 569), $183 \mathrm{p}$.

Pinçon G. (1988) - Sagaies de Lussac-Angles, in H. CampsFabrer (dir), Fiches typologiques de l'industrie osseuse préhistorique, cahier I, fiche 3bis, Aix-en-Provence, université de Provence.

Poplin F. (1983) - Incisives de renne sciées du Magdalénien d'Europe occidentale, in F. Poplin (dir.), La faune et l'homme préhistoriques : dix études en hommage à Jean Bouchud, Paris, Société préhistorique française (Mémoires, 16), p. 55-67. 
Pradel L. (1959) - La grotte magdalénienne de la Marche. Commune de Lussac-les-Chateaux (Vienne), Mémoires de la Société préhistorique française, 5, p. 170-191.

Primault J., Brou L., Gabilleau J., Langlais M., Berthet A.-L., Griggo C., Guérin S., Henry-Gambier D., Houmard C., Laroulandie V., Lebrun-Ricalens F., Liard M., Liolios D., Mistrot V., Rambaud D., Schmitt A., Soler L., Taborin Y., Vissac C. (2007) - La grotte du Taillis des Coteaux à Antigny (Vienne) : intérêts d'une séquence originale à la structuration des premiers temps du Magdalénien, Bulletin de la Société préhistorique française, 104, 4, p. 743-758.

Reimer P. J., Bard E., Bayliss A., Beck J. W., Blackwell P. G., Bronk Ramsey C., Grootes P. M., Guilderson T. P., Haflidason H., Hajdas I., Hatté C., Heaton T. J., Hoffmann D. L., Hogg A. G., Hughen K. A., Kaiser K. F., Kromer B., Manning S. W., Niu M., Reimer R. W., Richards D. A., Scott E. M., Southon J. R., Staff R. A., Turney C. S. M., Van Der Plicht J. (2013) - IntCal13 and Marine13 Radiocarbon Age Calibration Curves 0-50,000 Years cal BP, Radiocarbon, 55, p. 1869-1887.

Rendu W., Costamagno S., Meignen L., Soulier M.-C. (2012)-Monospecific Faunal Spectra in Mousterian Contexts: Implications for Social Behavior, Quaternary International, 247, p. 50-58.

Roden C., Vervaecke H., Van Elsacker L. (2005) - Dominance, Age and Weight in American Bison Males (Bison bison) during Non-rut in Semi-natural Conditions, Applied Animal Behavior Science, 92, 1-2, p. 169-177.

Roden C., Stevens J. M. G., Vervaecke H., Van Elsacker L. (2011)-Reproductive Effort of Bison Bulls (Bison bison) in Semi-natural Conditions, Journal of Ethology, 29, p. 285-291.

Rodiere J. (1996) - Façonnage de perles lithiques magdaléniennes, Techne, 3, p. 54-62.

Roussot A., Ferrier J. (1970)-Le Roc de Marcamps (Gironde). Quelques nouvelles observations, Bulletin de la Société préhistorique française, Études et travaux, 67, 1, p. 293-303.

SACchI D. (2003) - Le Magdalénien, apogée de l'art quaternaire, Paris, La Maison des roches, $126 \mathrm{p}$.

Saint-Perier R. (1947) - Les derniers objets magdaléniens d'Isturitz, L'Anthropologie, 51, p. 393-415.

SÉCHer A. (2013) - La genèse du Magdalénien moyen dans le Sud-Ouest de la France. Apports de la série lithique du Roc de Marcamps 2 (Prignac-et-Marcamps, Gironde), mémoire de master 2, université Bordeaux I, $80 \mathrm{p}$.

SÉcher A. (sous presse) - Le Magdalénien moyen du Roc de Marcamps 2 (Prignac-et-Marcamps, Gironde) : nouveaux regards sur l'industrie lithique, Préhistoire du Sud-Ouest.

SÉCHER A. (en cours) - La genèse du Magdalénien classique dans le Sud-Ouest de la France à travers ses équipements lithiques. Nouveau regard sur les implications sociales de changements techniques à l'aune d'une révolution symbolique, thèse de doctorat, université Bordeaux I.

Simon-Bounet B. (2006)-Expansion d'aire et processus d'introductions biologiques en milieu marin : le cas de Cyclope neritea (Nassariidae) sur les côtes françaises, thèse de doctorat, université de La Rochelle, 254 p.
Simonnet R., Bon F., Bordes J.-G., Primault J. (2007) - Le silex « grains de mil ». Localisation des gites, in N. Cazals, J. Gonzàles Urquijo et X. Terradas, Frontières naturelles et frontières culturelles dans les Pyrénées préhistoriques, actes de la table ronde internationale (Tarascon-sur-Ariège, 11-13 mars 2004), Santander, universidad de Cantabria (Monografías del Instituto Internacional de Investigaciones Prehistóricas de Cantabria, 2), p. 101-102.

Slott-Moller R. (1988) - Contribution à l'étude paléontologique d'un gisement préhistorique : l'exemple du Roc de Marcamps (Gironde), mémoire de DEA, université Bordeaux I, $173 \mathrm{p}$.

Soper J. D. (1941) - History, Range, and Home Life of the Northern Bison, Ecological Monographs, 11, 4, p. 347-412.

SOULIER M.-C. (2013) - Entre alimentaire et technique : l'exploitation animale aux débuts du Paléolithique supérieur. Stratégies de subsistance et chaînes opératoires de traitement du gibier à Isturitz, La Quina aval, Roc-de-Combe et Les Abeilles, thèse de doctorat, université Toulouse II, $548 \mathrm{p}$.

Stanford J. D., Rohling E. J., Bacon S., Roberts A. P., Grousset F. E., Bolshawa M. (2011) - A New Concept for the Paleoceanographic Evolution of Heinrich Event 1 in the North Atlantic, Quaternary Science Review, 30, p. 10471066.

Steele T. E., Weaver T. D. (2002) - The Modified Triangular Graph: A Refined Method for Comparing Mortality Profiles in Archaeological Samples, Journal of Archaeological Science, 29, p. 317-322.

Stiner M. C. (1990) - The Use of Mortality Patterns in Archaeological Studies of Hominid Predatory Adaptations, Journal of Anthropological Archaeology, 9, p. 305-351.

Stiner M. C. (1994) - Honor Among Thieves, Princeton, Princeton University Press, $447 \mathrm{p}$.

Stuart A. J., Lister A. M. (2007) - Patterns of Late quaternary Megafaunal Extinctions in Europe and Northern Asia, Courier Forschungsinstitut Senckenberg, 259, p. 287-297.

Stutz, A. J. (2002a) - Pursuing Past Seasons: A Re-evaluation of Cementum Increment Analysis in Paleolithic Archaeol$o g y$, thèse de doctorat, University of Michigan, Ann Arbor (Mi), $280 \mathrm{p}$.

StUTZ, A.J. (2002b) - Polarizing Microscopy Identification of Chemical Diagenesis in Archaeological Cementum, Journal of Archaeological Science, 29, p. 1327-1347.

TABORIN Y. (1993) - La parure en coquillage au Paléolithique, Paris, Éd. du CNRS (Supplément à Gallia Préhistoire, 29), $538 \mathrm{p}$.

Taborin Y., Tymula S. (2009) - Les coquillages des Magdaléniens de la Garenne à Saint-Marcel (Indre), in J. Despriée, $\mathrm{S}$. Tymula et A. Rigaud (dir.), Données récentes sur le Magdalénien de la Garenne (Saint-Marcel, Indre). La place du Magdalénien " à navettes » en Europe, actes du colloque (Argenton-sur-Creuse, 7-9 octobre 2004), Saint-Marcel, ASSAAM (Numéro spécial du Bulletin de l'association pour la sauvegarde du site archéologique d'Argentomagus et amis du musée, 2), p. 201-206.

TAYlor A. (2003) - Analyse de deux séries lithiques appartenant au Magdalénien moyen à navettes. Les secteurs intérieurs de la grotte Blanchard à la Garenne (Indre), couches 
C1 et C2-B5, mémoire de DEA, université Aix-Marseille I, Aix-en-Provence, $124 \mathrm{p}$.

Théry-Parisot I., Costamagno S., Brugal J.-P., Fosse P., Guilbert R. (2005) - The Use of Bone as Fuel During the Palaeolithic, Experimental Study of Bone Combustible Properties, in J. Mulville et A. K. Outram (dir.), The Zooarchaeology of Fats, Oils, Milk and Dairying, actes du colloque de l'ICAZ (Durham, août 2002), Oxford, Oxbow Books, p. 50-59.

Tyrberg T. (1998) - Pleistocene Birds of the Palearctic: A Catalogue, Cambridge, Publications of the Nuttall Ornithological Club, 27, $720 \mathrm{p}$.

Val A., Mallye J.-B. (2011) - Small Carnivore Skinning by Professionals: Skeletal Modifications and Implications for the European Upper Paleolithic, Journal of Taphonomy, 9, p. 221-243.

VANHAEREn M., D'ERrico F. (2003) - Le mobilier funéraire de la dame de Saint-Germain-la-Rivière (Gironde) et l'origine paléolithique des inégalités, Paléo, 15, p. 195-238.

Vigne J.-D., Marinval-Vigne M.-C. (1983) - Méthode pour la mise en évidence de la consommation du petit gibier, in J. Clutton-Brock et C. Grigson (dir.), Animals and Archaeology. 1. Hunters and their Prey, Oxford, Archaeopress (British Archaeological Reports, International Series 163), p. 239-242.

Villa P., Mahieu E. (1991) - Breakage Patterns of Human Long Bones, Journal of Human Evolution, 21, p. 27-48.

WARING G. H. (2003) - Horse Behavior, Norwich (N. Y.), Noyes Publ. et William Andrew Publ., 2e ed., 442 p.

Weaver T. D., Boyko R. H., Steele T. E. (2011) - Cross-platform Program for Likelihood-based Statistical Comparisons of Mortality Profiles on a Triangular Graph, Journal of Archaeological Science, 38, p. 2420-2423.

White T. D. (1992)-Prehistoric Cannibalism at Mancos 5MTUMR-2346, Oxford, Princeton University Press, 462 p.

\footnotetext{
Sandrine Costamagno Delphine KunTz Jean-Marc PÉtILlon UMR 5608 TRACES » Maison de la Recherche 5, allées Antonio Machado F-31058 Toulouse kuntz@univ-tlse2.fr costamag@univ-tlse2.fr petillon@univ-tlse2.fr
}

\section{Myriam Boudadi-Maligne \\ Mathieu LANGLAIS \\ Véronique LAROULANDIE \\ Jean-Baptiste MALLYE \\ Éric PuberT \\ Anthony SÉcher \\ UMR 5199 «PACEA » \\ université de Bordeaux \\ Allée Geoffroy St-Hilaire \\ CS 5002333615 PESSAC Cedex}

m.boudadi-maligne@pacea.u-bordeaux1.fr

mathieu.langlais@u-bordeaux.fr veronique.laroulandie@u-bordeaux.fr

jb.mallye@pacea.u-bordeaux1.fr

e.pubert@pacea.u-bordeaux1.fr

asecher@u-bordeaux.fr

Carolyn BarshaY-SzMIDT

University of Pennsylvania

Museum of Archaeology and Anthropology, 3260 South Street,

Philadelphia, PA, 19104-6324 (États-Unis) et Archaeology Centre,

University of Toronto, 19 Russell Streeet, Toronto, ON, M5S 2S2 (Canada) carolyn_szmidt22@yahoo.ca

Caroline Peschaux

UMR 7041 «ArScAn », équipe "Ethnologie préhistorique » Maison de l'archéologie et de l'ethnologie

21 allée de l'Université F-92023 Nanterre Cedex caroline.peschaux@mae.u-paris10.fr

William RENDU

UMI 3199 «CIRHUS » (CNRS-NYU) 4 Washington Square North,

New York, NY 10003 wrendu@nyu.edu 